\title{
Gender-of-interviewer Effects in Self-reported Gender Ideologies - Evidence Based on Interviewer Change in a Panel Survey
}

\author{
Gundula Zoch ${ }^{a}$ \\ [Accepted and revised version published as: Zoch, Gundula (2020): Gender-of-Interviewer Ef- \\ fects in Self-Reported Gender Ideologies: Evidence Based on Interviewer Change in a Panel \\ Survey. In: International Journal of Public Opinion Research; edaa017. DOI:
}

10.1093/ijpor/edaa017.]

\begin{abstract}
Previous research has largely overlooked whether and to what extent the observed variation in gender ideologies depends on the interviewer. This study examines gender-of-interviewer effects in gender ideologies among respondents, interviewed by different interviewers in multiple waves of a large-scale panel survey in Germany. By applying fixed-effects models to data from the adult cohort of the National Educational Panel Study (NEPS), the study finds that respondents report more egalitarian views to female interviewers. While gender-of-interviewer effects were more pronounced for men, in West Germany, and for egalitarian slanted attitude items, further effect heterogeneity seemed to be relatively low for respondents' characteristics. The results illustrate the influence of the interview situation on sensitive questions and their methodological consideration in further research.
\end{abstract}

Keywords: gender ideology; gender role attitudes; interviewer effects; education; social desirability

Acknowledgements: The author is grateful for comments on the paper from participants at the ECSR Conference 2018, RC28 Conference 2019, and ESRA Conference 2019 as well as comments on an earlier version of this paper from those at invited seminars at LIfBi and the 3rd NEPS user conference.

${ }^{a}$ Dr. Gundula Zoch, Leibniz Institute for Educational Trajectories, Wilhelmsplatz 3, 96047 Bamberg, Germany, E-Mail: gundula.zoch@lifbi.de, ORCID iD: 0000-0002-4398-4 


\section{Gender-of-interviewer Effects in Self-reported Gender Ideologies - Evidence Based on Interviewer Change in a Panel Survey}

Although several studies have shown that ideologies are formed in childhood and remain relatively stable thereafter (Cunningham, 2001; Min, Silverstein, \& Lendon, 2012; van Putten, Dykstra, \& Schippers, 2008), there is evidence of further change in gender ideologies in the life course. Recent longitudinal studies show that the formation of gender ideologies is not completed in early adolescence, but changes under the influence of later life-course events, for example, childbirth and related employment transitions (Baxter, Buchler, Perales, \& Western, 2015; Brooks \& Bolzendahl, 2004) or major family policy reforms (e.g., Zoch \& Schober, 2018).

However, the increasing number of studies on alterable gender ideologies does not take into account whether and to what extent changes in the interview situation are responsible for the observed variation in gender ideologies. Since most surveys contain very little information at the interviewer level, only a few studies report details on the interview situation (e.g., Bauernschuster \& Rainer, 2012; Baxter et al., 2015; Scott, 1999; Zoch \& Schober, 2018). At the same time, no previous study on ideology change seems to take into account possible biases due to the characteristics of the interviewer, in particular gender.

Survey methodology research has however provided evidence of a social desirability bias due to the interviewer's gender (see Krumpal, 2013 for an overview). Previous studies show that respondents tend to indicate less traditional views towards female interviewers (Benstead, 2014; Huddy et al., 1997, see Klein \& Kühhirt, 2010). However, by using (repeated) cross-sectional data, these studies could not investigate how the response behavior of the same person differed between a female and a male interviewer. Previous studies were therefore unable to assess a causal gender-of-interviewer effect.

This study is the first to use large-scale representative panel data to investigate whether respondents report less traditional gender ideologies to a female interviewer. Unlike many other panel surveys, this one uses different survey modes in the individual waves. This creates a random interviewer variation over waves. This study uses the random assignment of male and female interviewers in computer-assisted personal interviews (CAPI) and computer-assisted telephone interviews (CATI) to investigate whether a random change in 
the interviewer's gender results in a change in respondent's self-reported gender ideologies. Besides, the study analyses the extent to which the gender-of-interviewer effect varies according to respondents' educational level and age. Moreover, it is examined whether the influence of gender differs between the two contexts in East and West Germany.

Investigating gender ideologies is important to understand their formation and thus explain persistent gender inequalities in related behaviors, such as the gendered division of domestic work, parental care and paid employment (see Davis \& Greenstein, 2009 and Steiber \& Haas, 2012 for an overview). Gender ideologies refer to individuals' support for the division in paid and domestic work based on the belief in (multiple) gendered separate spheres (Grunow \& Veltkamp, 2016). By examining whether changes in self-reported gender ideologies are due to the interview situation, the study contributes to the recently growing literature on alterable ideologies based on panel studies. Furthermore, it complements existing methodological research on social desirability in the field of attitude and ideology research by using large-scale panel data.

\section{Previous Research on Gender-of-Interviewer Effects}

So far, only a few studies have investigated gender-of-interviewer effects in the context of gender ideologies, women's discrimination or political participation. Although some single studies did not find significant gender-of-interviewer effects (Jablonski, Krzewinska, \& Grzeszkiewicz-Radulska, 2017), in most of these cross-sectional studies, both men and women reported slightly less traditional gender ideologies when interviewed by a woman (Huddy et al., 1997; Kane \& Macaulay, 1993; Lipps \& Lutz, 2017; Lueptow, Moser, \& Pendleton, 1990). Evidence on gender-of-interviewer effects based on panel data is however very limited. By using Swiss telephone-interview panel data and taking into account interviewer non-response effects, Lipps and Lutz (2017) found respondents to state less traditional gender ideologies towards a female interviewer. Besides, it is still unclear whether gender-ofinterviewer effects are stronger for male or female respondents. While some studies found larger gender-of-interviewer effect for women compared to men (Fuchs, 2009; Huddy et al., 1997; Lueptow et al., 1990), other studies report larger effects for men (Fuchs, 2009), while others did not find any interaction effect (Kane \& Macaulay, 1993; Lipps \& Lutz, 2017).

Although gender-of-interviewer effects are presumed to be particularly pronounced for attitude and sensitive question, in previous studies the sizes of the gender-of-interviewer effects were generally small and on average about the size of a standard deviation (Huddy et 
al., 1997). However, most of these studies were based on cross-sectional datasets from western countries, particularly the US, with less than 500 respondents from face-to-face or telephone interviews. A small number of interviewers, often less than 100, conducts these surveys (Huddy et al., 1997; Lueptow et al., 1990). Most of these studies were therefore unable to estimate a more causal effect and, thus, "require future replication to assure their robustness" (Huddy et al., 1997, p. 208).

Variation In Gender-of-interviewer Effects According to Context, Respondent's characteristics and Survey Mode

A few studies from developing countries point to the relevance of gender culture and gender equality for investigating gender-of-interviewer effects. Using face-to-face survey data for Morocco, a context with strong patriarchal norms and persistent gender inequalities, Benstead (2014) confirmed earlier studies from developed countries and showed that Moroccan men also expressed more egalitarian views towards a female interviewer. Similarly, Flores-Macias and Lawson (2008) found pronounced female-interviewer-effects in face-to-face interviews on gender-sensitive items on abortion and women's rights for men from Mexico City. Conversely, there were no comparable effects for men from rural areas in Mexico or women from both regions. In contrast, Himelein (2016) shows that in South Asia it is women who are more likely to be influenced in their response behavior towards subjective and potentially sensitive questions than men, even if they are interviewed by another woman. However, by using cross-sectional designs with very small sample sizes, all studies were unable to account for unobserved heterogeneity and relied on comparatively small variation in interviewers' characteristics. Nevertheless, the results highlight the importance of cultural contexts when investigating interviewer-gender-effects. For Western countries, there are currently no findings on the different influences of gender cultures on interviewergender-effects.

The strength of interviewer-effects varies not only according to the content of the question or the cultural context of the interview situation but also according to other characteristics of the interview situation. In view of the stronger interaction between interviewer and respondent, face-to-face interviews are generally presumed to show greater interviewer-effects than telephone interviews or web surveys (Klein \& Kühhirt, 2010). It can be assumed that respondents want to avoid a potentially uncomfortable atmosphere with the 
interviewer and therefore provide answers that they believe may be consistent with the interviewer's attitudes (Liu, 2017; West \& Blom, 2017). However, evidence on mode effects on self-reported gender ideologies is scarce and findings ambiguous. To date, gender-of-interviewer has had an effect on answers in both face-to-face and telephone interviews. Accordingly, men tend to alter their attitudinal statements on gender inequalities in face-to-faceinterviews more compared to self-administered web surveys (Liu, 2017). However, some authors have also argued for stronger effects in telephone interviews where other characteristics of the interviewer are absent (Huddy et al., 1997).

In addition, the findings on further effect heterogeneity according to respondent's or interviewer's characteristics are limited and overall mixed. Slightly larger gender-of-interviewer effects among respondents of younger age (Huddy et al., 1997) and with higher educational attainment (Huddy et al., 1997; Lueptow et al., 1990) have been explained with anticipation effects. Accordingly, respondents with lower levels of education perceive the interviewers as well-educated and thus anticipate less traditional gender ideologies. Therefore, they try to articulate more egalitarian gender ideologies. However, the authors were unable to replicate these findings in a follow-up study (Huddy et al., 1997). Evidence on effect heterogeneity based on panel data is also scarce. By using Swiss telephone-interview panel data, Lipps and Lutz (2017) were unable to replicate more socially desired responses form highlyeducated respondents with more experienced interviewers in an earlier study (Lipps \& Lutz, 2010).

Lastly, some studies provide evidence for gender-of-interviewer effects when surveying behavior that is strongly related to gender inequalities and gender ideologies. Klein and Kühhirt (2010), for example, find that in a small sample of telephone interviews, male respondents systematically report larger shares of domestic work when they were interviewed by a woman. Conversely, this association did not exist for women. Additionally, the interviewer-of-gender effect was more pronounced for men of younger age and with medium levels of education.

Overall, earlier studies show that gender of interviewer effects are particularly relevant when interviewing gender ideologies. While some results point to gender-specific differences in response distortion, evidence of further effect heterogeneity due to other characteristics of the respondent or the cultural context is rare and previous results ambiguous. 


\section{Contribution to the Research Gap}

To contribute to a more sound understanding of gender-of-interviewer effects on gender ideologies, this study applies a more differentiated empirical investigation. It extends previous studies by investigating whether a change in interviewer's gender affects the selfreported gender ideologies of the respondent. Thereby, it offers a number of advantages over earlier research. First, the study contributes to previous literature by using a large-scale panel dataset conducted by a large number of interviewers. Second, it is the first study to use panel data with a random assignment of interviewers of both sexes across waves to investigate whether these random changes in interviewer's gender are associated with changes in reported gender ideologies. The study is, therefore, able to take into account constant unobserved heterogeneity and a large number of control variables for respondents, interviewers, and the interview situations in order to estimate a more causal gender-of-interviewer effect. Third, the study extends the existing literature by investigating whether the effects on self-reported gender ideologies vary with respondents' characteristics. Hence, the empirical analyses concentrate on examining gender ideologies separately for male and female respondents and investigate the role of respondents' educational attainment and age. Lastly, given persistent East-West differences in childcare provision, maternal employment, and gender ideologies, it is examined whether gender-of-interviewer effects vary for the different cultural contexts in East and West Germany. Thus, from a theoretical perspective, the study examines whether social desirability in the context of gender ideology is more pronounced among certain subgroups and contexts. Besides, it extends previous theoretical and methodological approaches to the investigation of social desirability bias in survey and attitudinal research.

\section{Theoretical Framework to Explain Gender-of-interviewer Effects}

\section{Explaining Differences in Gender Ideologies Between Men and Women}

Previous research has found persistent differences in the gender ideologies between men and women, with women from diverse social groups and welfare contexts reporting less traditional ideologies than men (Banaszak, 2006; Bauernschuster \& Rainer, 2012; Bolzendahl \& Myers, 2004). To understand these differences, socialization theories and theories of individual change can be applied. These theories share the common assumption that both parental socialization in early childhood and changing contexts or life-course events in 
later lifetime determine the formation and later changes of ideologies (Brooks \& Bolzendahl, 2004; Kraaykamp, 2012; Stets \& Burke, 2000). In line with socialization theory, the impressionable years' hypothesis assumes that young adults have the least stable preferences and experience the most substantial changes in their ideologies (Alwin \& Krosnick, 1991). With advancing age and certain life events, gender ideologies to which they were previously exposed to can be activated. Thus, early gender-specific socialization can lead to later differences in gender ideologies between women and men.

In addition, gender ideologies vary not only with early socialization and thus parents' ideologies, but also with contextual factors during this socialization period. Comparative research shows that gender ideologies are usually less traditional in welfare systems with more supportive family-work policies (e.g., Sjöberg, 2004). Especially women have less traditional attitudes in welfare regimes that support the equal division of domestic and paid work. In Germany, the persistently less traditional gender roles in the East, especially among women, are a consequence of the early socialization in the GDR regime. The GDR supported full-time maternal employment comprehensively with short parental leave and well-developed public childcare facilities. Even 25 years after the reunification of Germany, public childcare provision and maternal employment are still higher in East Germany. As a result, gender ideologies regarding maternal employment and childcare are still much more egalitarian in East Germany (Zoch \& Schober, 2018). This illustrates the long-term and lasting influence of state institutions.

According to sociological and psychological theories of role exposure and empirical studies on attitude change, gender ideologies do not necessarily remain stable over the lifecourse but can change over time. Contextual and interactional dynamics, especially during major life-course transitions such as marriage, childbirth, and employment transitions shape individual ideologies (e.g., Alwin \& Krosnick, 1991; Brooks \& Bolzendahl, 2004; Cunningham, 2001). The literature emphasizes two mechanisms for explaining short-term changes in ideologies: i) psychological adaptations to role exposure and ii) cultural diffusion and norm-setting effects (Bicchieri, 2017; Kumlin \& Stadelmann-Steffen, 2014).

According to identity theory and social identity theory (Stets \& Burke, 2000), individuals construct both passively and actively new images of themselves whenever they experience new roles or a change in social category or group. Since these changes occur over the course of a person's life, exposure-based perspectives presume a change in role exposure to 
be accompanied by psychological adaption, and thus, changes in gender ideologies. They, therefore, refer closely to perspectives that explain altered gender ideologies with direct exposure to new roles or interest-related concerns (Bolzendahl \& Myers, 2004). Thus, genderspecific roles and experiences due to life-course transitions are likely to lead to gender ideologies that differ between men and women.

As a second channel, norm-setting effects, e.g. induced by policy changes, may be relevant to understand individual changes in ideologies and social norms. Political changes cause people to adapt to these changes, which, in turn, alter people's empirical expectations of others' social actions and normative expectations as to what other people will think of one's own behavior and articulation towards social norms (Bicchieri, 2017). For Germany, most recent research shows family policy reforms that promote maternal participation or fathers' participation in family work to be positively associated with a modest shift towards less traditional attitudes, particularly among West German women (Zoch \& Schober 2018).

In summary, gender differences in gender ideologies are very likely due to differences in the formation of gender ideologies during early socialization, differences in the lifelong adaptation due to gendered role exposure, and differences in norm-setting effects in policy changes for women and men. This is in line with previous empirical research that has found women to report less traditional gender ideologies than men (Banaszak, 2006; Bauernschuster \& Rainer, 2012; Bolzendahl \& Myers, 2004; Zoch \& Schober, 2018).

\section{Explaining Gender-of-interviewer Effects in Surveying Gender Ideologies}

In view of the persistent gender differences in life-course trajectories and associated roles, it is assumed that the respondents are aware of gender differences in gender ideologies. Hence, the question arises as to whether respondents adapt their responses and express more or less traditional gender ideologies when interviewed by a person of the opposite sex.

Social desirability theories assume that survey respondents generally underreport socially undesirable activities or attitudes in order to avoid responses that would either violate existing social norms or violate the views of the interviewer (Krumpal, 2013). Therefore, respondents change their answers either in order to achieve a generally more socially favorable self-presentation or to maintain the interviewer's consent. 
Two sub-dimensions of social desirability are distinguished: the social attribution model and the conditional attribution model. The social attribution model argues that respondents attribute values and views to the interviewer that are based on social stereotypes. These are linked to observable characteristics of the interviewer, such as gender or age. Consequently, all respondents are presumed to edit their responses based exclusively on the observable characteristics of the interviewer (Krumpal, 2013). Conversely, the conditional attribution model assumes that respondents adjust their responses according to their own characteristics and those of the interviewer to reduce the perceived social distance based on the characteristics of both individuals (Krumpal, 2013). It is therefore assumed that heterogeneous interviewer effects depend on the relative social distance between the interviewer and respondent. If the respondent and the interviewer are similar in common characteristics such as gender or age, it is assumed that the respondents experience a smaller social distance, feel more comfortable, and therefore alter their responses less.

As women in different social groups and welfare contexts report less and less traditional ideologies (Banaszak, 2006; Bauernschuster \& Rainer, 2012; Bolzendahl \& Myers, 2004; Zoch \& Schober, 2018), it is assumed that respondents are aware that women on average hold more egalitarian gender ideologies. Based on the social attribution model it is therefore expected that both men and women report less traditional gender ideologies, i.e. more egalitarian views when interviewed by a woman compared to a man (H1).

However, by considering the interplay of interviewer and respondents characteristics according to the conditional attribution model, men are presumed to generally experience a greater social distance to female interviewers than women. To reduce this perceived distance, men must alter their ideologies more strongly. Consequently, the gender-of-interviewer effect is expected to be more pronounced for men compared to women $(H 2)$.

Due to the persistent East-West differences in gender ideologies, it can be assumed that the interviewer effect also differs according to the cultural context. Given the generally more traditional gender ideologies in West Germany, respondents there might feel more pressure to alter their attitudes when interviewed by a woman. Conversely, in East Germany, non-traditional gender ideologies are more common among both women and men and gender inequalities in paid employment less dominant compared to West Germany. 
Thus, East German respondents are likely to feel no need to adjust their attitudinal statement. Hence, the gender-of-interviewer effect is expected to be more pronounced for West Germans (H3).

In line with the impressionable years' hypothesis (Alwin \& Krosnick, 1991), previous research has revealed less traditional gender ideologies not only among women but also among respondents of younger ages and with higher educational attainment (Banaszak, 2006; Brooks \& Bolzendahl, 2004; Cunningham, 2008). Assuming that younger and bettereducated respondents are more aware of the importance of gender equality they might experience greater pressure to adapt their responses to social expectations or to the gender ideologies attributed to the interviewer. It is therefore presumed that gender-of-interviewer effects are more pronounced among younger respondents $(\mathrm{H} 4 \mathrm{a})$ and respondents with a higher level of education (H4b).

\section{Data and Empirical Strategy}

\section{The National Educational Panel Study}

To investigate gender-of-interviewer effects on respondents' self-reported gender ideologies this study uses data from the National Educational Panel Study (NEPS): Starting Cohort Adults, 10.5157/NEPS:SC6:10.0.0 and applies fixed-effects models. From 2008 to 2013, NEPS data was collected as part of the Framework Program for the Promotion of Empirical Educational Research funded by the German Federal Ministry of Education and Research (BMBF). As of 2014, NEPS is carried out by the Leibniz Institute for Educational Trajectories (LIfBi) at the University of Bamberg, Germany, in cooperation with a nationwide network.

The NEPS is one of the few German panel datasets, which include measures of gender ideologies. Starting in 2009, the NEPS Adult Cohort offers detailed information on about 12,000 persons of working age born between the mid-1940s and the mid-1980s (Blossfeld, Roßbach, \& Maurice, 2011). Among others, the data set contains detailed longitudinal information on individuals' educational careers and other individual and household characteristics.

Unlike many other panel surveys, the NEPS uses different survey modes in the individual panel waves. Hence, interviewers do not always survey the same NEPS respondents. In this study, the random variation in interviewers is used to examine whether a change in 
the interviewer's gender results in a change in the respondent's self-reported gender ideologies. Thus, conversely to previous cross-sectional research but also other panel studies, the NEPS-data allows modeling the effect of a change in interviewers' gender while controlling for various time-varying impact factors as well as observed and unobserved constant heterogeneity.

\section{Sample and Operationalization}

The sample. The analysis used waves 4 (2011/2012) and 7 (2014/2015) that include items on respondents' gender ideologies. The sample included male and female respondents aged 25 to 71 from East and West Germany. The few adults in education or vocational training and those with a homosexual orientation were excluded. Based on observation with full information on all relevant controls, the sample consists of 2473 male (4946 person-year observations) and 2732 female respondents (5464 person-year observations) interviewed by about 465 interviewers.

Given different interview modes in alternate waves, respondents in wave 4 experienced computer-assisted telephone interviews (CATI). In wave 7 respondents were interviewed in computer-assisted face-to-face interviews (CAPI). For face-to-face interviews, interviewers were assigned to single geographic areas. 282 interviewers conducted between 1 and 80 face-to-face interviews, with an average of about 29 interviews. For telephone interviews, respondents were assigned randomly based on an allocation algorithm. The 270 telephone interviewers completed between 1 and 205 interviews each, with an average of about 59 interviews.

Due to the two different interview situations at the two survey times, 97 percent of the respondents were interviewed by two different interviewers. As a result, 47 percent of the respondents were interviewed by an interviewer with a different sex. The proportion of respondents who changed from a male to a female interviewer (45 percent) was slightly lower than the proportion who changed from a woman to a man (55 percent).

Gender ideologies. In the NEPS, gender ideologies are measured with different gender role attitude items that aim at capturing the multi-dimensional concept of individuallevel gender ideologies (Davis \& Greenstein, 2009). The analyses focused on these five dependent attitudinal statements: (1) "Men are better suited for certain professions than women" (Professions), (2) "The proportion of women in politics should be equal to that of 
men" (Politics), (3) "Men and women should have the same duties in the home" (Household), (4) "Women can use technical devices as well as men" (Technology), and (5) "It's the man's job to earn money and the women's job to take care of the household and family" (Roles) (see Table 1). The response scale ranged from 1 (strongly disagree) to 4 (strongly agree). The two traditionally phrased items (1) and (5) were recoded so that for all items higher values represented more egalitarian gender ideologies. Thus, the items rely on the continuum of traditional and less traditional gender ideologies much in the same way as previous research on gender ideologies (Davis \& Greenstein, 2009; Steiber \& Haas, 2012).

Although an explanatory factor analysis supported the consideration of an underlying construct, the correlation between the attitude items and the single factors was low, ranging from .23 (item Professions) to .40 (item Household). The reliability of the combined index based on all five items seemed adequate (Cronbach's $\alpha$ coefficient: 0.54$)$, with a somewhat lower Cronbach's $\alpha$ for the scale of females (0.51) than males (0.55). Given these critical values, all items were analyzed separately. This takes into account theoretical considerations according to which the individual elements reflect conceptually different dimensions of gender ideologies (Grunow \& Veltkamp, 2016). However, results for the combined index were also included in order to illustrate the discrepancy with the results for individual items. To facilitate the comparability of the effect sizes across separate models, all outcomes were standardized beforehand.

Table 1 shows summary statistics on all attitudinal outcomes for male and female respondents by the interviewer's gender. For all items, patterns of response revealed lower values, i.e. more traditional gender ideologies, among respondents with a male interviewer compared to their counterpart with a female interviewer. Regardless of the gender of the interviewer, female respondents always stated less traditional gender roles than men.

\section{Table 1 here}

Independent variables. The key independent variable was the interviewers' gender, distinguishing males and females. All models included the following time-varying control variables at the individual level: Respondent's age and age squared and dummy variables indicating whether the respondent is currently employed, married, cohabitating or on parental leave. On the household level, models included the number of children and a logged indicator of the monthly net household income, adjusted for inflation with the base year 2015. 
To account for a change in the interview situation due to a change in the interviewer, models controlled for further interviewer characteristic: a pre-generated categorical variables on interviewer's age (under 29/30-49/50-65/65+), education (low/medium/high), experience as an interviewer for the survey company (0/1-2 years/2-3 years/4-5 years), and the length of the interview in minutes. For the face-to-face interviews, the interviewer and respondent are likely to know each other from previous waves and, thus, may be more familiar with each other. Hence, models include the number of past waves in which the respondent has already been interviewed by the respective interviewer. Lastly, models included a control variable indicating whether the respondent seemed tired (0-10).

Table A1 in the online appendix presents summary statistics of all control variables for male and female respondents by the interviewer's gender. Respondents did not differ in their individual characteristics when interviewed by a woman or a man. However, the male and female interviewers differed significantly in their further characteristics as well as in the interview situation they produced. Female interviewers were significantly more likely to conduct face-to-face interviews, to be low-skilled, older, and to have more than 3 years of interviewer experience. They also reported more often that the respondents seemed tired after the interview. These differences suggest that female interviewers differ from men in characteristics that may be relevant when surveying gender ideologies.

\section{Estimation Strategy}

The fixed-effects models estimate the relationship between changes in gender ideologies of respondents $\boldsymbol{y}_{\boldsymbol{i}}$ and changes in interviewers' gender $\boldsymbol{i}_{\boldsymbol{i}}$ as well as time-variant independent control variables at the individual-, household- and interviewer-level, denoted as a vector $\boldsymbol{x}_{\boldsymbol{i} \boldsymbol{t}}$ in equation 1.

(1) $y_{i t}=\beta_{1 t}+\beta_{2} i_{i t}+\beta_{3} x_{i t}+u_{i}+\varepsilon_{i t}$

By definition, fixed-effects panel models control for the average differences within individuals in any observable or even unobservable factor. Hence, the models account for any constant observed and unobserved heterogeneity and exploit only within-person variation in the dependent and independent variables. $\boldsymbol{\varepsilon}_{i t}$ represents random variation at each point in time and $\boldsymbol{u}_{\boldsymbol{i}}$ captures the combined effect of time-invariant unobserved variables on the dependent variable. To account for the nested interviewer structure, clustered standard errors on the interviewer-level were computed. 
Overall, four sets of models were estimated to investigate if (1) respondents report less traditional gender ideologies when interviewed by a woman and whether these genderof-interviewer effects differ for (2) male and female respondents. By estimating separate models for East and West German respondents, it was examined whether the effects vary in two different cultural contexts (3). Moreover, heterogonous gender-of-interviewer effects were investigated for different characteristics of the respondents (4).

\section{Findings}

\section{Gender-of-interviewer Effects on the Combined Index and Single Items}

Joint models for men and women with all control variables revealed a positive gender-of-interviewer effect, providing support for Hypothesis 1. Using predictive probabilities, Figure 1 shows that on average respondents stated more egalitarian gender ideologies when interviewed by a woman. The gender-of-interviewer effects were statistically significant for the combined index and all single items, except the item Roles (see also full models in Table A2 in the Online Appendix). Effect sizes were modest, ranging between 4 percent (profession) and 13 percent (combined index) of a standard deviation.

Figure 1 here

Separate models for male and female respondents provided support for Hypothesis 2 , assuming more pronounced gender-of-interviewer effects for male respondents. Figure 2 shows the effect of a female interviewer for the combined index and the single items, estimated separately for male and female respondents, using the user-written Stata-command coefplot (Jann, 2018). Confidence intervals were plotted at the 95\%-level (see also full models in Tables A3-A4). For men, the effects of a female interviewer were statistically significant for the combined index and all single items except the last item Roles (Table A3). For women, only the effects for the combined index and the non-traditionally formulated items (Politics, Household, Technology) were statistically significant (Table A4). Effect sizes were mostly larger for men, especially for the two items Politics and Technology, which touch on two topics with a particularly masculine connotation. Thus, the results suggested that the gender-of-interviewer effect for the combined index was particularly driven by male respondents and items formulated as an egalitarian statement. Estimating joint models with an interaction effect between respondent's and interviewer's gender in combination with a 
Wald test confirmed a statistically larger bias only for men and only for the combined index and the egalitarian slanted items Professions and Technology.

Figure 2 here

A stepwise integration of the controls into the separate models for men and women altered the gender-of-interviewer effects only marginally (see stepwise models in Tables A5A16). However, the importance of the control variables differed for men and women. Lifeevents such as employment transitions, cohabitation episodes or parental leave take-up were more strongly associated with attitudinal changes among men (Tables A5-A10). Overall, gender differences in the control variables were strongest for the survey mode. In almost all models, men stated less traditional ideologies in telephone surveys than in face-to-face interviews. For women, these differences were less pronounced and rarely statistically significant (Tables A11-A16). Differences in interviewer's age and education were also more frequently associated with attitudinal changes among men than women.

\section{Gender-of-interviewer Effects in Face-to-face and Telephone Interviews}

Surprisingly, respondents stated more egalitarian gender ideologies in telephone interviews (CATI) than in face-to-face interviews (CAPI) (see full models in Table A3 and A4). However, in both modes, results indicated more egalitarian gender ideologies for the combined index among men when interviewed by a woman, with slightly more egalitarian ideologies in telephone interviews (see Figure 3). For women, only CAPI interviews revealed a small gender-of-interviewer difference for the combined index. Estimating interaction effects between interviewer's gender and survey mode, however, revealed statistically significant differences only for the item Politics answered by men.

Figure 3 here

\section{Gender-of-interviewer Effects in East and West Germany}

Partly in line with Hypothesis 3, the results displayed in Figure 4 suggested larger gender-of-interviewer effects for the more traditional context in West Germany. However, East-West disparities were smaller for men than for women (full models presented in Table A17 and A18). For most items and the combined index, the female-interviewer effects were statistically significant for men in West and East Germany, and West German women. Conversely, for East German women neither the index nor the single items showed statistically significant female-interviewer-effects, except the item Technology. While for women, West 
Germany always showed stronger gender-of-interviewer effects than East Germany, West German men only stated less traditional ideologies in the case of item Politics. For all other items, East German men reported less traditional ideologies than West German men. However, with regard to effect sizes, East-West-differences were smaller for men than for women. Interaction effects in joint models confirmed statistically significant East-West differences for the items Politics and Roles for men and the items Housework and Technology for women.

Figure 4 here

\section{Gender-of-interviewer Effects According to Age and Educational Level}

Hypothesis 4 assumed stronger gender-of-interviewer effects for younger respondents ( $\mathrm{H} 4 \mathrm{a})$ and respondents with higher levels of education $(\mathrm{H} 4 \mathrm{~b})$. By testing linear, quadratic and categorical relationships, no significant interactions were found between the interviewer's gender and respondent's age. Hypothesis 4a, therefore, had to be rejected. However, partly in line with Hypothesis 4b, results suggested educational disparities in gender-of-interviewer effect for women (see Figure 5). Contrary to expectations, however, it was not women with medium and high levels of education but rather less-educated women who reported more egalitarian gender ideologies to another woman. The difference observed for the combined index was particularly driven by educational disparities in the items Professions, Politics, and Household. Similar to women, low-skilled men revealed less traditional ideologies towards a female interviewer compared to men with medium and higher levels of education. However, with the exception of the item Roles, educational disparities were statistically insignificant for men.

Figure 5 here

\section{Sensitivity Checks}

Interaction effects between interviewer's gender and interviewers' age or educational attainment were statistically insignificant. Investigating the role of interviewer-respondent matches in terms of age and educational attainment also showed small and mostly insignificant differences. Only younger females interviewed by another woman younger than 50 reported more egalitarian views than older women (see Figure A1 in the online appen- 
dix). Similar, three-way interaction effects between interviewers' gender, age, and respondents' education as well as between interviewers' gender, education, and respondents' education were mostly insignificant (see Figure A2 for education).

Lastly, interviewer and respondent might engage in side-conversations that may be related to the topic and, thus, impact on self-reported gender ideologies. Given no information on potential side-conversations, models were re-estimated with interview length as a proxy measure, assuming longer interview durations due to side conversations. However, results revealed very small and insignificant differences in the gender-of-interviewer bias.

\section{Discussion and Conclusion}

By exploiting large-scale panel data from Germany, this study provides evidence that survey respondents report less traditional gender ideologies to female interviewers. In contrast to most previous studies, the results also show effect heterogeneity with respect to respondents' gender, education, and the cultural context. The interviewer-gender-bias was mainly driven by male respondents and by adjusted responses to items formulated as egalitarian statements. While men adjusted their response behavior regardless of their educational background, only low-skilled women adapted their attitudinal statements when interviewed by another woman. This shows that the social distance between the sexes but also between women with different educational backgrounds is greater and leads to adjustment reactions due to presumed differences in gender ideologies. With respect to interview mode, the interviewer-gender-bias was somewhat larger for telephone interviews than for computer-assisted face-to-face interviews, particularly among male respondents. Avoiding spatial contact therefore does not seem to reduce social distance, so that respondents would feel less discomfort and pressure to adapt their responses.

Besides, the results for men showed only small East-West differences in the interviewer-gender-effect, whereas the different cultural contexts seem particularly important for women. In the more conservative West Germany, women showed greater gender-of-interviewer effects than East German women, who usually indicate the most egalitarian gender ideologies. Hence, the results illustrate the relevance of the entire cultural context, which is perceived by the respondents and apparently determines the degree of adaptation. In the more conservative context of West Germany, women may feel a greater social distance to men and therefore respond more traditionally. Against the background of a greater 
acceptance of women's employment and formal childcare services, and generally more egalitarian ideologies of both sexes in East Germany, women apparently feel a smaller distance between their and men's gender ideologies. Therefore, they adapt their gender ideologies less and respond to men in a generally more egalitarian way. What is surprising, however, is that the more egalitarian context of East Germany does not seem to reduce the gender-ofinterviewer bias of East German men.

\section{Limitations, Implications and Future Research Directions}

Overall, these results provide additional support to the conditional attribution model in the field of gender ideologies, assuming that preferences and gender ideologies may be subject to significant adjustments. From a methodological perspective, the results highlight the need to control for interviewer characteristics such as gender when investigating gender ideologies or gender sensitive topics. Furthermore, the discrepancies in the results for the individual items and the combined index highlight that the conceptual differentiation of the various dimensions of gender ideologies is important and must be taken into account when analyzing attitudinal differences and trends. From a broader perspective, the results point towards the importance of new survey methodological approaches for the collection of sensitive information such as attitudes and ideologies. However, the findings also show that the impact of interviewers' gender seems to be of modest size and concentrated among males and items with a more egalitarian language. Thus, it becomes clear, that egalitarian items seem to be more susceptible to bias than traditionally formulated items, especially among male respondents. This shows that the ongoing discussion on measuring non-traditional and multidimensional attitudes with egalitarian items (e.g., Braun, 2008) needs to be extended to include the possible influence of the interviewer.

Finally, some important limitations need to be considered. The study relied on a few gender role attitude items that were available only in two waves. Hence, the models might not capture all relevant life-course events in order to control for any other potential sources of ideology change. By applying fixed effects regression models, the models account for time-invariant unobserved heterogeneity at the individual level. Yet, there remains a small risk of bias due to other unobserved time-varying characteristics at the interview-level, which correlate with the change in gender ideologies. However, given no suitable data, for example on further interviewers' characteristics such as physical appearance or behavior in 
the interview situation this study could not account for other sources of bias that might affect self-reported gender ideologies or correlate with interviewer's gender. Nevertheless, the longitudinal data in combination with random variation in interviewers are unique to identify attitudinal changes in response to a change in interviewer's gender.

Overall, the study makes an important contribution by emphasizing the relevance of interviewers' gender for investigating change and trends in gender ideologies. As this is one of the first studies investigating gender-of-interviewer effects using large-scale panel data with a random variation in interviewers, future research should look more into the mechanisms of social desirability in the context of gender ideologies and other attitudes. Additionally, future research should carefully evaluate how contextual effects may alter self-reported ideologies among different groups and further account for effect heterogeneity with respect to individual and interviewers characteristics. The results have implications for interviewer selection and mode design when surveying gender ideologies in order to select appropriate survey designs that reduce the impact of interviewer's presence on respondent's discomfort when responding to sensitive questions. In the meantime, the results show that it is both in cross-sectional and longitudinal studies important to control for the interview situation in order to avoid distortions in the effects for influencing factors of ideology change. 


\section{References}

Alwin, D. F., \& Krosnick, J. A. (1991). Aging, Cohorts, and the Stability of Sociopolitical Orientations Over the Life Span. American Journal of Sociology, 97(1), 169-195. https://doi.org/10.1086/229744

Banaszak, L. A. (2006). The Gendering State and Citizens' Attitudes toward Women's Roles: State Policy, Employment, and Religion in Germany. Politics \& Gender, 2(1), 29-55. https://doi.org/10.1017/S1743923X06060016

Bauernschuster, S., \& Rainer, H. (2012). Political regimes and the family: how sex-role attitudes continue to differ in reunified Germany. Journal of Population Economics, 25(1), 5-27. https://doi.org/10.1007/s00148-011-0370-z

Baxter, J., Buchler, S., Perales, F., \& Western, M. (2015). A Life-Changing Event: First Births and Men's and Women's Attitudes to Mothering and Gender Divisions of Labor. Social Forces, 93(3), 9891014. https://doi.org/10.1093/sf/sou103

Benstead, L. J. (2014). Effects of Interviewer-Respondent Gender Interaction on Attitudes toward Women and Politics: Findings from Morocco. International Journal of Public Opinion Research, 26(3), 369-383. https://doi.org/10.1093/ijpor/edt024

Bicchieri, C. (2017). Norms in the wild: How to diagnose, measure, and change social norms. New York, NY: Oxford University Press.

Blossfeld, H.-P., Roßbach, H.-G., \& Maurice, J. von (2011). Education as a Lifelong Process - The German National Educational Panel Study (NEPS). Zeitschrift für Erziehungswissenschaft, Special Issue: 14.

Bolzendahl, C., \& Myers, D. J. (2004). Feminist Attitudes and Support for Gender Equality: Opinion Change in Women and Men, 1974-1998. Social Forces, 83(2), 759-789. https://doi.org/10.1353/sof.2005.0005

Braun, M. (2008). Using Egalitarian Items to Measure Men's and Women's Family Roles. Sex Roles, 59(9-10), 644-656. https://doi.org/10.1007/s11199-008-9468-5

Brooks, C., \& Bolzendahl, C. (2004). The transformation of US gender role attitudes: cohort replacement, social-structural change, and ideological learning. Social Science Research, 33(1), 106-133. https://doi.org/10.1016/S0049-089x(03)00041-3

Cunningham, M. (2001). The influence of parental attitudes and behaviors on children's attitudes toward gender and household labor in early adulthood. Journal of Marriage and Family, 63(1), 111122. https://doi.org/10.1111/j.1741-3737.2001.00111.x

Cunningham, M. (2008). Changing Attitudes toward the Male Breadwinner, Female Homemaker Family Model: Influences of Women's Employment and Education over the Lifecourse. Social Forces, 87(1), 299-323. https://doi.org/10.1353/sof.0.0097

Davis, S. N., \& Greenstein, T. N. (2009). Gender Ideology: Components, Predictors, and Consequences. Annual Review of Sociology, 35(1), 87-105. https://doi.org/10.1146/annurev-soc-070308-115920

Flores-Macias, F., \& Lawson, C. (2008). Effects of Interviewer Gender on Survey Responses: Findings from a Household Survey in Mexico. International Journal of Public Opinion Research, 20(1), 100110. https://doi.org/10.1093/ijpor/edn007

Fuchs, M. (2009). Gender-of-Interviewer Effects in a Video-Enhanced Web Survey. Social Psychology, 4O(1), 37-42. https://doi.org/10.1027/1864-9335.40.1.37

Grunow, D., \& Veltkamp, G. (2016). Institutions as reference points for parents-to-be in European societies: a theoretical and analytical framework. In D. Grunow \& M. Evertsson (Eds.), Couples' Transitions to Parenthood. Analysing Gender and Work in Europe. (pp. 3-33). Cheltenham, UK, Northhampton, MA: Edward Elgar Publishing.

Himelein, K. (2016). Interviewer Effects in Subjective Survey Questions: Evidence From Timor-Leste. International Journal of Public Opinion Research, 28(4), 511-533.

https://doi.org/10.1093/ijpor/edv031 
Huddy, L., Billig, J., Bracciodieta, J., Hoeffler, L., Moynihan, P. J., \& Pugliani, P. (1997). The Effect of Interviewer Gender on the Survey Response. Political Behavior, 19(3), 197-220.

Jablonski, W., Krzewinska, A., \& Grzeszkiewicz-Radulska, K. (2017). Interviewer Gender and Survey Responses: The Effects of Humanizing Cues Variations. European survey research associaton conference, ESRA, Lisbon, 22 November 2017.

Jann, B. (2018). Plotting Regression Coefficients and other Estimates. The Stata Journal, 14(4), 708737. https://doi.org/10.1177/1536867X1401400402

Kane, E. W., \& Macaulay, L. J. (1993). Interviewer Gender and Gender Attitudes. Public Opinion Quarterly, 57(1), 1-28. https://doi.org/10.1086/269352

Klein, M., \& Kühhirt, M. (2010). Sozial erwünschtes Antwortverhalten bezüglichder Teilung häuslicher Arbeit: die Interaktion vonInterviewergeschlecht und Befragtenmerkmalen inTelefoninterviews. Methoden, Daten, Analysen, 4, 70-104.

Kraaykamp, G. (2012). Employment status and family role attitudes: A trend analysis for the Netherlands. International Sociology, 27(3), 308-329. https://doi.org/10.1177/0268580911423046

Krumpal, I. (2013). Determinants of social desirability bias in sensitive surveys: A literature review. Quality \& Quantity, 47(4), 2025-2047. https://doi.org/10.1007/s11135-011-9640-9

Kumlin, S., \& Stadelmann-Steffen, I. (2014). Citizens, policy feedback, and European welfare states. In S. Kumlin \& I. Stadelmann-Steffen (Eds.), Globalization and Welfare series. How Welfare States Shape the Democratic Public: Policy Feedback, Participation, Voting, and Attitudes (pp. 3-18). Cheltenham: Edward Elgar Publishing.

Lipps, O., \& Lutz, G. (2010). How Answers on Political Attitudes are Shaped by Interviewers: Evidence from a Panel Survey. Swiss Journal of Sociology, 36(2), 345-357.

Lipps, O., \& Lutz, G. (2017). Gender of Interviewer Effects in a Multi-topic Centralized CATI Panel Survey. Methods, Data, Analyses : a Journal for Quantitative Methods and Survey Methodology (Mda), 11(1), 67-86. https://doi.org/10.12758/mda.2016.009

Liu, M. (2017). Data collection mode differences between national face-to-face and web surveys on gender inequality and discrimination questions. Women's Studies International Forum, 60, 11-16. https://doi.org/10.1016/j.wsif.2016.11.007

Lueptow, L. B., Moser, S. L., \& Pendleton, B. F. (1990). Gender and response effects in telephone interviews about gender characteristics. Sex Roles, 22(1-2), 29-42. https://doi.org/10.1007/BF00288152

Min, J., Silverstein, M., \& Lendon, J. P. (2012). Intergenerational transmission of values over the family life course. Advances in Life Course Research, 17(3), 112-120. https://doi.org/10.1016/j.alcr.2012.05.001

Scott, J. (1999). European attitudes towards maternal employment. International Journal of Sociology and Social Policy, 19(9/10/11), 144-177. https://doi.org/10.1108/01443339910788929

Sjöberg, O. (2004). The Role of Family Policy Institutions in Explaining Gender-Role Attitudes: A Comparative Multilevel Analysis of Thirteen Industrialized Countries. Journal of European Social Policy, 14(2), 107-123. https://doi.org/10.1177/0958928704042003

Steiber, N., \& Haas, B. (2012). Advances in explaining women's employment patterns. Socio-Economic Review, 10(2), 343-367. https://doi.org/10.1093/ser/mwr039

Stets, J. E., \& Burke, P. J. (2000). Identity Theory and Social Identity Theory. Social Psychology Quarterly, 63(3), 224-237.

Van Putten, A. E., Dykstra, P. A., \& Schippers, J. J. (2008). Just Like Mom? The Intergenerational Reproduction of Women's Paid Work. European Sociological Review, 24(4), 435-449. https://doi.org/10.1093/esr/jcn030

West, B. T., \& Blom, A. G. (2017). Explaining Interviewer Effects: A Research Synthesis. Journal of Survey Statistics and Methodology, 5(2), 175-211. https://doi.org/10.1093/jssam/smw024 
Zoch, G., \& Schober, P. S. (2018). Public Child-Care Expansion and Changing Gender Ideologies of Parents in Germany. Journal of Marriage and Family, 80(4), 1020-1039.

https://doi.org/10.1111/jomf.12486 


\section{Tables}

Table 1. Mean attitudes for male and female respondents by male and female Interviewer.

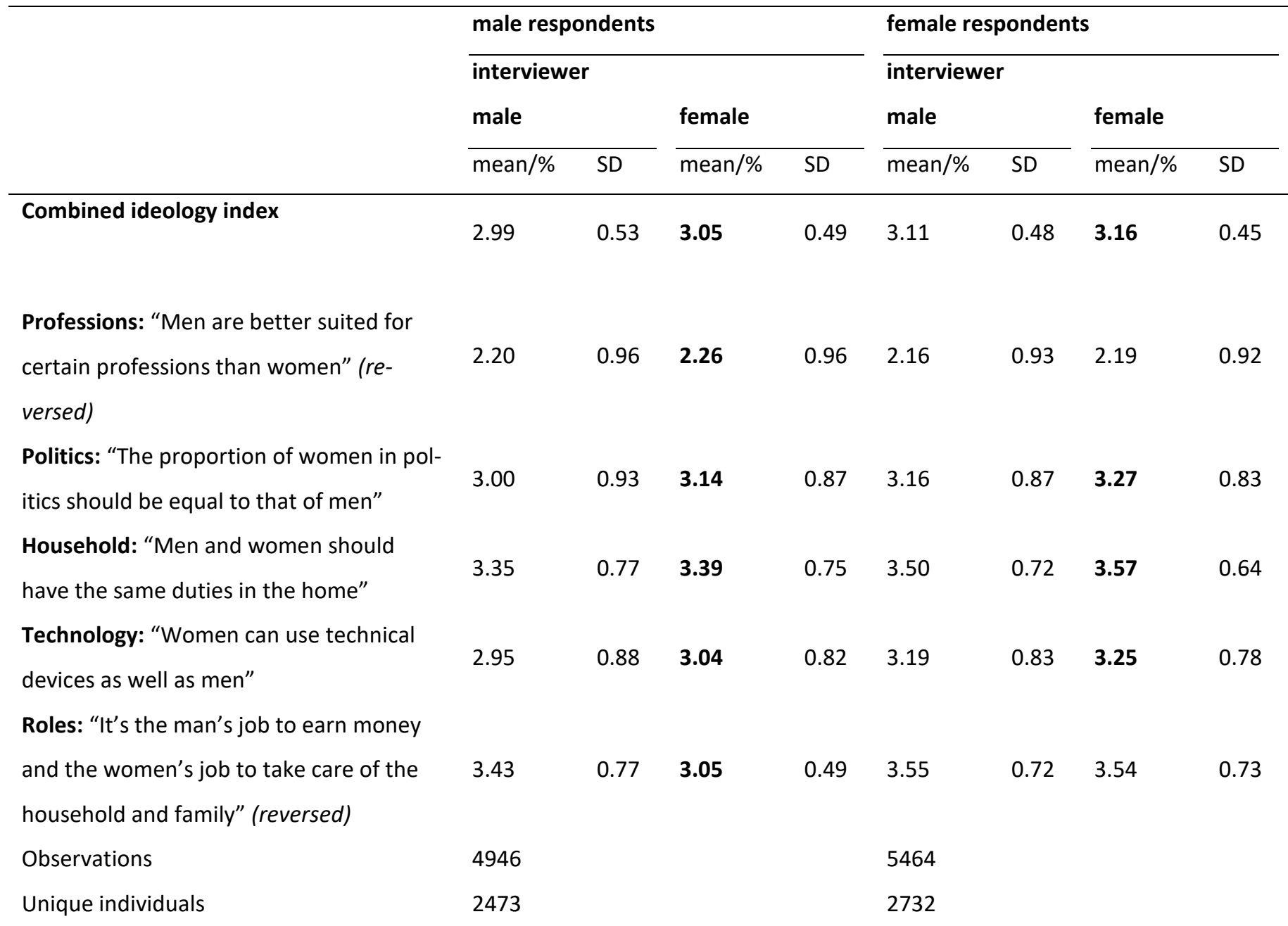

Note: Higher values indicate less traditional gender ideologies. Bold figures indicate significant mean differences between respondents with a male or female interviewer (t-test).

Source: NEPS:SC6:10.0.0. 


\section{Figures}

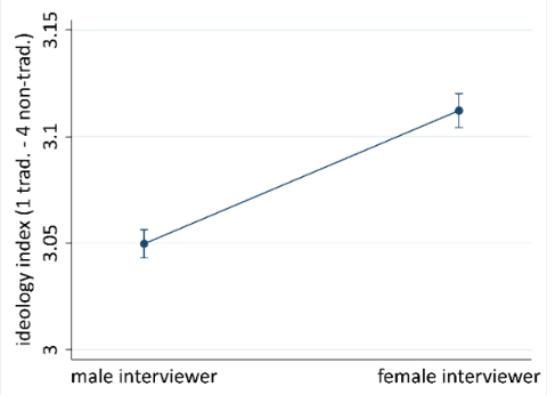

Fig. 1 Predicted gender ideologies by interviewer's gender

Note: The figure is based on Table A1 (m1) in the Online Appendix and plots the predictive margins with 95\% confidence intervals of the interviewer's gender on respondents' gender ideology index (Source: NEPS SC6, N=10410, Own calculation).

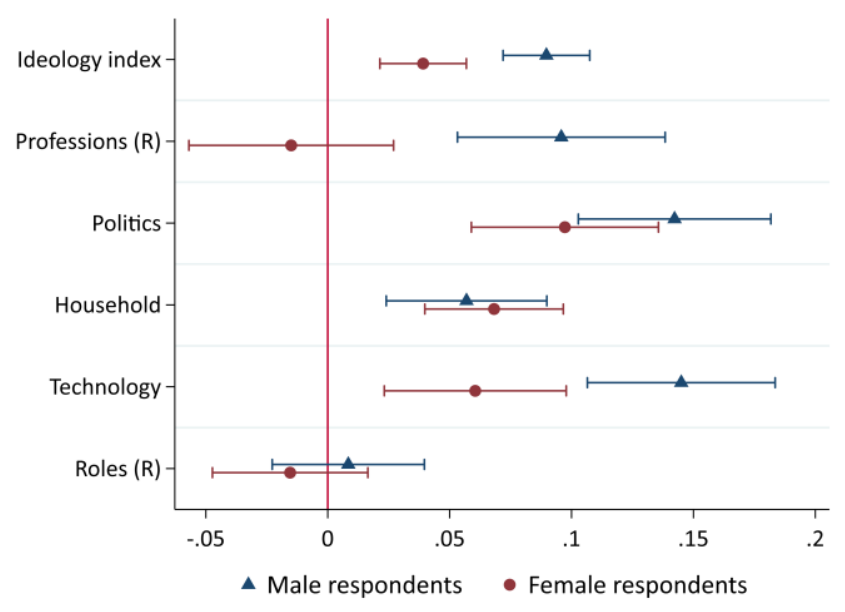

Fig. 2 Female-interviewer-effect on gender ideologies by respondent's gender

Note: The figure is based on Tables 3 and 4 and plots the effects with 95\% confidence intervals of a female interviewer on respondents' gender ideologies (Source: NEPS SC6, N=10410 (Males=4946, Females=5464), Own calculations).
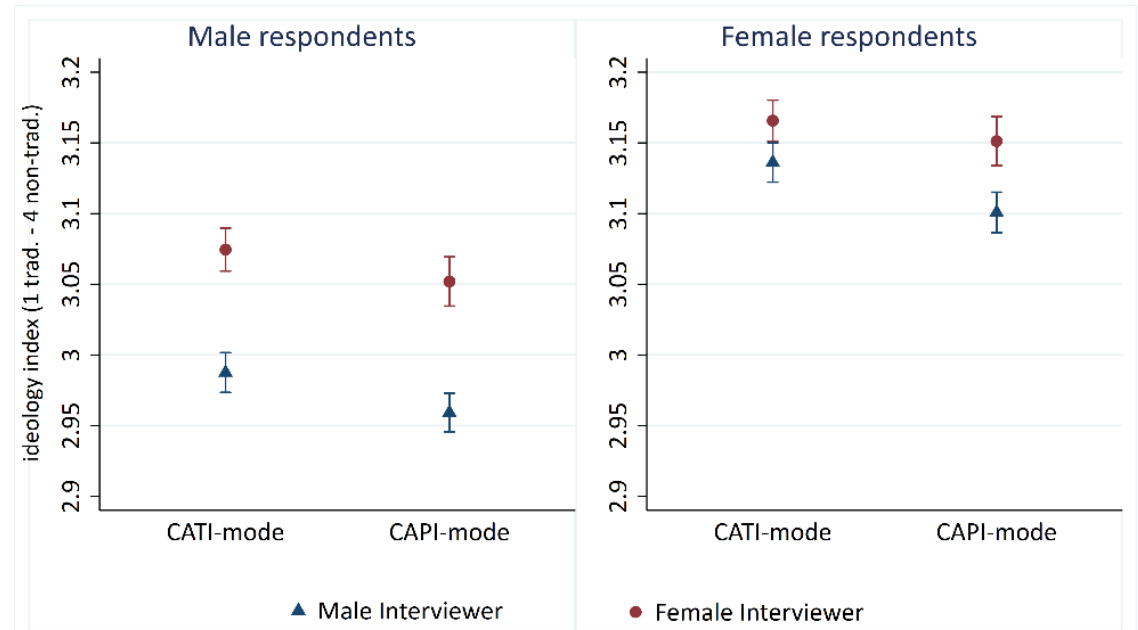

Fig. 3 Predicted gender ideologies for males and females by interviewer's gender and survey mode

Note: The figure plots the predictive margins with $95 \%$ confidence intervals of the interviewer's gender on respondents' gender ideology index by survey mode (Source: NEPS SC6, N=10410 (Males=4946, Females=5464), Own calculations). 


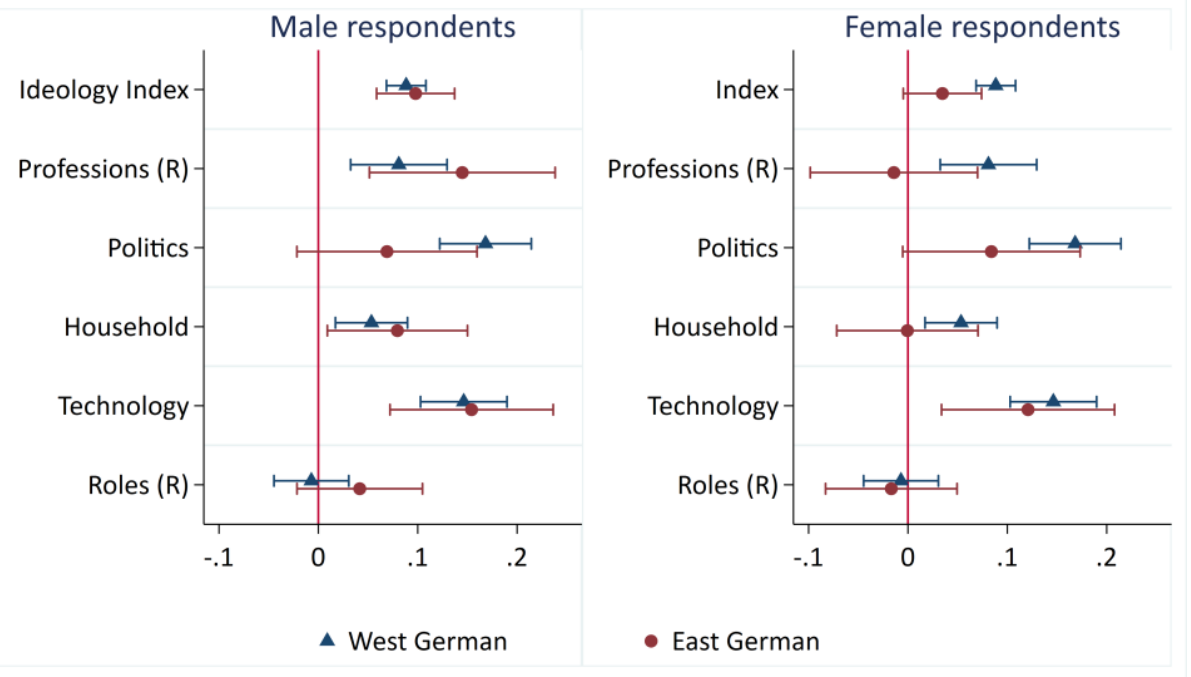

Fig. 4 Female-interviewer-effect for male and female respondents in East and West Germany

Note: The figure is based on Table A 14 and A15 in the Online Appendix and plots the effects with 95\% confidence intervals of a female interviewer on respondents' gender ideologies by West and East German residence (Source: NEPS SC6, N=10410 (Males=4946, Females=5464), Own calculations).

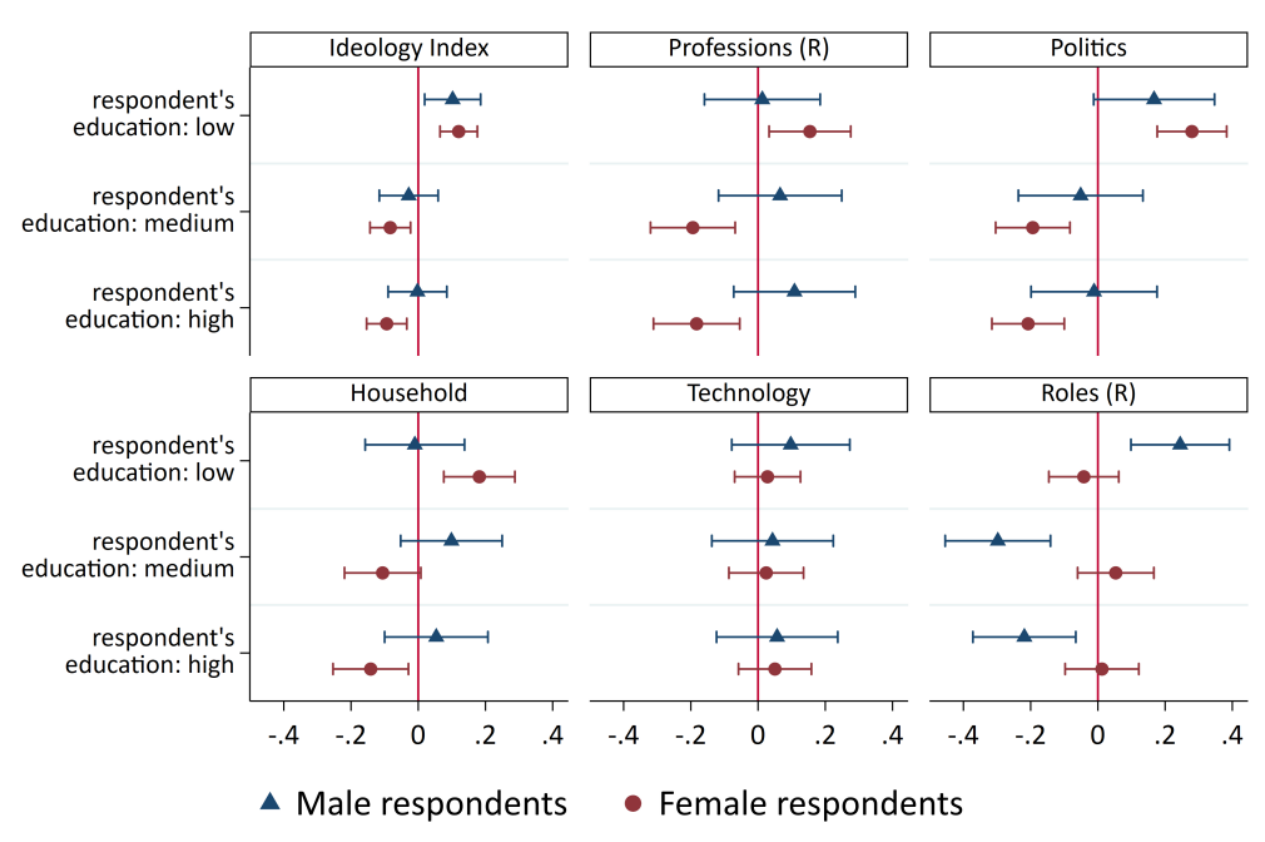

Fig. 5 Interaction effect between a female interviewer and respondent's education

Note: The figure plots the interaction effects with $95 \%$ confidence intervals between a female interviewer and respondents educational background on respondents' gender ideologies (Source: NEPS SC6, N=10410 (Males=4946, Females=5464), Own calculations). 


\section{Gender-of-interviewer Effects in Self-reported Gender Ideologies - Evidence Based on Interviewer Change in a Panel Survey.}

\section{Online Appendix}

Table A1. Descriptive statistics of control variables for male and female respondents by male and female Interviewer.

\begin{tabular}{|c|c|c|c|c|c|c|c|c|}
\hline & \multicolumn{4}{|c|}{ male respondents } & \multicolumn{4}{|c|}{ female respondents } \\
\hline & \multicolumn{2}{|c|}{$\begin{array}{l}\text { Interviewer } \\
\text { male }\end{array}$} & \multicolumn{2}{|l|}{ female } & \multicolumn{2}{|c|}{$\begin{array}{l}\text { Interviewer } \\
\text { male }\end{array}$} & \multicolumn{2}{|l|}{ female } \\
\hline & mean/\% & SD & mean $/ \%$ & SD & mean/\% & SD & mean $/ \%$ & SD \\
\hline Age & 50.33 & 10.85 & 50.79 & 10.73 & 50.33 & 10.29 & 49.98 & 10.36 \\
\hline education: low (ref.) & 0.06 & 0.24 & 0.07 & 0.26 & 0.09 & 0.29 & 0.10 & 0.30 \\
\hline education: medium & 0.37 & 0.48 & 0.38 & 0.49 & 0.42 & 0.49 & 0.40 & 0.49 \\
\hline education: high & 0.56 & 0.50 & 0.54 & 0.50 & 0.49 & 0.50 & 0.50 & 0.50 \\
\hline working (dummy) & 0.77 & 0.42 & 0.77 & 0.42 & 0.67 & 0.47 & 0.67 & 0.47 \\
\hline married (dummy) & 0.72 & 0.45 & 0.73 & 0.45 & 0.71 & 0.45 & 0.70 & 0.46 \\
\hline cohabitation (dummy) & 0.85 & 0.36 & 0.85 & 0.36 & 0.84 & 0.36 & 0.84 & 0.37 \\
\hline leave take-up (dummy) & 0.00 & 0.05 & 0.00 & 0.04 & 0.03 & 0.16 & 0.03 & 0.16 \\
\hline number children & 0.82 & 1.02 & 0.78 & 0.99 & 0.85 & 1.03 & 0.87 & 1.03 \\
\hline household income (defl. / net) & 3863.05 & 3265.95 & 3686.72 & 2353.45 & 3482.49 & 2372.92 & 3476.55 & 4373.04 \\
\hline interview mode: CAPI (ref.) & 0.48 & 0.50 & 0.52 & 0.50 & 0.48 & 0.50 & 0.55 & 0.50 \\
\hline interview mode: CATI & 0.52 & 0.50 & 0.47 & 0.50 & 0.52 & 0.50 & 0.45 & 0.50 \\
\hline interviewer's age: $<29$ (ref.) & 0.14 & 0.35 & 0.16 & 0.37 & 0.14 & 0.35 & 0.14 & 0.35 \\
\hline interviewer's age: 30-49 & 0.30 & 0.46 & 0.19 & 0.39 & 0.31 & 0.46 & 0.20 & 0.40 \\
\hline interviewer's age: $50-65$ & 0.33 & 0.47 & 0.58 & 0.49 & 0.32 & 0.47 & 0.60 & 0.49 \\
\hline interviewer's age: $65+$ & 0.22 & 0.41 & 0.07 & 0.25 & 0.22 & 0.42 & 0.06 & 0.24 \\
\hline interviewer's education: low (ref.) & 0.10 & 0.29 & 0.15 & 0.36 & 0.09 & 0.29 & 0.13 & 0.34 \\
\hline interviewer's education: medium & 0.19 & 0.39 & 0.19 & 0.39 & 0.17 & 0.37 & 0.19 & 0.39 \\
\hline interviewer's education: high & 0.71 & 0.45 & 0.66 & 0.47 & 0.74 & 0.44 & 0.68 & 0.47 \\
\hline interviewer's experience: 0 y (ref.) & 0.25 & 0.43 & 0.23 & 0.42 & 0.23 & 0.42 & 0.22 & 0.42 \\
\hline interviewer's experience: $1-2$ y & 0.25 & 0.43 & 0.23 & 0.42 & 0.26 & 0.44 & 0.21 & 0.40 \\
\hline interviewer's experience: $2-3 y$ & 0.21 & 0.40 & 0.21 & 0.41 & 0.21 & 0.41 & 0.22 & 0.42 \\
\hline interviewer's experience: $3 y+$ & 0.30 & 0.46 & 0.33 & 0.47 & 0.30 & 0.46 & 0.35 & 0.48 \\
\hline interview duration in minutes & 61.80 & 17.65 & 62.36 & 20.41 & 62.54 & 19.75 & 62.06 & 21.89 \\
\hline number of previous interviews & 1.52 & 0.83 & 1.52 & 0.87 & 1.53 & 0.85 & 1.53 & 0.89 \\
\hline respondent tired & 1.41 & 0.97 & 1.49 & 1.07 & 1.50 & 1.11 & 1.57 & 1.24 \\
\hline respondents cooperates & 1.97 & 0.25 & 1.95 & 0.31 & 1.96 & 0.28 & 1.96 & 0.29 \\
\hline East German & 0.18 & 0.39 & 0.21 & 0.41 & 0.20 & 0.40 & 0.22 & 0.42 \\
\hline Observations & 2820 & & 2126 & & 3009 & & 2455 & \\
\hline Unique individuals & 1999 & & 1652 & & 2158 & & 1881 & \\
\hline Observations (total) & 4946 & & & & 5464 & & & \\
\hline Unique individuals (total) & 2473 & & & & 2732 & & & \\
\hline
\end{tabular}

Note: Bold figures indicate significant mean differences between respondents with a male or female interviewer (t-test). Reference category indicated with .ref, net household income deflated with base year 2015.

Source: NEPS:SC6:10.0.0. 
Table A2. Fixed-effects-regression models for male and female respondents.

\begin{tabular}{|c|c|c|c|c|c|c|c|c|c|c|c|c|}
\hline & \multicolumn{2}{|c|}{ Index } & \multicolumn{2}{|c|}{ Profession (R) } & \multicolumn{2}{|c|}{ Politics } & \multicolumn{2}{|c|}{ Household } & \multicolumn{2}{|c|}{ Technology } & \multicolumn{2}{|c|}{ Roles (R) } \\
\hline & \multicolumn{2}{|c|}{$(\mathrm{m} 1)$} & \multicolumn{2}{|c|}{$(\mathrm{m} 2)$} & \multicolumn{2}{|c|}{ (m3) } & \multicolumn{2}{|c|}{ (m4) } & \multicolumn{2}{|c|}{ (m5) } & \multicolumn{2}{|c|}{ (m6) } \\
\hline & $b$ & RSE & $b$ & RSE & $b$ & RSE & $b$ & RSE & $b$ & RSE & $b$ & RSE \\
\hline interviewer: female & $0.06 * * *$ & $(0.01)$ & $0.04 *$ & $(0.02)$ & $0.12^{* * *}$ & $(0.01)$ & $0.06 * * *$ & $(0.01)$ & $0.10 * * *$ & $(0.01)$ & -0.00 & $(0.01)$ \\
\hline Age & $0.03^{* *}$ & $(0.01)$ & $0.06^{* *}$ & $(0.02)$ & 0.01 & $(0.02)$ & $0.04 * *$ & $(0.02)$ & $0.07 * * *$ & $(0.02)$ & $-0.04 *$ & $(0.02)$ \\
\hline age square & -0.00 & $(0.00)$ & -0.00 & $(0.00)$ & 0.00 & $(0.00)$ & $-0.00 *$ & $(0.00)$ & $-0.00 * *$ & $(0.00)$ & $0.00^{*}$ & $(0.00)$ \\
\hline working & -0.01 & $(0.01)$ & 0.02 & $(0.03)$ & -0.05 & $(0.03)$ & -0.00 & $(0.02)$ & 0.00 & $(0.03)$ & 0.01 & $(0.02)$ \\
\hline married & -0.01 & $(0.02)$ & -0.06 & $(0.06)$ & -0.00 & $(0.05)$ & -0.05 & $(0.04)$ & 0.05 & $(0.05)$ & -0.01 & $(0.04)$ \\
\hline cohabitation & 0.02 & $(0.03)$ & 0.01 & $(0.06)$ & 0.13 & $(0.07)$ & -0.01 & $(0.05)$ & 0.02 & $(0.06)$ & -0.07 & $(0.04)$ \\
\hline leave take-up & -0.04 & $(0.03)$ & -0.00 & $(0.07)$ & -0.10 & $(0.07)$ & 0.05 & $(0.06)$ & -0.06 & $(0.06)$ & $-0.10^{*}$ & $(0.05)$ \\
\hline number children & -0.01 & $(0.01)$ & 0.02 & $(0.02)$ & -0.01 & $(0.02)$ & $-0.03 *$ & $(0.01)$ & -0.00 & $(0.02)$ & -0.01 & $(0.01)$ \\
\hline net household income (log) & -0.02 & $(0.01)$ & 0.02 & $(0.03)$ & -0.04 & $(0.03)$ & 0.02 & $(0.02)$ & $-0.07^{*}$ & $(0.03)$ & -0.02 & $(0.02)$ \\
\hline CAPI (ref. CATI) & $-0.06 * * *$ & $(0.02)$ & $-0.12 * * *$ & $(0.04)$ & $-0.08 *$ & $(0.04)$ & $-0.08 * *$ & $(0.03)$ & $-0.08^{* *}$ & $(0.03)$ & 0.06 & $(0.03)$ \\
\hline interviewer's age: $30-49$ (ref. <30) & $0.03 * *$ & $(0.01)$ & -0.02 & $(0.03)$ & $0.08 * * *$ & $(0.02)$ & $0.07^{* * *}$ & $(0.02)$ & -0.00 & $(0.02)$ & 0.02 & $(0.02)$ \\
\hline interviewer's age: $50-65$ & 0.01 & $(0.01)$ & -0.04 & $(0.03)$ & 0.01 & $(0.02)$ & 0.02 & $(0.02)$ & 0.03 & $(0.02)$ & 0.01 & $(0.02)$ \\
\hline interviewer's age: $65+$ & 0.02 & $(0.01)$ & -0.02 & $(0.03)$ & 0.04 & $(0.03)$ & 0.04 & $(0.02)$ & 0.01 & $(0.03)$ & 0.03 & $(0.03)$ \\
\hline interviewer's education: medium (ref. low) & 0.02 & $(0.01)$ & 0.02 & $(0.03)$ & 0.02 & $(0.03)$ & 0.01 & $(0.02)$ & $0.05 *$ & $(0.02)$ & -0.02 & $(0.02)$ \\
\hline interviewer's education: high & $0.04 * * *$ & $(0.01)$ & 0.03 & $(0.03)$ & 0.04 & $(0.02)$ & 0.02 & $(0.02)$ & $0.07 * * *$ & $(0.02)$ & $0.03 *$ & $(0.01)$ \\
\hline interviewer's experience: $1-2$ y (ref. $<1$ y) & -0.01 & $(0.01)$ & 0.03 & $(0.02)$ & -0.03 & $(0.02)$ & $-0.04 * *$ & $(0.02)$ & 0.01 & $(0.02)$ & -0.02 & $(0.02)$ \\
\hline interviewer's experience: $2-3 y$ & -0.00 & $(0.01)$ & 0.04 & $(0.02)$ & -0.03 & $(0.02)$ & 0.00 & $(0.02)$ & -0.02 & $(0.02)$ & -0.01 & $(0.02)$ \\
\hline interviewer's experience: $3 y+$ & 0.01 & $(0.01)$ & 0.01 & $(0.02)$ & -0.01 & $(0.02)$ & 0.03 & $(0.02)$ & 0.01 & $(0.02)$ & 0.01 & $(0.02)$ \\
\hline interview duration in minutes & 0.00 & $(0.00)$ & 0.00 & $(0.00)$ & $-0.00 * *$ & $(0.00)$ & 0.00 & $(0.00)$ & 0.00 & $(0.00)$ & 0.00 & $(0.00)$ \\
\hline number of previous interviews & -0.01 & $(0.01)$ & $-0.03 *$ & $(0.01)$ & 0.00 & $(0.01)$ & -0.01 & $(0.01)$ & -0.02 & $(0.01)$ & 0.01 & $(0.01)$ \\
\hline respondent tired & $-0.01 *$ & $(0.00)$ & -0.00 & $(0.01)$ & -0.01 & $(0.01)$ & -0.01 & $(0.01)$ & 0.01 & $(0.01)$ & $-0.02 * *$ & $(0.01)$ \\
\hline cons & $2.17 * * *$ & $(0.25)$ & 0.01 & (0.59) & $2.74^{* * *}$ & $(0.65)$ & $1.97^{* * *}$ & $(0.46)$ & $1.34 *$ & $(0.52)$ & $4.82 * * *$ & $(0.52)$ \\
\hline Observations & \multicolumn{2}{|c|}{10410} & \multicolumn{2}{|c|}{10410} & \multicolumn{2}{|c|}{10410} & \multicolumn{2}{|c|}{10410} & \multicolumn{2}{|c|}{10410} & \multicolumn{2}{|c|}{10410} \\
\hline Individuals & \multicolumn{2}{|c|}{5205} & \multicolumn{2}{|c|}{5205} & \multicolumn{2}{|c|}{5205} & \multicolumn{2}{|c|}{5205} & \multicolumn{2}{|c|}{5205} & \multicolumn{2}{|c|}{5205} \\
\hline Number of Interviewers & \multicolumn{2}{|c|}{465} & \multicolumn{2}{|c|}{465} & \multicolumn{2}{|c|}{465} & & & & & & \\
\hline $\mathrm{F}$ & & & & & & & & & & & & \\
\hline r2_w & & & & & & & & & & & & \\
\hline $\mathrm{p}$ & & & & & & & & & & & & \\
\hline
\end{tabular}

Note: Higher attitude scores indicate less traditional attitudes. Robust standard errors (RSE) in parentheses. Reference category indicated with .ref, net household income deflated with base year 2015.

${ }^{*} \mathrm{p}<0.05,{ }^{* *} \mathrm{p}<0.01,{ }^{* * *} \mathrm{p}<0.001$, Source: NEPS:SC6:10.0.0, own calculations. 
Table A3. Fixed-effects-regression models for male respondents.

\begin{tabular}{|c|c|c|c|c|c|c|c|c|c|c|c|c|}
\hline & \multicolumn{2}{|c|}{ Index } & \multicolumn{2}{|c|}{ Profession (R) } & \multicolumn{2}{|c|}{ Politics } & \multicolumn{2}{|c|}{ Household } & \multicolumn{2}{|c|}{ Technology } & \multicolumn{2}{|c|}{ Roles (R) } \\
\hline & \multicolumn{2}{|c|}{ (m1) } & \multicolumn{2}{|c|}{$(\mathrm{m} 2)$} & \multicolumn{2}{|c|}{ (m3) } & \multicolumn{2}{|c|}{$(\mathrm{m} 4)$} & \multicolumn{2}{|c|}{$(\mathrm{m} 5)$} & \multicolumn{2}{|c|}{ (m6) } \\
\hline & $b$ & RSE & $b$ & RSE & $b$ & RSE & $b$ & RSE & $b$ & RSE & $b$ & RSE \\
\hline interviewer: female & $0.09 * * *$ & $(0.01)$ & $0.10 * * *$ & $(0.02)$ & $0.14 * * *$ & $(0.02)$ & $0.06 * * *$ & $(0.02)$ & $0.15^{* * *}$ & $(0.02)$ & 0.01 & $(0.02)$ \\
\hline Age & $0.03^{*}$ & $(0.01)$ & $0.08 * *$ & $(0.03)$ & 0.02 & $(0.03)$ & 0.04 & $(0.02)$ & $0.07 * *$ & $(0.03)$ & $-0.06^{*}$ & $(0.03)$ \\
\hline age square & -0.00 & $(0.00)$ & -0.00 & $(0.00)$ & 0.00 & $(0.00)$ & -0.00 & $(0.00)$ & -0.00 & $(0.00)$ & $0.00 * *$ & $(0.00)$ \\
\hline Working & -0.03 & $(0.02)$ & -0.03 & $(0.05)$ & $-0.08 *$ & $(0.04)$ & $-0.08 *$ & $(0.03)$ & 0.06 & $(0.05)$ & -0.00 & $(0.03)$ \\
\hline Married & -0.03 & $(0.04)$ & -0.01 & (0.09) & -0.07 & $(0.08)$ & -0.12 & $(0.07)$ & 0.00 & $(0.07)$ & 0.01 & $(0.05)$ \\
\hline Cohabitation & $0.09 * *$ & $(0.03)$ & 0.02 & $(0.08)$ & $0.23 *$ & $(0.10)$ & 0.07 & $(0.08)$ & $0.22 *$ & $(0.08)$ & -0.09 & $(0.06)$ \\
\hline leave take-up & $0.16^{*}$ & $(0.07)$ & 0.00 & $(0.17)$ & 0.31 & $(0.21)$ & 0.15 & $(0.16)$ & 0.24 & (0.19) & 0.10 & $(0.12)$ \\
\hline number children & -0.00 & $(0.01)$ & 0.02 & (0.03) & -0.02 & $(0.02)$ & -0.02 & $(0.02)$ & -0.01 & $(0.03)$ & 0.01 & $(0.02)$ \\
\hline net household income (log) & 0.01 & $(0.02)$ & 0.05 & $(0.04)$ & -0.01 & $(0.04)$ & 0.02 & $(0.04)$ & -0.02 & $(0.04)$ & 0.00 & $(0.03)$ \\
\hline CAPI (ref. CATI) & $-0.10 * * *$ & $(0.02)$ & $-0.25 * * *$ & $(0.05)$ & -0.06 & $(0.05)$ & $-0.09 *$ & $(0.03)$ & $-0.14^{* *}$ & $(0.05)$ & 0.04 & $(0.04)$ \\
\hline interviewer's education: medium (ref. low) & $0.04^{*}$ & $(0.02)$ & -0.03 & $(0.04)$ & 0.05 & $(0.04)$ & 0.03 & $(0.03)$ & $0.10^{* *}$ & $(0.03)$ & 0.03 & $(0.03)$ \\
\hline interviewer's education: high & $0.07 * * *$ & $(0.01)$ & 0.03 & $(0.03)$ & 0.06 & $(0.04)$ & $0.07^{*}$ & $(0.03)$ & $0.13^{* * *}$ & $(0.03)$ & $0.08 * * *$ & $(0.02)$ \\
\hline interviewer's age: $30-49$ (ref. <30) & $0.03 *$ & $(0.01)$ & -0.05 & $(0.03)$ & $0.11 * * *$ & $(0.03)$ & $0.06^{*}$ & $(0.03)$ & 0.02 & $(0.03)$ & -0.00 & $(0.03)$ \\
\hline interviewer's age: $50-65$ & -0.00 & $(0.01)$ & $-0.08 *$ & $(0.03)$ & 0.03 & $(0.03)$ & -0.00 & $(0.03)$ & 0.03 & $(0.03)$ & -0.01 & $(0.03)$ \\
\hline interviewer's age: $65+$ & 0.03 & $(0.02)$ & 0.04 & $(0.04)$ & 0.01 & $(0.04)$ & 0.03 & $(0.04)$ & 0.03 & $(0.04)$ & 0.04 & $(0.04)$ \\
\hline interviewer's experience: $1-2$ y (ref. $<1$ y) & $-0.03 *$ & $(0.01)$ & -0.00 & $(0.03)$ & -0.04 & $(0.03)$ & $-0.08 * *$ & $(0.02)$ & 0.00 & $(0.03)$ & -0.01 & $(0.02)$ \\
\hline interviewer's experience: $2-3 y$ & -0.01 & $(0.01)$ & 0.02 & $(0.03)$ & -0.03 & $(0.03)$ & -0.00 & $(0.02)$ & -0.03 & $(0.03)$ & -0.03 & $(0.03)$ \\
\hline interviewer's experience: $3 y+$ & 0.02 & $(0.01)$ & 0.00 & $(0.03)$ & -0.00 & $(0.03)$ & $0.06^{*}$ & $(0.03)$ & 0.01 & $(0.03)$ & 0.02 & $(0.02)$ \\
\hline interview duration in minutes & $0.00 *$ & $(0.00)$ & $0.00 *$ & $(0.00)$ & -0.00 & $(0.00)$ & 0.00 & $(0.00)$ & 0.00 & $(0.00)$ & 0.00 & $(0.00)$ \\
\hline number of previous interviews & -0.01 & $(0.01)$ & -0.01 & $(0.02)$ & -0.00 & $(0.02)$ & -0.02 & $(0.01)$ & -0.01 & $(0.02)$ & 0.01 & $(0.02)$ \\
\hline respondent tired & $-0.01^{*}$ & $(0.00)$ & 0.01 & $(0.01)$ & $-0.03 * *$ & $(0.01)$ & -0.01 & $(0.01)$ & 0.01 & $(0.01)$ & $-0.03 * *$ & $(0.01)$ \\
\hline cons & $1.51^{* * *}$ & $(0.38)$ & -1.07 & $(0.91)$ & $1.85^{*}$ & $(0.92)$ & $1.82^{* *}$ & $(0.68)$ & -0.01 & $(0.87)$ & $4.96 * * *$ & $(0.77)$ \\
\hline Observations & \multicolumn{2}{|c|}{4946} & \multicolumn{2}{|c|}{4946} & \multicolumn{2}{|c|}{4946} & \multicolumn{2}{|c|}{4946} & \multicolumn{2}{|c|}{4946} & \multicolumn{2}{|c|}{4946} \\
\hline Individuals & \multicolumn{2}{|c|}{2473} & \multicolumn{2}{|c|}{2473} & \multicolumn{2}{|c|}{2473} & \multicolumn{2}{|c|}{2473} & \multicolumn{2}{|c|}{2473} & \multicolumn{2}{|c|}{2473} \\
\hline Number of Interviewers & \multicolumn{2}{|c|}{440} & \multicolumn{2}{|c|}{440} & \multicolumn{2}{|c|}{440} & 44 & & 44 & & 44 & \\
\hline $\mathrm{F}$ & 10.7 & & 5.5 & & 4.9 & & 6. & & 5.9 & & 4.0 & \\
\hline r2_w & 0.0 & & 0.0 & & 0.0 & & 0. & & 0.0 & & 0.0 & \\
\hline$P^{-}$ & 0.0 & & 0.0 & & 0.0 & & 0. & & 0.0 & & 0.0 & \\
\hline
\end{tabular}

Source: NEPS:SC6:10.0.0, own calculations. 
Table A4. Fixed-effects-regression models for female respondents.

\begin{tabular}{|c|c|c|c|c|c|c|c|c|c|c|c|c|}
\hline & \multicolumn{2}{|c|}{ Index } & \multicolumn{2}{|c|}{ Profession (R) } & \multicolumn{2}{|c|}{ Politics } & \multicolumn{2}{|c|}{ Household } & \multicolumn{2}{|c|}{ Technology } & \multicolumn{2}{|c|}{ Roles (R) } \\
\hline & \multicolumn{2}{|c|}{ (m1) } & \multicolumn{2}{|c|}{$(\mathrm{m} 2)$} & \multicolumn{2}{|c|}{$(\mathrm{m} 3)$} & \multicolumn{2}{|c|}{$(\mathrm{m} 4)$} & \multicolumn{2}{|c|}{ (m5) } & \multicolumn{2}{|c|}{ (m6) } \\
\hline & $B$ & RSE & $b$ & RSE & $b$ & RSE & $b$ & RSE & $b$ & RSE & $b$ & RSE \\
\hline interviewer: female & $0.04 * * *$ & $(0.01)$ & -0.01 & $(0.02)$ & $0.10^{* * *}$ & $(0.02)$ & $0.07^{* * *}$ & $(0.01)$ & $0.06^{* *}$ & $(0.02)$ & -0.02 & $(0.02)$ \\
\hline Age & $0.02 *$ & $(0.01)$ & 0.03 & $(0.03)$ & 0.00 & $(0.03)$ & $0.04^{*}$ & $(0.02)$ & $0.06 * *$ & $(0.02)$ & -0.02 & $(0.02)$ \\
\hline age square & -0.00 & $(0.00)$ & -0.00 & $(0.00)$ & 0.00 & $(0.00)$ & -0.00 & $(0.00)$ & $-0.00 *$ & $(0.00)$ & 0.00 & $(0.00)$ \\
\hline Working & 0.01 & $(0.02)$ & 0.03 & $(0.04)$ & -0.02 & $(0.04)$ & 0.06 & $(0.03)$ & -0.05 & $(0.03)$ & 0.01 & $(0.03)$ \\
\hline Married & -0.00 & $(0.03)$ & -0.11 & $(0.07)$ & 0.04 & $(0.07)$ & 0.01 & $(0.04)$ & 0.08 & $(0.07)$ & -0.03 & $(0.06)$ \\
\hline Cohabitation & -0.08 & $(0.04)$ & -0.01 & (0.09) & -0.00 & $(0.11)$ & -0.09 & $(0.07)$ & $-0.24 * *$ & $(0.08)$ & -0.04 & $(0.06)$ \\
\hline leave take-up & -0.05 & $(0.03)$ & -0.00 & $(0.07)$ & -0.11 & $(0.07)$ & 0.09 & $(0.06)$ & $-0.12 *$ & $(0.06)$ & $-0.11^{*}$ & $(0.06)$ \\
\hline number children & -0.01 & $(0.01)$ & 0.03 & (0.03) & -0.01 & $(0.02)$ & $-0.04 *$ & $(0.02)$ & -0.00 & $(0.02)$ & -0.03 & $(0.02)$ \\
\hline net household income (log) & $-0.04 *$ & $(0.02)$ & 0.01 & $(0.05)$ & -0.07 & $(0.04)$ & 0.02 & $(0.03)$ & $-0.11 * *$ & $(0.03)$ & -0.05 & (0.03) \\
\hline CAPI (ref. CATI) & -0.03 & $(0.02)$ & -0.01 & $(0.05)$ & $-0.10 *$ & $(0.04)$ & -0.08 & $(0.05)$ & -0.03 & $(0.04)$ & 0.08 & $(0.04)$ \\
\hline interviewer's education: medium (ref. low) & -0.00 & $(0.02)$ & 0.07 & $(0.04)$ & -0.03 & $(0.03)$ & -0.01 & $(0.03)$ & 0.01 & $(0.03)$ & $-0.06 *$ & $(0.03)$ \\
\hline interviewer's education: high & 0.00 & $(0.01)$ & 0.04 & $(0.03)$ & 0.01 & $(0.03)$ & -0.02 & $(0.03)$ & 0.01 & $(0.03)$ & -0.02 & $(0.02)$ \\
\hline interviewer's age: $30-49$ (ref. <30) & $0.03 *$ & $(0.01)$ & 0.01 & $(0.04)$ & 0.06 & $(0.03)$ & $0.08 * * *$ & $(0.02)$ & -0.02 & $(0.03)$ & 0.05 & $(0.03)$ \\
\hline interviewer's age: $50-65$ & 0.02 & $(0.02)$ & 0.01 & $(0.04)$ & -0.01 & $(0.03)$ & $0.05^{*}$ & $(0.02)$ & 0.02 & $(0.03)$ & 0.04 & $(0.03)$ \\
\hline interviewer's age: $65+$ & 0.01 & $(0.02)$ & -0.06 & $(0.05)$ & 0.06 & $(0.04)$ & 0.05 & $(0.03)$ & -0.01 & $(0.04)$ & 0.02 & $(0.03)$ \\
\hline interviewer's experience: $1-2$ y (ref. $<1$ y) & 0.01 & $(0.01)$ & 0.06 & $(0.03)$ & -0.02 & $(0.03)$ & -0.01 & $(0.02)$ & 0.02 & $(0.02)$ & -0.02 & $(0.02)$ \\
\hline interviewer's experience: $2-3 y$ & 0.01 & $(0.01)$ & 0.05 & $(0.04)$ & -0.03 & $(0.03)$ & 0.01 & $(0.02)$ & -0.01 & $(0.03)$ & 0.01 & $(0.02)$ \\
\hline interviewer's experience: $3 y+$ & 0.01 & $(0.01)$ & 0.03 & $(0.03)$ & -0.02 & $(0.03)$ & 0.01 & $(0.02)$ & 0.01 & $(0.03)$ & 0.01 & $(0.02)$ \\
\hline interview duration in minutes & -0.00 & $(0.00)$ & 0.00 & $(0.00)$ & -0.00 & $(0.00)$ & -0.00 & $(0.00)$ & 0.00 & $(0.00)$ & 0.00 & $(0.00)$ \\
\hline number of previous interviews & -0.01 & $(0.01)$ & $-0.06 * *$ & $(0.02)$ & 0.01 & $(0.02)$ & -0.00 & $(0.02)$ & -0.02 & $(0.02)$ & 0.02 & $(0.02)$ \\
\hline respondent tired & -0.00 & $(0.00)$ & -0.01 & $(0.01)$ & 0.00 & $(0.01)$ & -0.01 & $(0.01)$ & 0.01 & $(0.01)$ & -0.01 & $(0.01)$ \\
\hline _cons & $2.78 * * *$ & $(0.35)$ & 1.00 & $(0.88)$ & $3.54 * * *$ & $(0.86)$ & $2.14 * *$ & $(0.67)$ & $2.63 * * *$ & $(0.70)$ & $4.61 * * *$ & $(0.67)$ \\
\hline Observations & \multicolumn{2}{|c|}{5464} & \multicolumn{2}{|c|}{5464} & \multicolumn{2}{|c|}{5464} & \multicolumn{2}{|c|}{5464} & \multicolumn{2}{|c|}{5464} & \multicolumn{2}{|c|}{5464} \\
\hline Individuals & \multicolumn{2}{|c|}{2732} & \multicolumn{2}{|c|}{2732} & \multicolumn{2}{|c|}{2732} & \multicolumn{2}{|c|}{2732} & \multicolumn{2}{|c|}{2732} & \multicolumn{2}{|c|}{2732} \\
\hline Number of Interviewers & \multicolumn{2}{|c|}{445} & \multicolumn{2}{|c|}{445} & \multicolumn{2}{|c|}{445} & 44 & & 44 & & 44 & \\
\hline $\mathrm{F}$ & & & 2. & & 5. & & 3.9 & & 3.2 & & 4.1 & \\
\hline r2_w & & & 0. & & 0. & & 0.0 & & 0.0 & & 0.0 & \\
\hline$P^{-}$ & 0 & & $0 .($ & & 0. & & 0.0 & & 0.0 & & 0.0 & \\
\hline
\end{tabular}

Source: NEPS:SC6:10.0.0. 
Table A5. Female-interviewer-effect on male respondents' agreement with attitudinal statement "Index" (Stepwise fixed-effects-regression models).

\begin{tabular}{|c|c|c|c|c|c|c|c|c|c|c|c|c|c|c|c|c|}
\hline & \multirow{2}{*}{\multicolumn{2}{|c|}{$\frac{\text { Index }}{\text { (m1) }}$}} & \multirow{2}{*}{\multicolumn{2}{|c|}{$\frac{\text { Index }}{\text { (m2) }}$}} & \multirow{2}{*}{\multicolumn{2}{|c|}{$\frac{\text { Index }}{(\mathrm{m} 3)}$}} & \multirow{2}{*}{\multicolumn{2}{|c|}{$\frac{\text { Index }}{\text { (m4) }}$}} & \multirow{2}{*}{\multicolumn{2}{|c|}{$\frac{\text { Index }}{\text { (m5) }}$}} & \multirow{2}{*}{\multicolumn{2}{|c|}{$\frac{\text { Index }}{\text { (m6) }}$}} & \multirow{2}{*}{\multicolumn{2}{|c|}{$\frac{\text { Index }}{(\mathrm{m} 7)}$}} & \multirow{2}{*}{\multicolumn{2}{|c|}{$\frac{\text { Index }}{\text { (m8) }}$}} \\
\hline & & & & & & & & & & & & & & & & \\
\hline & $b$ & RSE & $b$ & RSE & $b$ & RSE & $b$ & RSE & $b$ & RSE & $b$ & RSE & $b$ & RSE & $b$ & RSE \\
\hline interviewer: female & $0.08 * * *$ & (0.01) & $0.08 * * *$ & (0.01) & $0.08 * * *$ & (0.01) & $0.08 * * *$ & $(0.01)$ & $0.09 * * *$ & $(0.01)$ & $0.09 * * *$ & (0.01) & $0.09 * * *$ & $(0.01)$ & $0.09 * * *$ & $(0.01)$ \\
\hline age & & & 0.00 & $(0.01)$ & $0.03^{*}$ & $(0.01)$ & $0.03^{*}$ & (0.01) & $0.03^{*}$ & $(0.01)$ & $0.03^{*}$ & $(0.01)$ & $0.03^{*}$ & $(0.01)$ & $0.03 *$ & $(0.01)$ \\
\hline age square & & & -0.00 & $(0.00)$ & -0.00 & $(0.00)$ & -0.00 & $(0.00)$ & -0.00 & $(0.00)$ & -0.00 & $(0.00)$ & -0.00 & $(0.00)$ & -0.00 & $(0.00)$ \\
\hline working & & & -0.02 & $(0.02)$ & -0.02 & $(0.02)$ & -0.02 & $(0.02)$ & -0.02 & $(0.02)$ & -0.03 & $(0.02)$ & -0.03 & $(0.02)$ & -0.03 & $(0.02)$ \\
\hline married & & & -0.03 & $(0.04)$ & -0.03 & $(0.04)$ & -0.03 & $(0.04)$ & -0.03 & $(0.04)$ & -0.03 & $(0.04)$ & -0.03 & $(0.04)$ & -0.03 & $(0.04)$ \\
\hline cohabitation & & & $0.08^{*}$ & $(0.03)$ & $0.09 *$ & $(0.03)$ & $0.09 * *$ & $(0.03)$ & $0.09 * *$ & $(0.03)$ & $0.09 * *$ & $(0.03)$ & $0.09 * *$ & $(0.03)$ & $0.09 * *$ & $(0.03)$ \\
\hline leave take-up & & & $0.17^{*}$ & $(0.07)$ & $0.16^{*}$ & $(0.07)$ & $0.16^{*}$ & $(0.07)$ & $0.15^{*}$ & $(0.07)$ & $0.16^{*}$ & $(0.07)$ & $0.16^{*}$ & $(0.07)$ & $0.16^{*}$ & $(0.07)$ \\
\hline number children & & & -0.00 & $(0.01)$ & -0.00 & $(0.01)$ & -0.00 & $(0.01)$ & -0.00 & $(0.01)$ & -0.00 & $(0.01)$ & -0.00 & $(0.01)$ & -0.00 & $(0.01)$ \\
\hline net household income (log) & & & 0.00 & $(0.02)$ & 0.01 & $(0.02)$ & 0.00 & $(0.02)$ & 0.00 & $(0.02)$ & 0.00 & $(0.02)$ & 0.00 & $(0.02)$ & 0.01 & $(0.02)$ \\
\hline CAPI (ref. CATI) & & & & & $-0.09 * * *$ & $(0.02)$ & $-0.09 * * *$ & $(0.02)$ & $-0.09 * * *$ & $(0.02)$ & $-0.09 * * *$ & $(0.02)$ & $-0.10 * * *$ & $(0.02)$ & $-0.10 * * *$ & $(0.02)$ \\
\hline interviewer's education: medium (ref. low) & & & & & & & $0.04^{*}$ & $(0.02)$ & $0.04^{*}$ & $(0.02)$ & $0.04^{*}$ & $(0.02)$ & $0.04^{*}$ & $(0.02)$ & $0.04^{*}$ & $(0.02)$ \\
\hline interviewer's education: high & & & & & & & $0.08^{* * *}$ & $(0.01)$ & $0.07^{* * *}$ & $(0.01)$ & $0.08 * * *$ & $(0.01)$ & $0.07^{* * *}$ & $(0.01)$ & $0.07 * * *$ & $(0.01)$ \\
\hline interviewer's age: $30-49$ (ref. <30) & & & & & & & & & $0.03 *$ & $(0.01)$ & $0.03 *$ & $(0.01)$ & $0.03^{*}$ & $(0.01)$ & $0.03^{*}$ & $(0.01)$ \\
\hline interviewer's age: $50-65$ & & & & & & & & & -0.00 & $(0.01)$ & -0.00 & $(0.01)$ & -0.00 & $(0.01)$ & -0.00 & $(0.01)$ \\
\hline interviewer's age: $65+$ & & & & & & & & & $0.04^{*}$ & $(0.02)$ & 0.04 & $(0.02)$ & 0.03 & $(0.02)$ & 0.03 & $(0.02)$ \\
\hline interviewer's experience: $1-2$ y (ref. $<1$ y) & & & & & & & & & & & $-0.03 *$ & $(0.01)$ & $-0.03^{*}$ & $(0.01)$ & $-0.03 *$ & $(0.01)$ \\
\hline interviewer's experience: $2-3 y$ & & & & & & & & & & & -0.02 & $(0.01)$ & -0.02 & $(0.01)$ & -0.01 & $(0.01)$ \\
\hline interviewer's experience: $3 y+$ & & & & & & & & & & & 0.01 & $(0.01)$ & 0.01 & $(0.01)$ & 0.02 & $(0.01)$ \\
\hline interview duration in minutes & & & & & & & & & & & & & $0.00^{*}$ & $(0.00)$ & $0.00 *$ & $(0.00)$ \\
\hline number of previous interviews & & & & & & & & & & & & & & & -0.01 & $(0.01)$ \\
\hline respondent tired & & & & & & & & & & & & & & & $-0.01^{*}$ & $(0.00)$ \\
\hline _cons & $2.98 * * *$ & $(0.01)$ & $3.02 * * *$ & $(0.27)$ & $1.74 * * *$ & $(0.36)$ & $1.54 * * *$ & $(0.37)$ & $1.57^{* * *}$ & $(0.37)$ & $1.63 * * *$ & $(0.38)$ & $1.51 * * *$ & $(0.38)$ & $1.51^{* * *}$ & $(0.38)$ \\
\hline Observations & 494 & & 494 & & 494 & & 494 & & 494 & & 494 & & 494 & & 494 & \\
\hline Individuals & 247 & & 247 & & 247 & & 247 & & 247 & & 247 & & 247 & & 247 & \\
\hline Number of Interviewers & 44 & & 44 & & 44 & & $44 C$ & & 440 & & 44 & & 44 & & 44 & \\
\hline $\mathrm{F}$ & 78.4 & & 11.7 & & 13.6 & & 14.3 & & 12.6 & & 11.6 & & 11.1 & & 10.7 & \\
\hline r2_w & 0.0 & & 0.0 & & 0.0 & & 0.0 & & 0.0 & & 0.0 & & 0.0 & & 0.0 & \\
\hline $\mathrm{p}$ & 0.0 & & 0.0 & & 0.0 & & 0.0 & & 0.0 & & 0.0 & & 0.0 & & 0.0 & \\
\hline
\end{tabular}

Note: Higher attitude scores indicate less traditional attitudes. Robust standard errors (RSE) in parentheses. Reference category indicated with .ref, net household income deflated with base year 2015

${ }^{*} p<0.05,{ }^{* *} p<0.01,{ }^{* * *} p<0.001$

Source: NEPS:SC6:10.0.0, own calculations. 
Table A6. Female-interviewer-effect on male respondents' agreement with attitudinal statement "Profession (R)" (Stepwise fixed-effects-regression models).

\begin{tabular}{|c|c|c|c|c|c|c|c|c|c|c|c|c|c|c|c|c|}
\hline & \multicolumn{2}{|c|}{$\begin{array}{c}\text { Profession (R) } \\
(\mathrm{m} 1)\end{array}$} & \multicolumn{2}{|c|}{$\begin{array}{c}\text { Profession (R) } \\
(\mathrm{m} 2)\end{array}$} & \multicolumn{2}{|c|}{$\begin{array}{c}\text { Profession (R) } \\
(\mathrm{m} 3)\end{array}$} & \multicolumn{2}{|c|}{$\begin{array}{c}\text { Profession (R) } \\
(\mathrm{m} 4)\end{array}$} & \multicolumn{2}{|c|}{$\begin{array}{c}\text { Profession (R) } \\
(\mathrm{m} 5)\end{array}$} & \multicolumn{2}{|c|}{$\begin{array}{c}\text { Profession (R) } \\
(\mathrm{m} 6)\end{array}$} & \multicolumn{2}{|c|}{$\begin{array}{c}\text { Profession (R) } \\
(\mathrm{m} 7)\end{array}$} & \multicolumn{2}{|c|}{$\begin{array}{c}\text { Profession (R) } \\
(\mathrm{m} 8)\end{array}$} \\
\hline & $b$ & RSE & $b$ & RSE & b & RSE & b & RSE & b & RSE & b & RSE & $\mathrm{b}$ & RSE & $\mathrm{b}$ & RSE \\
\hline interviewer: female & $0.09 * * *$ & $(0.02)$ & $0.08 * * *$ & $(0.02)$ & $0.08 * * *$ & $(0.02)$ & $0.08 * * *$ & $(0.02)$ & $0.10 * * *$ & $(0.02)$ & $0.10 * * *$ & $(0.02)$ & $0.10 * * *$ & $(0.02)$ & $0.10 * * *$ & $(0.02)$ \\
\hline age & & & 0.01 & $(0.02)$ & $0.07^{*}$ & $(0.03)$ & $0.07^{*}$ & $(0.03)$ & $0.07 * *$ & $(0.03)$ & $0.07 * *$ & $(0.03)$ & $0.08 * *$ & $(0.03)$ & $0.08^{* *}$ & $(0.03)$ \\
\hline age square & & & -0.00 & $(0.00)$ & -0.00 & $(0.00)$ & -0.00 & $(0.00)$ & -0.00 & $(0.00)$ & -0.00 & $(0.00)$ & -0.00 & $(0.00)$ & -0.00 & $(0.00)$ \\
\hline working & & & -0.01 & $(0.05)$ & -0.02 & $(0.05)$ & -0.02 & $(0.05)$ & -0.03 & $(0.05)$ & -0.03 & $(0.05)$ & -0.03 & $(0.05)$ & -0.03 & (0.05) \\
\hline married & & & -0.01 & $(0.09)$ & -0.00 & $(0.09)$ & -0.00 & $(0.09)$ & -0.00 & $(0.09)$ & -0.00 & (0.09) & -0.01 & $(0.09)$ & -0.01 & (0.09) \\
\hline cohabitation & & & 0.01 & $(0.08)$ & 0.02 & $(0.08)$ & 0.02 & $(0.08)$ & 0.02 & $(0.08)$ & 0.02 & $(0.08)$ & 0.02 & $(0.08)$ & 0.02 & (0.08) \\
\hline leave take-up & & & 0.01 & $(0.18)$ & 0.00 & $(0.17)$ & -0.00 & $(0.17)$ & 0.01 & $(0.17)$ & 0.01 & $(0.17)$ & 0.01 & $(0.17)$ & 0.00 & $(0.17)$ \\
\hline number children & & & 0.02 & $(0.03)$ & 0.02 & $(0.03)$ & 0.01 & $(0.03)$ & 0.02 & $(0.03)$ & 0.02 & (0.03) & 0.02 & $(0.03)$ & 0.02 & (0.03) \\
\hline net household income (log) & & & 0.04 & $(0.04)$ & 0.04 & $(0.04)$ & 0.04 & $(0.04)$ & 0.04 & $(0.04)$ & 0.04 & $(0.04)$ & 0.05 & $(0.04)$ & 0.05 & $(0.04)$ \\
\hline CAPI (ref. CATI) & & & & & $-0.21 * * *$ & $(0.04)$ & $-0.21 * * *$ & $(0.04)$ & $-0.22 * * *$ & $(0.04)$ & $-0.22 * * *$ & $(0.04)$ & $-0.25 * * *$ & $(0.05)$ & $-0.25 * * *$ & (0.05) \\
\hline interviewer's education: medium (ref. low) & & & & & & & -0.02 & $(0.04)$ & -0.02 & $(0.04)$ & -0.03 & $(0.04)$ & -0.03 & $(0.04)$ & -0.03 & $(0.04)$ \\
\hline interviewer's education: high & & & & & & & 0.05 & $(0.03)$ & 0.04 & $(0.03)$ & 0.04 & $(0.03)$ & 0.03 & $(0.03)$ & 0.03 & $(0.03)$ \\
\hline interviewer's age: $30-49$ (ref. <30) & & & & & & & & & -0.05 & $(0.03)$ & -0.05 & $(0.03)$ & -0.05 & $(0.03)$ & -0.05 & $(0.03)$ \\
\hline interviewer's age: 50-65 & & & & & & & & & $-0.07^{*}$ & $(0.03)$ & $-0.08^{*}$ & $(0.04)$ & $-0.08^{*}$ & $(0.03)$ & $-0.08^{*}$ & (0.03) \\
\hline interviewer's age: $65+$ & & & & & & & & & 0.05 & $(0.04)$ & 0.04 & $(0.04)$ & 0.04 & $(0.04)$ & 0.04 & (0.04) \\
\hline interviewer's experience: $1-2$ y (ref. $<1$ y) & & & & & & & & & & & -0.00 & $(0.03)$ & 0.00 & $(0.03)$ & -0.00 & (0.03) \\
\hline interviewer's experience: $2-3 y$ & & & & & & & & & & & 0.02 & $(0.03)$ & 0.02 & $(0.03)$ & 0.02 & (0.03) \\
\hline interviewer's experience: $3 y+$ & & & & & & & & & & & -0.00 & $(0.03)$ & -0.00 & $(0.03)$ & 0.00 & $(0.03)$ \\
\hline interview duration in minutes & & & & & & & & & & & & & $0.00^{*}$ & $(0.00)$ & $0.00 *$ & $(0.00)$ \\
\hline number of previous interviews & & & & & & & & & & & & & & & -0.01 & $(0.02)$ \\
\hline respondent tired & & & & & & & & & & & & & & & 0.01 & (0.01) \\
\hline _cons & $2.19 * * *$ & $(0.01)$ & $2.56^{* * *}$ & $(0.65)$ & -0.48 & $(0.88)$ & -0.61 & $(0.88)$ & -0.67 & $(0.88)$ & -0.68 & $(0.88)$ & -0.99 & $(0.91)$ & -1.07 & (0.91) \\
\hline Observations & 494 & & 494 & & 494 & & 494 & & 494 & & 494 & & 494 & & 494 & \\
\hline Individuals & 247 & & 247 & & 247 & & 247 & & 247 & & 247 & & 247 & & 247 & \\
\hline Number of Interviewers & 44 & & 44 & & 440 & & 44 & & 44 & & $44 C$ & & 440 & & 440 & \\
\hline $\mathrm{F}$ & 16. & & 6.3 & & 8.6 & & 7.7 & & 7.3 & & 6.7 & & 6.45 & & 5.9 & \\
\hline r2_w & 0.0 & & 0.0 & & 0.0 & & 0.0 & & 0.0 & & 0.0 & & 0.03 & & 0.0 & \\
\hline$p^{-}$ & 0.0 & & 0.0 & & 0.0 & & 0.0 & & 0.0 & & 0.0 & & 0.00 & & 0.0 & \\
\hline
\end{tabular}

Note: Higher attitude scores indicate less traditional attitudes. Robust standard errors (RSE) in parentheses. Reference category indicated with .ref, net household income deflated with base year 2015.

$* \mathrm{p}<0.05, * * \mathrm{p}<0.01, * * * \mathrm{p}<0.001$

Source: NEPS:SC6:10.0.0, own calculations. 
Table A7. Female-interviewer-effect on male respondents' agreement with attitudinal statement "Politics" (Stepwise fixed-effects-regression models).

\begin{tabular}{|c|c|c|c|c|c|c|c|c|c|c|c|c|c|c|c|c|}
\hline & \multirow{2}{*}{\multicolumn{2}{|c|}{$\begin{array}{c}\text { Politics } \\
\text { (m1) }\end{array}$}} & \multirow{2}{*}{\multicolumn{2}{|c|}{$\begin{array}{c}\text { Politics } \\
\text { (m2) }\end{array}$}} & \multirow{2}{*}{\multicolumn{2}{|c|}{$\begin{array}{c}\text { Politics } \\
\text { (m3) }\end{array}$}} & \multirow{2}{*}{\multicolumn{2}{|c|}{$\begin{array}{l}\text { Politics } \\
\text { (m4) }\end{array}$}} & \multirow{2}{*}{\multicolumn{2}{|c|}{$\begin{array}{c}\text { Politics } \\
\text { (m5) }\end{array}$}} & \multirow{2}{*}{\multicolumn{2}{|c|}{$\begin{array}{l}\text { Politics } \\
\text { (m6) }\end{array}$}} & \multirow{2}{*}{\multicolumn{2}{|c|}{$\begin{array}{l}\text { Politics } \\
\text { (m7) }\end{array}$}} & \multirow{2}{*}{\multicolumn{2}{|c|}{$\begin{array}{c}\text { Politics } \\
\text { (m8) }\end{array}$}} \\
\hline & & & & & & & & & & & & & & & & \\
\hline & $b$ & RSE & $b$ & RSE & $b$ & RSE & $b$ & RSE & $b$ & RSE & $b$ & RSE & $b$ & RSE & $b$ & RSE \\
\hline interviewer: female & $0.13^{* * *}$ & $(0.02)$ & $0.13^{* * *}$ & $(0.02)$ & $0.13^{* * *}$ & $(0.02)$ & $0.13^{* * *}$ & $(0.02)$ & $0.14^{* * *}$ & $(0.02)$ & $0.14^{* * *}$ & $(0.02)$ & $0.14^{* * *}$ & $(0.02)$ & $0.14^{* * *}$ & $(0.02)$ \\
\hline age & & & -0.00 & $(0.03)$ & 0.03 & $(0.03)$ & 0.03 & $(0.03)$ & 0.03 & $(0.03)$ & 0.03 & $(0.03)$ & 0.02 & $(0.03)$ & 0.02 & (0.03) \\
\hline age square & & & -0.00 & $(0.00)$ & 0.00 & $(0.00)$ & 0.00 & $(0.00)$ & 0.00 & $(0.00)$ & 0.00 & $(0.00)$ & 0.00 & $(0.00)$ & 0.00 & $(0.00)$ \\
\hline working & & & $-0.09^{*}$ & $(0.04)$ & $-0.09 *$ & $(0.04)$ & $-0.09 *$ & $(0.04)$ & $-0.09^{*}$ & $(0.04)$ & $-0.09^{*}$ & $(0.04)$ & $-0.08^{*}$ & $(0.04)$ & $-0.08^{*}$ & $(0.04)$ \\
\hline married & & & -0.06 & $(0.08)$ & -0.06 & $(0.08)$ & -0.06 & $(0.08)$ & -0.07 & $(0.08)$ & -0.06 & $(0.08)$ & -0.06 & $(0.08)$ & -0.07 & $(0.08)$ \\
\hline cohabitation & & & $0.22^{*}$ & $(0.10)$ & $0.22^{*}$ & $(0.10)$ & $0.23^{*}$ & $(0.10)$ & $0.23^{*}$ & $(0.10)$ & $0.23^{*}$ & $(0.10)$ & $0.23 *$ & $(0.10)$ & $0.23 *$ & (0.10) \\
\hline leave take-up & & & 0.32 & $(0.21)$ & 0.31 & $(0.21)$ & 0.32 & $(0.21)$ & 0.30 & $(0.21)$ & 0.30 & $(0.21)$ & 0.30 & $(0.21)$ & 0.31 & $(0.21)$ \\
\hline number children & & & -0.02 & $(0.02)$ & -0.02 & $(0.02)$ & -0.02 & $(0.02)$ & -0.02 & $(0.02)$ & -0.02 & $(0.02)$ & -0.02 & $(0.02)$ & -0.02 & $(0.02)$ \\
\hline net household income (log) & & & -0.01 & $(0.04)$ & -0.01 & $(0.04)$ & -0.01 & $(0.04)$ & -0.01 & $(0.04)$ & -0.01 & $(0.04)$ & -0.01 & $(0.04)$ & -0.01 & $(0.04)$ \\
\hline CAPI (ref. CATI) & & & & & $-0.11 *$ & $(0.04)$ & $-0.11 * *$ & $(0.04)$ & $-0.09 *$ & $(0.04)$ & $-0.09 *$ & $(0.04)$ & -0.06 & $(0.05)$ & -0.06 & $(0.05)$ \\
\hline interviewer's education: medium (ref. low) & & & & & & & 0.05 & $(0.04)$ & 0.05 & $(0.04)$ & 0.05 & $(0.04)$ & 0.05 & $(0.04)$ & 0.05 & (0.04) \\
\hline interviewer's education: high & & & & & & & 0.05 & $(0.03)$ & 0.06 & $(0.03)$ & 0.06 & $(0.03)$ & 0.06 & $(0.04)$ & 0.06 & $(0.04)$ \\
\hline interviewer's age: $30-49$ (ref. <30) & & & & & & & & & $0.10^{* * *}$ & $(0.03)$ & $0.10^{* * *}$ & $(0.03)$ & $0.11^{* * *}$ & $(0.03)$ & $0.11^{* * *}$ & (0.03) \\
\hline interviewer's age: $50-65$ & & & & & & & & & 0.03 & $(0.03)$ & 0.03 & $(0.03)$ & 0.04 & $(0.03)$ & 0.03 & (0.03) \\
\hline interviewer's age: $65+$ & & & & & & & & & 0.01 & $(0.04)$ & 0.02 & $(0.04)$ & 0.02 & $(0.04)$ & 0.01 & $(0.04)$ \\
\hline interviewer's experience: $1-2$ y (ref. $<1$ y) & & & & & & & & & & & -0.04 & $(0.03)$ & -0.05 & $(0.03)$ & -0.04 & $(0.03)$ \\
\hline interviewer's experience: $2-3 y$ & & & & & & & & & & & -0.03 & $(0.03)$ & -0.04 & $(0.03)$ & -0.03 & $(0.03)$ \\
\hline interviewer's experience: $3 y+$ & & & & & & & & & & & -0.01 & $(0.03)$ & -0.01 & $(0.03)$ & -0.00 & $(0.03)$ \\
\hline interview duration in minutes & & & & & & & & & & & & & -0.00 & $(0.00)$ & -0.00 & $(0.00)$ \\
\hline number of previous interviews & & & & & & & & & & & & & & & -0.00 & $(0.02)$ \\
\hline respondent tired & & & & & & & & & & & & & & & $-0.03 * *$ & $(0.01)$ \\
\hline _cons & $3.00 * * *$ & $(0.01)$ & $3.07 * * *$ & $(0.66)$ & 1.54 & $(0.89)$ & 1.39 & $(0.90)$ & 1.50 & $(0.90)$ & 1.55 & $(0.91)$ & 1.77 & $(0.92)$ & $1.85^{*}$ & (0.92) \\
\hline Observations & \multicolumn{2}{|c|}{4946} & \multicolumn{2}{|c|}{4946} & \multicolumn{2}{|c|}{4946} & \multicolumn{2}{|c|}{4946} & \multicolumn{2}{|c|}{4946} & \multicolumn{2}{|c|}{4946} & \multicolumn{2}{|c|}{4946} & \multicolumn{2}{|c|}{4946} \\
\hline Individuals & \multicolumn{2}{|c|}{2473} & \multicolumn{2}{|c|}{2473} & \multicolumn{2}{|c|}{2473} & \multicolumn{2}{|c|}{2473} & \multicolumn{2}{|c|}{2473} & \multicolumn{2}{|c|}{2473} & \multicolumn{2}{|c|}{2473} & \multicolumn{2}{|c|}{2473} \\
\hline Number of Interviewers & \multicolumn{2}{|c|}{440} & 44 & & 44 & & 44 & & 44 & & 44 & & 44 & & 44 & \\
\hline $\mathrm{F}$ & 44. & & 6.4 & & 5.9 & & 5.2 & & 5.2 & & 4.5 & & 4.7 & & 4.9 & \\
\hline r2_w & 0.0 & & 0.0 & & 0.0 & & $0 . c_{0}$ & & $0 . c$ & & 0.0 & & 0.0 & & 0.0 & \\
\hline $\mathrm{p}$ & 0.0 & & 0.0 & & 0.0 & & $0 . c_{0}$ & & $0 . c$ & & 0.0 & & 0.0 & & 0.0 & \\
\hline
\end{tabular}

Note: Higher attitude scores indicate less traditional attitudes. Robust standard errors (RSE) in parentheses. Reference category indicated with .ref, net household income deflated with base year 2015

${ }^{*} p<0.05,{ }^{* *} p<0.01,{ }^{* * *} p<0.001$

Source: NEPS:SC6:10.0.0, own calculations. 
Table A8. Female-interviewer-effect on male respondents' agreement with attitudinal statement "Household" (Stepwise fixed-effects-regression models).

\begin{tabular}{|c|c|c|c|c|c|c|c|c|c|c|c|c|c|c|c|c|}
\hline & \multicolumn{2}{|c|}{$\begin{array}{c}\text { Household } \\
(\mathrm{m} 1)\end{array}$} & \multicolumn{2}{|c|}{$\frac{\text { Household }}{(\mathrm{m} 2)}$} & \multicolumn{2}{|c|}{$\begin{array}{c}\text { Household } \\
\text { (m3) }\end{array}$} & \multicolumn{2}{|c|}{$\begin{array}{c}\text { Household } \\
(\mathrm{m} 4)\end{array}$} & \multicolumn{2}{|c|}{$\frac{\text { Household }}{\text { (m5) }}$} & \multicolumn{2}{|c|}{$\begin{array}{c}\text { Household } \\
(\mathrm{m} 6)\end{array}$} & \multicolumn{2}{|c|}{$\begin{array}{c}\text { Household } \\
(\mathrm{m} 7)\end{array}$} & \multicolumn{2}{|c|}{$\begin{array}{c}\text { Household } \\
(\mathrm{m} 8)\end{array}$} \\
\hline & $b$ & RSE & $b$ & RSE & $b$ & RSE & $b$ & RSE & $b$ & RSE & $b$ & RSE & $b$ & RSE & $b$ & RSE \\
\hline interviewer: female & $0.04 * *$ & $(0.02)$ & $0.04^{*}$ & $(0.02)$ & $0.04^{*}$ & $(0.02)$ & $0.05^{* *}$ & $(0.02)$ & $0.06 * * *$ & $(0.02)$ & $0.06^{* * *}$ & $(0.02)$ & $0.06^{* * *}$ & $(0.02)$ & $0.06 * * *$ & $(0.02)$ \\
\hline age & & & 0.02 & $(0.02)$ & 0.04 & $(0.02)$ & $0.04 *$ & $(0.02)$ & 0.04 & $(0.02)$ & 0.04 & $(0.02)$ & 0.04 & $(0.02)$ & 0.04 & $(0.02)$ \\
\hline age square & & & -0.00 & $(0.00)$ & -0.00 & $(0.00)$ & -0.00 & $(0.00)$ & -0.00 & $(0.00)$ & -0.00 & $(0.00)$ & -0.00 & $(0.00)$ & -0.00 & $(0.00)$ \\
\hline working & & & $-0.07 *$ & $(0.03)$ & $-0.07 *$ & $(0.03)$ & $-0.07 *$ & $(0.03)$ & $-0.07 *$ & $(0.03)$ & $-0.08 *$ & $(0.03)$ & $-0.08^{*}$ & $(0.03)$ & $-0.08 *$ & (0.03) \\
\hline married & & & -0.11 & $(0.07)$ & -0.11 & $(0.07)$ & -0.11 & $(0.07)$ & -0.11 & $(0.07)$ & -0.11 & $(0.07)$ & -0.11 & $(0.07)$ & -0.12 & $(0.07)$ \\
\hline cohabitation & & & 0.07 & $(0.08)$ & 0.07 & $(0.08)$ & 0.07 & $(0.08)$ & 0.07 & $(0.08)$ & 0.07 & $(0.08)$ & 0.07 & $(0.08)$ & 0.07 & $(0.08)$ \\
\hline leave take-up & & & 0.16 & $(0.15)$ & 0.15 & $(0.15)$ & 0.15 & $(0.16)$ & 0.13 & $(0.16)$ & 0.14 & $(0.17)$ & 0.14 & $(0.17)$ & 0.15 & (0.16) \\
\hline number children & & & -0.02 & $(0.02)$ & -0.02 & $(0.02)$ & -0.02 & $(0.02)$ & -0.02 & $(0.02)$ & -0.02 & $(0.02)$ & -0.02 & $(0.02)$ & -0.02 & $(0.02)$ \\
\hline net household income (log) & & & 0.02 & $(0.04)$ & 0.02 & $(0.04)$ & 0.02 & $(0.04)$ & 0.01 & $(0.04)$ & 0.01 & $(0.04)$ & 0.02 & $(0.04)$ & 0.02 & $(0.04)$ \\
\hline CAPI (ref. CATI) & & & & & $-0.09 * *$ & $(0.03)$ & $-0.09 * *$ & $(0.03)$ & $-0.09 * *$ & $(0.03)$ & $-0.08 *$ & $(0.03)$ & $-0.10 * *$ & $(0.03)$ & $-0.09 *$ & (0.03) \\
\hline interviewer's education: medium (ref. low) & & & & & & & 0.04 & $(0.03)$ & 0.04 & $(0.03)$ & 0.03 & $(0.03)$ & 0.03 & $(0.03)$ & 0.03 & (0.03) \\
\hline interviewer's education: high & & & & & & & $0.07 * *$ & $(0.03)$ & $0.07 * *$ & $(0.03)$ & $0.07 * *$ & $(0.03)$ & $0.07^{*}$ & $(0.03)$ & $0.07^{*}$ & (0.03) \\
\hline interviewer's age: $30-49$ (ref. <30) & & & & & & & & & $0.07 * *$ & $(0.03)$ & $0.07 * *$ & $(0.03)$ & $0.07^{*}$ & $(0.03)$ & $0.06^{*}$ & $(0.03)$ \\
\hline interviewer's age: 50-65 & & & & & & & & & 0.02 & $(0.03)$ & 0.01 & $(0.03)$ & 0.00 & $(0.03)$ & -0.00 & $(0.03)$ \\
\hline interviewer's age: $65+$ & & & & & & & & & 0.06 & $(0.04)$ & 0.04 & $(0.04)$ & 0.04 & $(0.04)$ & 0.03 & $(0.04)$ \\
\hline interviewer's experience: $1-2$ y (ref. $<1$ y) & & & & & & & & & & & $-0.08 * *$ & $(0.02)$ & $-0.08 * *$ & $(0.02)$ & $-0.08 * *$ & $(0.02)$ \\
\hline interviewer's experience: $2-3 y$ & & & & & & & & & & & -0.01 & $(0.02)$ & -0.01 & $(0.02)$ & -0.00 & $(0.02)$ \\
\hline interviewer's experience: $3 y+$ & & & & & & & & & & & 0.04 & $(0.02)$ & 0.04 & $(0.02)$ & $0.06^{*}$ & (0.03) \\
\hline interview duration in minutes & & & & & & & & & & & & & 0.00 & $(0.00)$ & 0.00 & $(0.00)$ \\
\hline number of previous interviews & & & & & & & & & & & & & & & -0.02 & $(0.01)$ \\
\hline respondent tired & & & & & & & & & & & & & & & -0.01 & $(0.01)$ \\
\hline _cons & $3.35^{* * *}$ & $(0.01)$ & $3.27^{* * *}$ & $(0.54)$ & $1.99 * *$ & $(0.66)$ & $1.80^{* *}$ & $(0.66)$ & $1.88^{* *}$ & $(0.66)$ & $2.10^{* *}$ & $(0.68)$ & $1.90^{* *}$ & $(0.69)$ & $1.82^{* *}$ & (0.68) \\
\hline Observations & \multicolumn{2}{|c|}{4946} & \multicolumn{2}{|c|}{4946} & \multicolumn{2}{|c|}{4946} & \multicolumn{2}{|c|}{4946} & \multicolumn{2}{|c|}{4946} & \multicolumn{2}{|c|}{4946} & \multicolumn{2}{|c|}{4946} & \multicolumn{2}{|c|}{4946} \\
\hline Individuals & \multicolumn{2}{|c|}{2473} & \multicolumn{2}{|c|}{2473} & \multicolumn{2}{|c|}{2473} & \multicolumn{2}{|c|}{2473} & \multicolumn{2}{|c|}{2473} & \multicolumn{2}{|c|}{2473} & \multicolumn{2}{|c|}{2473} & \multicolumn{2}{|c|}{2473} \\
\hline Number of Interviewers & \multicolumn{2}{|c|}{440} & \multicolumn{2}{|c|}{440} & & & & & 44 & & 44 & & $44 c$ & & 440 & \\
\hline $\mathrm{F}$ & 7.4 & & 2. & & & & & & 3.6 & & 6.5 & & 6.2 & & 6.1 & \\
\hline r2_w & 0.0 & & 0. & & & & & & 0.0 & & 0.0 & & 0.0 & & 0.0 & \\
\hline $\mathrm{p}$ & 0.0 & & 0. & & & & & & 0.0 & & 0.0 & & 0.0 & & 0.0 & \\
\hline
\end{tabular}

Note: Higher attitude scores indicate
$* p<0.05,{ }^{* *} p<0.01, * * * p<0.001$

Source: NEPS:SC6:10.0.0, own calculations. 
Table A9. Female-interviewer-effect on male respondents' agreement with attitudinal statement "Technology" (Stepwise fixed-effects-regression models).

\begin{tabular}{|c|c|c|c|c|c|c|c|c|c|c|c|c|c|c|c|c|}
\hline & \multirow{2}{*}{\multicolumn{2}{|c|}{$\begin{array}{c}\text { Technology } \\
\text { (m1) }\end{array}$}} & \multirow{2}{*}{\multicolumn{2}{|c|}{$\begin{array}{c}\text { Technology } \\
(\mathrm{m} 2)\end{array}$}} & \multirow{2}{*}{\multicolumn{2}{|c|}{$\begin{array}{c}\text { Technology } \\
\text { (m3) }\end{array}$}} & \multirow{2}{*}{\multicolumn{2}{|c|}{$\begin{array}{c}\text { Technology } \\
\text { (m4) }\end{array}$}} & \multirow{2}{*}{\multicolumn{2}{|c|}{$\begin{array}{c}\text { Technology } \\
\text { (m5) }\end{array}$}} & \multirow{2}{*}{\multicolumn{2}{|c|}{$\begin{array}{c}\text { Technology } \\
\text { (m6) }\end{array}$}} & \multirow{2}{*}{\multicolumn{2}{|c|}{$\begin{array}{c}\text { Technology } \\
(\mathrm{m} 7)\end{array}$}} & \multicolumn{2}{|c|}{ Technology } \\
\hline & & & & & & & & & & & & & & & \multicolumn{2}{|c|}{ (m8) } \\
\hline & $b$ & RSE & $b$ & RSE & $b$ & RSE & $b$ & RSE & $b$ & RSE & $b$ & RSE & $b$ & RSE & $b$ & RSE \\
\hline interviewer: female & $0.14^{* * *}$ & $(0.02)$ & $0.14^{* * *}$ & $(0.02)$ & $0.14^{* * *}$ & $(0.02)$ & $0.15^{* * *}$ & $(0.02)$ & $0.15^{* * *}$ & $(0.02)$ & $0.15^{* * *}$ & $(0.02)$ & $0.14^{* * *}$ & $(0.02)$ & $0.15^{* * *}$ & $(0.02)$ \\
\hline age & & & 0.03 & $(0.02)$ & $0.06^{*}$ & $(0.03)$ & $0.07^{* *}$ & $(0.03)$ & $0.07^{*}$ & $(0.03)$ & $0.07^{* *}$ & $(0.03)$ & $0.07 * *$ & $(0.03)$ & $0.07^{* *}$ & (0.03) \\
\hline age square & & & -0.00 & $(0.00)$ & -0.00 & $(0.00)$ & -0.00 & $(0.00)$ & -0.00 & $(0.00)$ & -0.00 & $(0.00)$ & -0.00 & $(0.00)$ & -0.00 & $(0.00)$ \\
\hline working & & & 0.06 & $(0.05)$ & 0.06 & (0.05) & 0.07 & $(0.05)$ & 0.07 & $(0.05)$ & 0.07 & $(0.05)$ & 0.06 & $(0.05)$ & 0.06 & (0.05) \\
\hline married & & & 0.00 & $(0.07)$ & 0.00 & $(0.07)$ & 0.00 & $(0.07)$ & 0.00 & $(0.07)$ & 0.00 & $(0.07)$ & 0.00 & $(0.07)$ & 0.00 & $(0.07)$ \\
\hline cohabitation & & & $0.21 *$ & $(0.08)$ & $0.21 *$ & (0.08) & $0.22 *$ & (0.08) & $0.22 *$ & (0.08) & $0.22 *$ & $(0.08)$ & $0.22 *$ & $(0.08)$ & $0.22 *$ & (0.08) \\
\hline leave take-up & & & 0.26 & (0.19) & 0.25 & (0.19) & 0.25 & (0.19) & 0.24 & (0.19) & 0.24 & $(0.19)$ & 0.24 & (0.19) & 0.24 & (0.19) \\
\hline number children & & & -0.00 & $(0.03)$ & -0.00 & $(0.03)$ & -0.00 & $(0.03)$ & -0.01 & $(0.03)$ & -0.01 & $(0.03)$ & -0.01 & $(0.03)$ & -0.01 & (0.03) \\
\hline net household income (log) & & & -0.02 & $(0.04)$ & -0.02 & $(0.04)$ & -0.02 & $(0.04)$ & -0.02 & $(0.04)$ & -0.02 & $(0.04)$ & -0.02 & $(0.04)$ & -0.02 & (0.04) \\
\hline CAPI (ref. CATI) & & & & & $-0.11^{*}$ & $(0.04)$ & $-0.12^{* *}$ & $(0.04)$ & $-0.12^{* *}$ & $(0.05)$ & $-0.13^{* *}$ & $(0.05)$ & $-0.15^{* *}$ & $(0.05)$ & $-0.14^{* *}$ & (0.05) \\
\hline interviewer's education: medium (ref. low) & & & & & & & $0.10^{* *}$ & $(0.03)$ & $0.10^{* *}$ & $(0.03)$ & $0.10^{* *}$ & $(0.03)$ & $0.10^{* *}$ & $(0.03)$ & $0.10^{* *}$ & (0.03) \\
\hline interviewer's education: high & & & & & & & $0.13^{* * *}$ & $(0.03)$ & $0.13^{* * *}$ & $(0.03)$ & $0.14^{* * *}$ & $(0.03)$ & $0.13^{* * *}$ & $(0.03)$ & $0.13^{* * *}$ & (0.03) \\
\hline interviewer's age: $30-49$ (ref. <30) & & & & & & & & & 0.02 & (0.03) & 0.02 & $(0.03)$ & 0.02 & $(0.03)$ & 0.02 & (0.03) \\
\hline interviewer's age: $50-65$ & & & & & & & & & 0.03 & $(0.03)$ & 0.04 & $(0.03)$ & 0.04 & $(0.03)$ & 0.03 & (0.03) \\
\hline interviewer's age: $65+$ & & & & & & & & & 0.02 & $(0.04)$ & 0.03 & $(0.04)$ & 0.03 & $(0.04)$ & 0.03 & (0.04) \\
\hline interviewer's experience: $1-2$ y (ref. $<1$ y) & & & & & & & & & & & 0.00 & $(0.03)$ & 0.00 & $(0.03)$ & 0.00 & (0.03) \\
\hline interviewer's experience: $2-3 y$ & & & & & & & & & & & -0.03 & $(0.03)$ & -0.03 & $(0.03)$ & -0.03 & (0.03) \\
\hline interviewer's experience: $3 y+$ & & & & & & & & & & & 0.00 & $(0.03)$ & 0.00 & $(0.03)$ & 0.01 & (0.03) \\
\hline interview duration in minutes & & & & & & & & & & & & & 0.00 & $(0.00)$ & 0.00 & $(0.00)$ \\
\hline number of previous interviews & & & & & & & & & & & & & & & -0.01 & (0.02) \\
\hline respondent tired & & & & & & & & & & & & & & & 0.01 & (0.01) \\
\hline _cons & $2.92^{* * *}$ & $(0.01)$ & $2.13^{* * *}$ & $(0.60)$ & 0.55 & $(0.83)$ & 0.19 & $(0.84)$ & 0.23 & $(0.84)$ & 0.23 & $(0.85)$ & 0.06 & $(0.86)$ & -0.01 & $(0.87)$ \\
\hline Observations & 49 & & 49 & & 494 & & 494 & & 494 & & 49 & & 49 & & 494 & \\
\hline Individuals & 24 & & 24 & & 247 & & 247 & & 247 & & 247 & & 24 & & 247 & \\
\hline Number of Interviewers & 4 & & 4 & & 44 & & 44 & & 44 & & 4 & & & & 44 & \\
\hline $\mathrm{F}$ & 63. & & 9. & & 8.7 & & 8.7 & & 7.5 & & 6.6 & & 6. & & 5.9 & \\
\hline r2_w & 0. & & 0. & & 0.0 & & 0.0 & & 0.0 & & $0 . c$ & & 0. & & 0.0 & \\
\hline $\mathrm{p}$ & 0. & & 0. & & 0.0 & & 0.0 & & 0.0 & & $0 . c$ & & 0. & & 0.0 & \\
\hline
\end{tabular}

Note: Higher attitude scores indicate less traditional attitudes. Robust standard errors (RSE) in parentheses. Reference category indicated with .ref, net household income deflated with base year 2015.

$* \mathrm{p}<0.05, * * \mathrm{p}<0.01, * * * \mathrm{p}<0.001$

Source: NEPS:SC6:10.0.0, own calculations. 
Table A10: Female-interviewer-effect on male respondents' agreement with attitudinal statement "Roles (R)" (Stepwise fixed-effects-regression models).

\begin{tabular}{|c|c|c|c|c|c|c|c|c|c|c|c|c|c|c|c|c|}
\hline & \multirow{2}{*}{\multicolumn{2}{|c|}{$\begin{array}{c}\text { Roles (R) } \\
\text { (m1) }\end{array}$}} & \multirow{2}{*}{\multicolumn{2}{|c|}{$\begin{array}{c}\text { Roles (R) } \\
(\mathrm{m} 2)\end{array}$}} & \multirow{2}{*}{\multicolumn{2}{|c|}{$\frac{\text { Roles (R) }}{(\mathrm{m} 3)}$}} & \multirow{2}{*}{\multicolumn{2}{|c|}{$\begin{array}{c}\text { Roles (R) } \\
(\mathrm{m} 4)\end{array}$}} & \multicolumn{2}{|c|}{ Roles (R) } & \multicolumn{2}{|c|}{ Roles (R) } & \multicolumn{2}{|c|}{ Roles (R) } & \multicolumn{2}{|c|}{ Roles (R) } \\
\hline & & & & & & & & & (m & & \multicolumn{2}{|c|}{ (m6) } & \multicolumn{2}{|c|}{$(\mathrm{m} 7)$} & \multicolumn{2}{|c|}{$(\mathrm{m} 8)$} \\
\hline & $b$ & RSE & $b$ & RSE & $b$ & RSE & $b$ & RSE & $b$ & RSE & $b$ & RSE & $b$ & RSE & $b$ & RSE \\
\hline interviewer: female & -0.01 & $(0.02)$ & -0.00 & $(0.02)$ & -0.00 & $(0.02)$ & 0.00 & $(0.02)$ & 0.01 & $(0.02)$ & 0.01 & $(0.02)$ & 0.01 & $(0.02)$ & 0.01 & $(0.02)$ \\
\hline age & & & $-0.05 *$ & $(0.02)$ & $-0.07 * *$ & $(0.03)$ & $-0.06 *$ & $(0.03)$ & $-0.06^{*}$ & $(0.03)$ & $-0.06^{*}$ & $(0.03)$ & $-0.06 *$ & $(0.03)$ & $-0.06 *$ & $(0.03)$ \\
\hline age square & & & $0.00 * *$ & $(0.00)$ & $0.00 * *$ & $(0.00)$ & $0.00 * *$ & $(0.00)$ & $0.00 * *$ & $(0.00)$ & $0.00 * *$ & $(0.00)$ & $0.00 * *$ & $(0.00)$ & $0.00 * *$ & $(0.00)$ \\
\hline working & & & -0.00 & $(0.03)$ & 0.00 & $(0.03)$ & 0.00 & $(0.03)$ & -0.00 & $(0.03)$ & -0.00 & $(0.03)$ & -0.00 & $(0.03)$ & -0.00 & $(0.03)$ \\
\hline married & & & 0.03 & $(0.06)$ & 0.03 & $(0.06)$ & 0.03 & $(0.06)$ & 0.02 & $(0.05)$ & 0.03 & $(0.05)$ & 0.02 & $(0.05)$ & 0.01 & $(0.05)$ \\
\hline cohabitation & & & -0.09 & $(0.06)$ & -0.09 & $(0.06)$ & -0.09 & $(0.06)$ & -0.09 & $(0.06)$ & -0.09 & $(0.06)$ & -0.09 & $(0.06)$ & -0.09 & $(0.06)$ \\
\hline leave take-up & & & 0.09 & $(0.12)$ & 0.09 & $(0.12)$ & 0.09 & $(0.12)$ & 0.09 & $(0.12)$ & 0.09 & $(0.12)$ & 0.09 & $(0.12)$ & 0.10 & $(0.12)$ \\
\hline number children & & & 0.01 & $(0.02)$ & 0.01 & $(0.02)$ & 0.01 & $(0.02)$ & 0.01 & $(0.02)$ & 0.01 & $(0.02)$ & 0.01 & $(0.02)$ & 0.01 & $(0.02)$ \\
\hline net household income (log) & & & -0.00 & $(0.03)$ & -0.00 & $(0.03)$ & -0.00 & $(0.03)$ & -0.00 & $(0.03)$ & -0.00 & $(0.03)$ & -0.00 & $(0.03)$ & 0.00 & $(0.03)$ \\
\hline CAPI (ref. CATI) & & & & & $0.07 *$ & $(0.03)$ & $0.07 *$ & $(0.03)$ & 0.06 & $(0.03)$ & 0.06 & $(0.03)$ & 0.04 & $(0.04)$ & 0.04 & $(0.04)$ \\
\hline interviewer's education: medium (ref. low) & & & & & & & 0.03 & $(0.03)$ & 0.03 & $(0.03)$ & 0.03 & $(0.03)$ & 0.03 & $(0.03)$ & 0.03 & $(0.03)$ \\
\hline interviewer's education: high & & & & & & & $0.07 * *$ & $(0.02)$ & $0.07^{* *}$ & $(0.02)$ & $0.08 * * *$ & $(0.02)$ & $0.08^{* *}$ & $(0.02)$ & $0.08^{* * *}$ & $(0.02)$ \\
\hline interviewer's age: $30-49$ (ref. <30) & & & & & & & & & -0.00 & $(0.03)$ & -0.00 & $(0.03)$ & -0.01 & $(0.03)$ & -0.00 & $(0.03)$ \\
\hline interviewer's age: $50-65$ & & & & & & & & & -0.01 & $(0.03)$ & -0.00 & $(0.03)$ & -0.01 & $(0.03)$ & -0.01 & $(0.03)$ \\
\hline interviewer's age: $65+$ & & & & & & & & & 0.05 & $(0.04)$ & 0.05 & $(0.04)$ & 0.05 & $(0.04)$ & 0.04 & $(0.04)$ \\
\hline interviewer's experience: $1-2$ y (ref. $<1$ y) & & & & & & & & & & & -0.02 & $(0.02)$ & -0.01 & $(0.02)$ & -0.01 & $(0.02)$ \\
\hline interviewer's experience: $2-3 y$ & & & & & & & & & & & -0.03 & $(0.03)$ & -0.03 & $(0.03)$ & -0.03 & $(0.03)$ \\
\hline interviewer's experience: $3 y+$ & & & & & & & & & & & 0.02 & $(0.02)$ & 0.02 & $(0.02)$ & 0.02 & $(0.02)$ \\
\hline interview duration in minutes & & & & & & & & & & & & & 0.00 & $(0.00)$ & 0.00 & $(0.00)$ \\
\hline number of previous interviews & & & & & & & & & & & & & & & 0.01 & $(0.02)$ \\
\hline respondent tired & & & & & & & & & & & & & & & $-0.03 * *$ & $(0.01)$ \\
\hline _cons & $3.43^{* * *}$ & $(0.01)$ & $4.09 * * *$ & $(0.57)$ & $5.12^{* * *}$ & $(0.74)$ & $4.92^{* * *}$ & $(0.75)$ & $4.92 * * *$ & $(0.76)$ & $4.98 * * *$ & $(0.76)$ & $4.79 * * *$ & $(0.78)$ & $4.96^{* * *}$ & $(0.77)$ \\
\hline Observations & \multicolumn{2}{|c|}{4946} & \multicolumn{2}{|c|}{4946} & \multicolumn{2}{|c|}{4946} & \multicolumn{2}{|c|}{4946} & \multicolumn{2}{|c|}{4946} & \multicolumn{2}{|c|}{4946} & \multicolumn{2}{|c|}{4946} & \multicolumn{2}{|c|}{4946} \\
\hline Individuals & \multicolumn{2}{|c|}{2473} & \multicolumn{2}{|c|}{2473} & \multicolumn{2}{|c|}{2473} & \multicolumn{2}{|c|}{2473} & \multicolumn{2}{|c|}{2473} & \multicolumn{2}{|c|}{2473} & 247 & & 247 & \\
\hline Number of Interviewers & 44 & & 44 & & 44 & & 44 & & 44 & & 44 & & 44 & & 44 & \\
\hline $\mathrm{F}$ & 0.4 & & 4.3 & & 4.3 & & 5. & & 4.6 & & 4.0 & & 3.8 & & 4.0 & \\
\hline r2_w & $0 . c$ & & 0.0 & & 0.0 & & $0 .($ & & $0 . c$ & & 0.0 & & 0.0 & & 0.0 & \\
\hline $\mathrm{p}$ & 0.4 & & 0.0 & & 0.0 & & $0 .($ & & 0.0 & & 0.0 & & 0.0 & & 0.0 & \\
\hline
\end{tabular}

Note: Higher attitude scores indicate less traditional attitudes. Robust standard errors (RSE) in parentheses. Reference category indicated with .ref, net household income deflated with base year 2015.

$* p<0.05, * * p<0.01, * * * p<0.001$

Source: NEPS:SC6:10.0.0, own calculations. 
Table A11. Female-interviewer-effect on female respondents' agreement with attitudinal statement "Index" (Stepwise fixed-effects-regression models).

\begin{tabular}{|c|c|c|c|c|c|c|c|c|c|c|c|c|c|c|c|c|}
\hline & \multirow{2}{*}{\multicolumn{2}{|c|}{$\begin{array}{l}\text { Index } \\
\text { (m1) }\end{array}$}} & \multirow{2}{*}{\multicolumn{2}{|c|}{$\frac{\text { Index }}{\text { (m2) }}$}} & \multirow{2}{*}{\multicolumn{2}{|c|}{$\begin{array}{c}\text { Index } \\
\text { (m3) }\end{array}$}} & \multirow{2}{*}{\multicolumn{2}{|c|}{$\frac{\text { Index }}{\text { (m4) }}$}} & \multirow{2}{*}{\multicolumn{2}{|c|}{$\begin{array}{c}\text { Index } \\
\text { (m5) }\end{array}$}} & \multirow{2}{*}{\multicolumn{2}{|c|}{$\frac{\text { Index }}{\text { (m6) }}$}} & \multirow{2}{*}{\multicolumn{2}{|c|}{$\frac{\text { Index }}{\text { (m7) }}$}} & \multirow{2}{*}{\multicolumn{2}{|c|}{$\frac{\text { Index }}{\text { (m8) }}$}} \\
\hline & & & & & & & & & & & & & & & & \\
\hline & $b$ & RSE & $b$ & RSE & $b$ & RSE & $b$ & RSE & $b$ & RSE & $b$ & RSE & $b$ & RSE & $b$ & RSE \\
\hline interviewer: female & $0.04 * * *$ & $(0.01)$ & $0.04 * * *$ & $(0.01)$ & $0.04 * * *$ & $(0.01)$ & $0.04 * * *$ & $(0.01)$ & $0.04 * * *$ & $(0.01)$ & $0.04 * * *$ & $(0.01)$ & $0.04 * * *$ & $(0.01)$ & $0.04 * * *$ & $(0.01)$ \\
\hline age & & & 0.01 & $(0.01)$ & $0.02 *$ & $(0.01)$ & $0.02 *$ & (0.01) & $0.02 *$ & $(0.01)$ & $0.02 *$ & $(0.01)$ & 0.02 & $(0.01)$ & $0.02 *$ & $(0.01)$ \\
\hline age square & & & -0.00 & $(0.00)$ & -0.00 & $(0.00)$ & -0.00 & $(0.00)$ & -0.00 & $(0.00)$ & -0.00 & $(0.00)$ & -0.00 & $(0.00)$ & -0.00 & $(0.00)$ \\
\hline working & & & 0.01 & $(0.02)$ & 0.01 & $(0.02)$ & 0.01 & $(0.02)$ & 0.01 & $(0.02)$ & 0.01 & $(0.02)$ & 0.01 & $(0.02)$ & 0.01 & $(0.02)$ \\
\hline married & & & -0.00 & $(0.03)$ & -0.00 & $(0.03)$ & -0.00 & $(0.03)$ & -0.00 & $(0.03)$ & -0.00 & $(0.03)$ & 0.00 & $(0.03)$ & -0.00 & (0.03) \\
\hline cohabitation & & & -0.08 & $(0.04)$ & -0.07 & $(0.04)$ & -0.07 & $(0.04)$ & -0.08 & $(0.04)$ & -0.08 & $(0.04)$ & -0.08 & $(0.04)$ & -0.08 & $(0.04)$ \\
\hline leave take-up & & & -0.05 & $(0.03)$ & -0.05 & $(0.03)$ & -0.05 & $(0.03)$ & -0.05 & $(0.03)$ & -0.05 & $(0.03)$ & -0.05 & $(0.03)$ & -0.05 & (0.03) \\
\hline number children & & & -0.01 & $(0.01)$ & -0.01 & $(0.01)$ & -0.01 & $(0.01)$ & -0.01 & $(0.01)$ & -0.01 & $(0.01)$ & -0.01 & $(0.01)$ & -0.01 & $(0.01)$ \\
\hline net household income (log) & & & $-0.04^{*}$ & $(0.02)$ & $-0.04 *$ & $(0.02)$ & $-0.04^{*}$ & $(0.02)$ & $-0.04^{*}$ & $(0.02)$ & $-0.04^{*}$ & $(0.02)$ & $-0.04 *$ & $(0.02)$ & $-0.04 *$ & $(0.02)$ \\
\hline CAPI (ref. CATI) & & & & & $-0.04^{*}$ & $(0.02)$ & $-0.04^{*}$ & $(0.02)$ & $-0.04^{*}$ & $(0.02)$ & $-0.04^{*}$ & $(0.02)$ & -0.03 & $(0.02)$ & -0.03 & $(0.02)$ \\
\hline interviewer's education: medium (ref. low) & & & & & & & -0.00 & $(0.02)$ & -0.00 & $(0.02)$ & -0.00 & $(0.02)$ & -0.00 & $(0.02)$ & -0.00 & $(0.02)$ \\
\hline interviewer's education: high & & & & & & & 0.00 & $(0.01)$ & 0.01 & $(0.01)$ & 0.01 & $(0.01)$ & 0.01 & $(0.01)$ & 0.00 & $(0.01)$ \\
\hline interviewer's age: $30-49$ (ref. <30) & & & & & & & & & $0.04 * *$ & $(0.01)$ & $0.04 * *$ & $(0.01)$ & $0.04 * *$ & $(0.01)$ & $0.03^{*}$ & $(0.01)$ \\
\hline interviewer's age: $50-65$ & & & & & & & & & 0.02 & $(0.01)$ & 0.02 & $(0.02)$ & 0.02 & $(0.02)$ & 0.02 & $(0.02)$ \\
\hline interviewer's age: $65+$ & & & & & & & & & 0.01 & $(0.02)$ & 0.01 & $(0.02)$ & 0.01 & $(0.02)$ & 0.01 & $(0.02)$ \\
\hline interviewer's experience: $1-2$ y (ref. $<1$ y) & & & & & & & & & & & 0.01 & $(0.01)$ & 0.01 & $(0.01)$ & 0.01 & $(0.01)$ \\
\hline interviewer's experience: $2-3 y$ & & & & & & & & & & & 0.00 & $(0.01)$ & 0.00 & $(0.01)$ & 0.01 & $(0.01)$ \\
\hline interviewer's experience: $3 y+$ & & & & & & & & & & & -0.00 & $(0.01)$ & -0.00 & $(0.01)$ & 0.01 & $(0.01)$ \\
\hline interview duration in minutes & & & & & & & & & & & & & -0.00 & $(0.00)$ & -0.00 & $(0.00)$ \\
\hline number of previous interviews & & & & & & & & & & & & & & & -0.01 & $(0.01)$ \\
\hline respondent tired & & & & & & & & & & & & & & & -0.00 & $(0.00)$ \\
\hline _cons & $3.12 * * *$ & $(0.01)$ & $3.37 * * *$ & $(0.28)$ & $2.80^{* * *}$ & $(0.34)$ & $2.79 * * *$ & $(0.35)$ & $2.80 * * *$ & $(0.35)$ & $2.80 * * *$ & $(0.35)$ & $2.85^{* * *}$ & $(0.36)$ & $2.78^{* * *}$ & $(0.35)$ \\
\hline Observations & 546 & & 546 & & 54 & & 546 & & 546 & & 54 & & 546 & & 546 & \\
\hline Individuals & 273 & & 273 & & 273 & & 273 & & 273 & & 27 & & 273 & & 273 & \\
\hline Number of Interviewers & 44 & & 44 & & 44 & & 445 & & 445 & & 44 & & 44 & & 44 & \\
\hline $\mathrm{F}$ & 20.8 & & 6.2 & & 6.0 & & 5.2 & & 4.9 & & 4.1 & & 3.9 & & 3.8 & \\
\hline r2_w & 0.0 & & 0.0 & & 0.0 & & 0.0 & & 0.0 & & 0.0 & & 0.0 & & 0.0 & \\
\hline $\mathrm{p}$ & 0.0 & & 0.0 & & 0.0 & & 0.0 & & 0.0 & & 0.0 & & 0.0 & & 0.0 & \\
\hline
\end{tabular}

Note: Higher attitude scores indicate less traditional attitudes. Robust standard errors (RSE) in parentheses. Reference category indicated with .ref, net household income deflated with base year 2015.

${ }^{*} p<0.05,{ }^{* *} p<0.01, * * * p<0.001$

Source: NEPS:SC6:10.0.0, own calculations. 
Table A12: Female-interviewer-effect on female respondents' agreement with attitudinal statement "Profession (R)" (Stepwise fixed-effects-regression models)

\begin{tabular}{|c|c|c|c|c|c|c|c|c|c|c|c|c|c|c|c|c|}
\hline & \multirow{2}{*}{\multicolumn{2}{|c|}{$\begin{array}{c}\text { Profession (R) } \\
(\mathrm{m} 1)\end{array}$}} & \multirow{2}{*}{\multicolumn{2}{|c|}{$\begin{array}{c}\text { Profession (R) } \\
(\mathrm{m} 2)\end{array}$}} & \multirow{2}{*}{\multicolumn{2}{|c|}{$\begin{array}{c}\text { Profession (R) } \\
(\mathrm{m} 3)\end{array}$}} & \multirow{2}{*}{\multicolumn{2}{|c|}{$\begin{array}{c}\text { Profession (R) } \\
(\mathrm{m} 4)\end{array}$}} & \multirow{2}{*}{\multicolumn{2}{|c|}{$\begin{array}{c}\text { Profession (R) } \\
(\mathrm{m} 5)\end{array}$}} & \multirow{2}{*}{\multicolumn{2}{|c|}{$\begin{array}{c}\text { Profession (R) } \\
(\mathrm{m} 6)\end{array}$}} & \multirow{2}{*}{\multicolumn{2}{|c|}{$\begin{array}{c}\text { Profession (R) } \\
(\mathrm{m} 7)\end{array}$}} & \multirow{2}{*}{\multicolumn{2}{|c|}{$\begin{array}{c}\text { Profession (R) } \\
(\mathrm{m} 8)\end{array}$}} \\
\hline & & & & & & & & & & & & & & & & \\
\hline & $b$ & RSE & $b$ & RSE & $b$ & RSE & $b$ & RSE & $b$ & RSE & $b$ & RSE & $b$ & RSE & $b$ & RSE \\
\hline interviewer: female & -0.01 & $(0.02)$ & -0.01 & $(0.02)$ & -0.01 & $(0.02)$ & -0.01 & $(0.02)$ & -0.02 & $(0.02)$ & -0.02 & $(0.02)$ & -0.02 & $(0.02)$ & -0.01 & $(0.02)$ \\
\hline age & & & 0.01 & $(0.02)$ & 0.03 & $(0.03)$ & 0.03 & $(0.03)$ & 0.03 & $(0.03)$ & 0.03 & $(0.03)$ & 0.02 & $(0.03)$ & 0.03 & $(0.03)$ \\
\hline age square & & & -0.00 & $(0.00)$ & -0.00 & $(0.00)$ & -0.00 & $(0.00)$ & -0.00 & $(0.00)$ & -0.00 & $(0.00)$ & -0.00 & $(0.00)$ & -0.00 & $(0.00)$ \\
\hline working & & & 0.04 & $(0.04)$ & 0.04 & $(0.04)$ & 0.04 & $(0.04)$ & 0.04 & $(0.04)$ & 0.04 & $(0.04)$ & 0.04 & $(0.04)$ & 0.03 & $(0.04)$ \\
\hline married & & & -0.10 & $(0.07)$ & -0.10 & $(0.07)$ & -0.11 & $(0.07)$ & -0.11 & $(0.07)$ & -0.10 & $(0.07)$ & -0.10 & $(0.07)$ & -0.11 & $(0.07)$ \\
\hline cohabitation & & & -0.00 & $(0.09)$ & -0.00 & $(0.09)$ & -0.00 & (0.09) & -0.00 & $(0.09)$ & -0.00 & $(0.09)$ & -0.00 & $(0.09)$ & -0.01 & (0.09) \\
\hline leave take-up & & & 0.01 & $(0.07)$ & 0.01 & $(0.07)$ & 0.01 & $(0.07)$ & 0.00 & $(0.07)$ & 0.00 & $(0.07)$ & 0.00 & $(0.07)$ & -0.00 & $(0.07)$ \\
\hline number children & & & 0.03 & $(0.03)$ & 0.03 & $(0.03)$ & 0.03 & $(0.03)$ & 0.03 & $(0.03)$ & 0.03 & $(0.03)$ & 0.03 & $(0.03)$ & 0.03 & $(0.03)$ \\
\hline net household income (log) & & & 0.01 & $(0.05)$ & 0.01 & $(0.05)$ & 0.01 & $(0.05)$ & 0.00 & $(0.05)$ & 0.00 & $(0.05)$ & 0.00 & $(0.05)$ & 0.01 & $(0.05)$ \\
\hline CAPI (ref. CATI) & & & & & -0.04 & $(0.04)$ & -0.04 & $(0.04)$ & -0.03 & $(0.04)$ & -0.04 & $(0.04)$ & -0.03 & $(0.05)$ & -0.01 & $(0.05)$ \\
\hline interviewer's education: medium (ref. low) & & & & & & & 0.07 & $(0.04)$ & $0.08^{*}$ & $(0.04)$ & $0.08^{*}$ & $(0.04)$ & $0.08^{*}$ & $(0.04)$ & 0.07 & $(0.04)$ \\
\hline interviewer's education: high & & & & & & & 0.05 & $(0.03)$ & 0.05 & $(0.03)$ & 0.05 & $(0.03)$ & 0.05 & $(0.03)$ & 0.04 & $(0.03)$ \\
\hline interviewer's age: $30-49$ (ref. <30) & & & & & & & & & 0.03 & $(0.04)$ & 0.03 & $(0.04)$ & 0.03 & $(0.04)$ & 0.01 & $(0.04)$ \\
\hline interviewer's age: 50-65 & & & & & & & & & 0.02 & $(0.04)$ & 0.03 & $(0.04)$ & 0.03 & $(0.04)$ & 0.01 & $(0.04)$ \\
\hline interviewer's age: $65+$ & & & & & & & & & -0.05 & $(0.05)$ & -0.05 & $(0.05)$ & -0.05 & $(0.05)$ & -0.06 & $(0.05)$ \\
\hline interviewer's experience: $1-2$ y (ref. $<1$ y) & & & & & & & & & & & 0.06 & $(0.03)$ & 0.06 & $(0.03)$ & 0.06 & $(0.03)$ \\
\hline interviewer's experience: 2-3y & & & & & & & & & & & 0.03 & $(0.03)$ & 0.03 & $(0.03)$ & 0.05 & $(0.04)$ \\
\hline interviewer's experience: $3 y+$ & & & & & & & & & & & -0.01 & $(0.03)$ & -0.01 & $(0.03)$ & 0.03 & $(0.03)$ \\
\hline interview duration in minutes & & & & & & & & & & & & & -0.00 & $(0.00)$ & 0.00 & $(0.00)$ \\
\hline number of previous interviews & & & & & & & & & & & & & & & $-0.06 * *$ & $(0.02)$ \\
\hline respondent tired & & & & & & & & & & & & & & & -0.01 & $(0.01)$ \\
\hline _cons & $2.18^{* * *}$ & $(0.01)$ & $2.01 * * *$ & $(0.61)$ & 1.48 & $(0.88)$ & 1.31 & $(0.90)$ & 1.33 & $(0.90)$ & 1.31 & $(0.89)$ & 1.33 & $(0.92)$ & 1.00 & $(0.88)$ \\
\hline Observations & 54 & & 546 & & & & & & & & & & & & & \\
\hline Individuals & 27 & & 273 & & & & & & & & & & & & & \\
\hline Number of Interviewers & 44 & & 44 & & & & & & & & & & & & & \\
\hline$F$ & 0.1 & & 1.1 & & & & & & & & & & & & & \\
\hline r2_w & $0 . c$ & & 0.0 & & & & & & & & & & & & & \\
\hline $\mathrm{p}$ & 0.6 & & 0.3 & & & & & & & & & & & & & \\
\hline
\end{tabular}

Note: Higher attitude scores indicate less traditional attitudes. Robust standard errors (RSE) in parentheses. Reference category indicated with .ref, net household income deflated with base year 2015.

${ }^{*} p<0.05,{ }^{* *} p<0.01,{ }^{* * *} p<0.001$

Source: NEPS:SC6:10.0.0, own calculations. 
Table A13. Female-interviewer-effect on female respondents' agreement with attitudinal statement "Politics" (Stepwise fixed-effects-regression models).

\begin{tabular}{|c|c|c|c|c|c|c|c|c|c|c|c|c|c|c|c|c|}
\hline & \multirow{2}{*}{\multicolumn{2}{|c|}{$\begin{array}{c}\text { Politics } \\
\text { (m1) }\end{array}$}} & \multirow{2}{*}{\multicolumn{2}{|c|}{$\begin{array}{c}\text { Politics } \\
\text { (m2) }\end{array}$}} & \multirow{2}{*}{\multicolumn{2}{|c|}{$\begin{array}{c}\text { Politics } \\
\text { (m3) }\end{array}$}} & \multirow{2}{*}{\multicolumn{2}{|c|}{$\begin{array}{c}\text { Politics } \\
\text { (m4) }\end{array}$}} & \multirow{2}{*}{\multicolumn{2}{|c|}{$\begin{array}{c}\text { Politics } \\
\text { (m5) }\end{array}$}} & \multirow{2}{*}{\multicolumn{2}{|c|}{$\begin{array}{c}\text { Politics } \\
\text { (m6) }\end{array}$}} & \multirow{2}{*}{\multicolumn{2}{|c|}{$\begin{array}{c}\text { Politics } \\
\text { (m7) }\end{array}$}} & \multirow{2}{*}{\multicolumn{2}{|c|}{$\begin{array}{c}\text { Politics } \\
\text { (m8) }\end{array}$}} \\
\hline & & & & & & & & & & & & & & & & \\
\hline & $b$ & RSE & $b$ & RSE & $b$ & RSE & $b$ & RSE & $b$ & RSE & $b$ & RSE & $b$ & RSE & $b$ & RSE \\
\hline interviewer: female & $0.09 * * *$ & $(0.02)$ & $0.08^{* * *}$ & $(0.02)$ & $0.08^{* * *}$ & $(0.02)$ & $0.08^{* * *}$ & $(0.02)$ & $0.10 * * *$ & $(0.02)$ & $0.10 * * *$ & $(0.02)$ & $0.10 * * *$ & $(0.02)$ & $0.10 * * *$ & $(0.02)$ \\
\hline age & & & -0.03 & $(0.03)$ & 0.01 & $(0.03)$ & 0.01 & $(0.03)$ & 0.01 & $(0.03)$ & 0.01 & $(0.03)$ & 0.00 & $(0.03)$ & 0.00 & (0.03) \\
\hline age square & & & 0.00 & $(0.00)$ & 0.00 & $(0.00)$ & 0.00 & $(0.00)$ & 0.00 & $(0.00)$ & 0.00 & $(0.00)$ & 0.00 & $(0.00)$ & 0.00 & $(0.00)$ \\
\hline working & & & -0.03 & $(0.04)$ & -0.02 & $(0.04)$ & -0.02 & $(0.04)$ & -0.02 & $(0.04)$ & -0.02 & $(0.04)$ & -0.02 & $(0.04)$ & -0.02 & $(0.04)$ \\
\hline married & & & 0.03 & $(0.07)$ & 0.04 & $(0.06)$ & 0.04 & $(0.07)$ & 0.04 & $(0.07)$ & 0.04 & $(0.07)$ & 0.04 & $(0.07)$ & 0.04 & $(0.07)$ \\
\hline cohabitation & & & -0.01 & (0.11) & -0.00 & $(0.11)$ & 0.00 & $(0.11)$ & -0.00 & $(0.11)$ & -0.00 & $(0.11)$ & -0.00 & $(0.11)$ & -0.00 & (0.11) \\
\hline leave take-up & & & -0.11 & $(0.07)$ & -0.11 & $(0.07)$ & -0.11 & $(0.07)$ & -0.11 & $(0.07)$ & -0.11 & $(0.07)$ & -0.12 & $(0.07)$ & -0.11 & $(0.07)$ \\
\hline number children & & & -0.01 & $(0.02)$ & -0.02 & $(0.02)$ & -0.02 & $(0.02)$ & -0.02 & $(0.02)$ & -0.02 & $(0.02)$ & -0.01 & $(0.02)$ & -0.01 & $(0.02)$ \\
\hline net household income (log) & & & -0.07 & $(0.04)$ & -0.07 & $(0.04)$ & -0.07 & $(0.04)$ & -0.07 & $(0.04)$ & -0.07 & $(0.04)$ & -0.07 & $(0.04)$ & -0.07 & $(0.04)$ \\
\hline CAPI (ref. CATI) & & & & & $-0.13 * * *$ & $(0.04)$ & $-0.13 * * *$ & $(0.04)$ & $-0.12 * *$ & $(0.04)$ & $-0.12 * *$ & $(0.04)$ & $-0.10^{*}$ & $(0.04)$ & $-0.10^{*}$ & $(0.04)$ \\
\hline interviewer's education: medium (ref. low) & & & & & & & -0.03 & $(0.03)$ & -0.03 & $(0.03)$ & -0.03 & $(0.03)$ & -0.03 & $(0.03)$ & -0.03 & $(0.03)$ \\
\hline interviewer's education: high & & & & & & & 0.01 & $(0.03)$ & 0.01 & $(0.03)$ & 0.01 & $(0.03)$ & 0.01 & $(0.03)$ & 0.01 & (0.03) \\
\hline interviewer's age: $30-49$ (ref. <30) & & & & & & & & & 0.05 & $(0.03)$ & 0.05 & $(0.03)$ & 0.05 & $(0.03)$ & 0.06 & (0.03) \\
\hline interviewer's age: $50-65$ & & & & & & & & & -0.02 & $(0.03)$ & -0.01 & $(0.03)$ & -0.01 & $(0.03)$ & -0.01 & (0.03) \\
\hline interviewer's age: $65+$ & & & & & & & & & 0.05 & $(0.04)$ & 0.05 & $(0.04)$ & 0.05 & $(0.04)$ & 0.06 & (0.04) \\
\hline interviewer's experience: $1-2$ y (ref. $<1$ y) & & & & & & & & & & & -0.02 & $(0.03)$ & -0.02 & $(0.03)$ & -0.02 & $(0.03)$ \\
\hline interviewer's experience: $2-3 y$ & & & & & & & & & & & -0.02 & $(0.03)$ & -0.02 & $(0.03)$ & -0.03 & (0.03) \\
\hline interviewer's experience: $3 y+$ & & & & & & & & & & & -0.02 & $(0.03)$ & -0.02 & $(0.03)$ & -0.02 & (0.03) \\
\hline interview duration in minutes & & & & & & & & & & & & & -0.00 & $(0.00)$ & -0.00 & $(0.00)$ \\
\hline number of previous interviews & & & & & & & & & & & & & & & 0.01 & $(0.02)$ \\
\hline respondent tired & & & & & & & & & & & & & & & 0.00 & $(0.01)$ \\
\hline _cons & $3.17 * * *$ & $(0.01)$ & $5.20^{* * *}$ & $(0.67)$ & $3.33^{* * *}$ & $(0.82)$ & $3.35^{* * *}$ & $(0.83)$ & $3.28 * * *$ & $(0.82)$ & $3.27 * * *$ & $(0.82)$ & $3.48 * * *$ & $(0.86)$ & $3.54 * * *$ & $(0.86)$ \\
\hline Observations & 546 & & $54 \epsilon$ & & 546 & & 546 & & 546 & & 546 & & 546 & & 546 & \\
\hline Individuals & 273 & & 273 & & 273 & & 273 & & 273 & & 273 & & 273 & & 273 & \\
\hline Number of Interviewers & 44 & & 44 & & 44 & & 445 & & 44 & & 445 & & 44 & & 445 & \\
\hline$F$ & $19 . C$ & & 7.7 & & 8.5 & & 7.4 & & 6.7 & & 5.9 & & 5.7 & & 5.4 & \\
\hline r2_w & 0.0 & & 0.0 & & 0.0 & & 0.0 & & 0.0 & & 0.0 & & 0.0 & & 0.0 & \\
\hline $\mathrm{p}$ & 0.0 & & 0.0 & & 0.0 & & 0.0 & & 0.0 & & 0.0 & & 0.0 & & 0.0 & \\
\hline
\end{tabular}

Note: Higher attitude scores indicate
$* p<0.05,{ }^{* *} p<0.01, * * * p<0.001$

Source: NEPS:SC6:10.0.0, own calculations. 
Table A14. Female-interviewer-effect on female respondents' agreement with attitudinal statement "Household" (Stepwise fixed-effects-regression models).

\begin{tabular}{|c|c|c|c|c|c|c|c|c|c|c|c|c|c|c|c|c|}
\hline & \multirow{2}{*}{\multicolumn{2}{|c|}{$\begin{array}{l}\text { Household } \\
(\mathrm{m} 1)\end{array}$}} & \multirow{2}{*}{\multicolumn{2}{|c|}{$\begin{array}{c}\text { Household } \\
(\mathrm{m} 2)\end{array}$}} & \multirow{2}{*}{\multicolumn{2}{|c|}{$\begin{array}{c}\text { Household } \\
(\mathrm{m} 3)\end{array}$}} & \multirow{2}{*}{\multicolumn{2}{|c|}{$\begin{array}{c}\text { Household } \\
(\mathrm{m} 4)\end{array}$}} & \multirow{2}{*}{\multicolumn{2}{|c|}{$\begin{array}{c}\text { Household } \\
(\mathrm{m} 5)\end{array}$}} & \multirow{2}{*}{\multicolumn{2}{|c|}{$\begin{array}{c}\text { Household } \\
(\mathrm{m} 6)\end{array}$}} & \multirow{2}{*}{\multicolumn{2}{|c|}{$\begin{array}{c}\text { Household } \\
(\mathrm{m} 7)\end{array}$}} & \multirow{2}{*}{\multicolumn{2}{|c|}{$\begin{array}{c}\text { Household } \\
(\mathrm{m} 8)\end{array}$}} \\
\hline & & & & & & & & & & & & & & & & \\
\hline & $b$ & RSE & $b$ & RSE & $b$ & RSE & $b$ & RSE & $b$ & RSE & $b$ & RSE & $b$ & RSE & $b$ & RSE \\
\hline interviewer: female & $0.07 * * *$ & $(0.01)$ & $0.07 * * *$ & $(0.01)$ & $0.07^{* * *}$ & $(0.01)$ & $0.06 * * *$ & $(0.01)$ & $0.07 * * *$ & $(0.01)$ & $0.07 * * *$ & $(0.01)$ & $0.07 * * *$ & $(0.01)$ & $0.07 * * *$ & $(0.01)$ \\
\hline age & & & 0.02 & $(0.02)$ & $0.05^{*}$ & $(0.02)$ & $0.05^{*}$ & $(0.02)$ & $0.05^{*}$ & $(0.02)$ & $0.05^{*}$ & $(0.02)$ & $0.04 *$ & $(0.02)$ & $0.04 *$ & $(0.02)$ \\
\hline age square & & & -0.00 & $(0.00)$ & -0.00 & $(0.00)$ & -0.00 & $(0.00)$ & -0.00 & $(0.00)$ & -0.00 & $(0.00)$ & -0.00 & $(0.00)$ & -0.00 & $(0.00)$ \\
\hline working & & & 0.06 & $(0.03)$ & 0.06 & $(0.03)$ & 0.06 & $(0.03)$ & 0.06 & $(0.03)$ & 0.06 & $(0.03)$ & 0.06 & $(0.03)$ & 0.06 & $(0.03)$ \\
\hline married & & & 0.01 & $(0.04)$ & 0.01 & $(0.04)$ & 0.01 & $(0.04)$ & 0.01 & $(0.04)$ & 0.01 & $(0.04)$ & 0.01 & $(0.04)$ & 0.01 & $(0.04)$ \\
\hline cohabitation & & & -0.09 & $(0.07)$ & -0.09 & $(0.07)$ & -0.09 & $(0.07)$ & -0.09 & $(0.07)$ & -0.09 & $(0.07)$ & -0.09 & $(0.07)$ & -0.09 & $(0.07)$ \\
\hline leave take-up & & & 0.09 & $(0.06)$ & 0.09 & $(0.06)$ & 0.09 & $(0.06)$ & 0.09 & $(0.06)$ & 0.09 & $(0.06)$ & 0.09 & $(0.06)$ & 0.09 & $(0.06)$ \\
\hline number children & & & $-0.04 *$ & $(0.02)$ & $-0.04 *$ & $(0.02)$ & $-0.04 *$ & $(0.02)$ & $-0.04 *$ & $(0.02)$ & $-0.04 *$ & $(0.02)$ & $-0.04 *$ & $(0.02)$ & $-0.04 *$ & $(0.02)$ \\
\hline net household income (log) & & & 0.02 & $(0.03)$ & 0.02 & $(0.03)$ & 0.02 & $(0.03)$ & 0.02 & $(0.03)$ & 0.02 & $(0.03)$ & 0.02 & $(0.03)$ & 0.02 & $(0.03)$ \\
\hline CAPI (ref. CATI) & & & & & $-0.09 *$ & $(0.04)$ & $-0.09 *$ & $(0.04)$ & $-0.09 *$ & $(0.04)$ & $-0.09 *$ & $(0.04)$ & -0.08 & $(0.04)$ & -0.08 & $(0.05)$ \\
\hline interviewer's education: medium (ref. low) & & & & & & & -0.00 & $(0.03)$ & -0.00 & $(0.03)$ & -0.00 & $(0.03)$ & -0.00 & $(0.03)$ & -0.01 & $(0.03)$ \\
\hline interviewer's education: high & & & & & & & -0.02 & $(0.02)$ & -0.02 & $(0.02)$ & -0.02 & $(0.02)$ & -0.02 & $(0.02)$ & -0.02 & $(0.03)$ \\
\hline interviewer's age: $30-49$ (ref. <30) & & & & & & & & & $0.08 * * *$ & $(0.02)$ & $0.08 * * *$ & $(0.02)$ & $0.08^{* * *}$ & $(0.02)$ & $0.08 * * *$ & $(0.02)$ \\
\hline interviewer's age: $50-65$ & & & & & & & & & $0.06^{*}$ & $(0.02)$ & $0.05 *$ & $(0.02)$ & $0.05^{*}$ & $(0.02)$ & $0.05^{*}$ & $(0.02)$ \\
\hline interviewer's age: $65+$ & & & & & & & & & 0.06 & $(0.03)$ & 0.05 & $(0.03)$ & 0.05 & $(0.03)$ & 0.05 & (0.03) \\
\hline interviewer's experience: $1-2$ y (ref. $<1$ y) & & & & & & & & & & & -0.01 & $(0.02)$ & -0.01 & $(0.02)$ & -0.01 & $(0.02)$ \\
\hline interviewer's experience: $2-3 y$ & & & & & & & & & & & 0.01 & $(0.02)$ & 0.01 & $(0.02)$ & 0.01 & $(0.02)$ \\
\hline interviewer's experience: $3 y+$ & & & & & & & & & & & 0.01 & $(0.02)$ & 0.01 & $(0.02)$ & 0.01 & $(0.02)$ \\
\hline interview duration in minutes & & & & & & & & & & & & & -0.00 & $(0.00)$ & -0.00 & $(0.00)$ \\
\hline number of previous interviews & & & & & & & & & & & & & & & -0.00 & $(0.02)$ \\
\hline respondent tired & & & & & & & & & & & & & & & -0.01 & $(0.01)$ \\
\hline _cons & $3.50 * * *$ & $(0.01)$ & $3.20 * * *$ & $(0.46)$ & $1.99 * *$ & $(0.66)$ & $2.04 * *$ & $(0.67)$ & $2.06 * *$ & $(0.68)$ & $2.05 * *$ & $(0.67)$ & $2.15^{* *}$ & $(0.69)$ & $2.14^{* *}$ & $(0.67)$ \\
\hline Observations & 546 & & 54 & & 546 & & 546 & & 54 & & 54 & & 54 & & 546 & \\
\hline Individuals & 273 & & 27 & & 273 & & 273 & & 27 & & 27 & & 27 & & 273 & \\
\hline Number of Interviewers & 44 & & 44 & & 44 & & 44 & & 44 & & 44 & & 44 & & 44 & \\
\hline $\mathrm{F}$ & 24.8 & & $5 .($ & & 5.8 & & 5.4 & & 5.1 & & 4. & & 4.2 & & 3.9 & \\
\hline r2_w & 0.0 & & $0 .($ & & 0.0 & & 0.0 & & 0.0 & & 0. & & $0 .($ & & 0.0 & \\
\hline $\mathrm{p}$ & 0.0 & & 0. & & 0.0 & & 0.0 & & 0.0 & & 0. & & $0 .($ & & 0.0 & \\
\hline
\end{tabular}

Note: Higher attitude scores indicate less traditional attitudes. Robust standard errors (RSE) in parentheses. Reference category indicated with .ref, net household income deflated with base year 2015.

${ }^{*} p<0.05, * * p<0.01, * * * p<0.001$

Source: NEPS:SC6:10.0.0, own calculations. 
Table A15. Female-interviewer-effect on female respondents' agreement with attitudinal statement "Technology" (Stepwise fixed-effects-regression models).

\begin{tabular}{|c|c|c|c|c|c|c|c|c|c|c|c|c|c|c|c|c|}
\hline & \multirow{2}{*}{\multicolumn{2}{|c|}{$\begin{array}{c}\text { Technology } \\
\text { (m1) }\end{array}$}} & \multirow{2}{*}{\multicolumn{2}{|c|}{$\begin{array}{c}\text { Technology } \\
\text { (m2) }\end{array}$}} & \multirow{2}{*}{\multicolumn{2}{|c|}{$\begin{array}{c}\text { Technology } \\
\text { (m3) }\end{array}$}} & \multirow{2}{*}{\multicolumn{2}{|c|}{$\begin{array}{c}\text { Technology } \\
(\mathrm{m} 4)\end{array}$}} & \multirow{2}{*}{\multicolumn{2}{|c|}{$\begin{array}{c}\text { Technology } \\
\text { (m5) }\end{array}$}} & \multirow{2}{*}{\multicolumn{2}{|c|}{$\begin{array}{c}\text { Technology } \\
\text { (m6) }\end{array}$}} & \multirow{2}{*}{\multicolumn{2}{|c|}{$\begin{array}{c}\text { Technology } \\
(\mathrm{m} 7)\end{array}$}} & \multirow{2}{*}{\multicolumn{2}{|c|}{$\begin{array}{c}\text { Technology } \\
\text { (m8) }\end{array}$}} \\
\hline & & & & & & & & & & & & & & & & \\
\hline & $b$ & RSE & $b$ & RSE & $b$ & RSE & $b$ & RSE & $b$ & RSE & $b$ & RSE & $b$ & RSE & $b$ & RSE \\
\hline interviewer: female & $0.07^{* * *}$ & $(0.02)$ & $0.07^{* * *}$ & $(0.02)$ & $0.07 * * *$ & $(0.02)$ & $0.07^{* * *}$ & $(0.02)$ & $0.06 * *$ & $(0.02)$ & $0.06^{* *}$ & $(0.02)$ & $0.06 * *$ & $(0.02)$ & $0.06^{* *}$ & $(0.02)$ \\
\hline age & & & $0.05 *$ & $(0.02)$ & $0.06 * *$ & $(0.02)$ & $0.06 * *$ & $(0.02)$ & $0.06 *$ & $(0.02)$ & $0.06^{*}$ & $(0.02)$ & $0.06^{*}$ & $(0.02)$ & $0.06^{* *}$ & (0.02) \\
\hline age square & & & $-0.00 * *$ & $(0.00)$ & $-0.00 * *$ & $(0.00)$ & $-0.00 * *$ & $(0.00)$ & $-0.00 * *$ & $(0.00)$ & $-0.00 * *$ & $(0.00)$ & $-0.00 *$ & $(0.00)$ & $-0.00 *$ & $(0.00)$ \\
\hline working & & & -0.05 & $(0.03)$ & -0.05 & $(0.03)$ & -0.05 & $(0.03)$ & -0.05 & $(0.03)$ & -0.05 & $(0.03)$ & -0.05 & $(0.03)$ & -0.05 & (0.03) \\
\hline married & & & 0.09 & $(0.07)$ & 0.09 & $(0.07)$ & 0.09 & $(0.07)$ & 0.08 & $(0.07)$ & 0.09 & $(0.07)$ & 0.09 & $(0.07)$ & 0.08 & $(0.07)$ \\
\hline cohabitation & & & $-0.24 * *$ & $(0.08)$ & $-0.24 * *$ & $(0.08)$ & $-0.24 * *$ & $(0.08)$ & $-0.24 * *$ & $(0.08)$ & $-0.24 * *$ & $(0.08)$ & $-0.24 * *$ & $(0.08)$ & $-0.24^{* *}$ & (0.08) \\
\hline leave take-up & & & $-0.12^{*}$ & $(0.06)$ & $-0.12^{*}$ & $(0.06)$ & $-0.12^{*}$ & $(0.06)$ & $-0.12^{*}$ & $(0.06)$ & $-0.12^{*}$ & $(0.06)$ & $-0.12^{*}$ & $(0.06)$ & $-0.12^{*}$ & (0.06) \\
\hline number children & & & -0.00 & $(0.02)$ & -0.00 & $(0.02)$ & -0.00 & $(0.02)$ & -0.00 & $(0.02)$ & -0.00 & $(0.02)$ & -0.00 & $(0.02)$ & -0.00 & (0.02) \\
\hline net household income (log) & & & $-0.11^{* *}$ & $(0.03)$ & $-0.11 * *$ & $(0.03)$ & $-0.11^{* *}$ & $(0.03)$ & $-0.11^{* *}$ & $(0.03)$ & $-0.11^{* *}$ & $(0.03)$ & $-0.11^{* *}$ & $(0.03)$ & $-0.11^{* *}$ & (0.03) \\
\hline CAPI (ref. CATI) & & & & & -0.03 & $(0.04)$ & -0.03 & $(0.04)$ & -0.03 & $(0.04)$ & -0.04 & $(0.04)$ & -0.04 & $(0.04)$ & -0.03 & $(0.04)$ \\
\hline interviewer's education: medium (ref. low) & & & & & & & 0.00 & $(0.03)$ & 0.00 & $(0.03)$ & 0.01 & $(0.03)$ & 0.01 & $(0.03)$ & 0.01 & (0.03) \\
\hline interviewer's education: high & & & & & & & 0.00 & $(0.03)$ & 0.01 & $(0.03)$ & 0.01 & $(0.03)$ & 0.01 & $(0.03)$ & 0.01 & (0.03) \\
\hline interviewer's age: $30-49$ (ref. <30) & & & & & & & & & -0.02 & $(0.03)$ & -0.02 & $(0.03)$ & -0.02 & $(0.03)$ & -0.02 & (0.03) \\
\hline interviewer's age: $50-65$ & & & & & & & & & 0.01 & $(0.03)$ & 0.02 & $(0.03)$ & 0.02 & $(0.03)$ & 0.02 & (0.03) \\
\hline interviewer's age: $65+$ & & & & & & & & & -0.02 & $(0.04)$ & -0.01 & $(0.04)$ & -0.01 & $(0.04)$ & -0.01 & $(0.04)$ \\
\hline interviewer's experience: $1-2$ y (ref. $<1$ y) & & & & & & & & & & & 0.02 & $(0.02)$ & 0.02 & $(0.02)$ & 0.02 & $(0.02)$ \\
\hline interviewer's experience: $2-3 y$ & & & & & & & & & & & -0.02 & $(0.03)$ & -0.02 & $(0.03)$ & -0.01 & (0.03) \\
\hline interviewer's experience: $3 y+$ & & & & & & & & & & & -0.00 & $(0.02)$ & -0.00 & $(0.02)$ & 0.01 & (0.03) \\
\hline interview duration in minutes & & & & & & & & & & & & & 0.00 & $(0.00)$ & 0.00 & $(0.00)$ \\
\hline number of previous interviews & & & & & & & & & & & & & & & -0.02 & $(0.02)$ \\
\hline respondent tired & & & & & & & & & & & & & & & 0.01 & $(0.01)$ \\
\hline _cons & $3.18^{* * *}$ & $(0.01)$ & $3.14^{* * *}$ & $(0.50)$ & $2.73 * * *$ & $(0.69)$ & $2.72 * * *$ & $(0.70)$ & $2.76 * * *$ & $(0.70)$ & $2.78 * * *$ & $(0.70)$ & $2.75^{* * *}$ & $(0.72)$ & $2.63^{* * *}$ & (0.70) \\
\hline Observations & 546 & & 54 & & 546 & & 546 & & 546 & & 546 & & 546 & & 546 & \\
\hline Individuals & 273 & & 273 & & 273 & & 273 & & 273 & & 273 & & 273 & & 273 & \\
\hline Number of Interviewers & 44 & & 44 & & 44 & & 445 & & 44 & & 445 & & 44 & & 445 & \\
\hline $\mathrm{F}$ & 17. & & 5.8 & & 5.3 & & 4.4 & & 4.0 & & 3.7 & & 3.5 & & 3.2 & \\
\hline r2_w & 0.0 & & 0.0 & & 0.0 & & 0.0 & & 0.0 & & 0.0 & & 0.0 & & 0.0 & \\
\hline $\mathrm{p}$ & 0.0 & & 0.0 & & 0.0 & & 0.0 & & 0.0 & & 0.0 & & 0.0 & & 0.0 & \\
\hline
\end{tabular}

Note: Higher attitude scores indicate less traditional attitudes. Robust standard errors (RSE) in parentheses. Reference category indicated with .ref, net household income deflated with base year 2015.

$* p<0.05, * * p<0.01, * * * p<0.001$

Source: NEPS:SC6:10.0.0, own calculations. 
Table A16. Female-interviewer-effect on female respondents' agreement with attitudinal statement "Roles (R)" (Stepwise fixed-effects-regression models).

\begin{tabular}{|c|c|c|c|c|c|c|c|c|c|c|c|c|c|c|c|c|}
\hline & \multirow{2}{*}{\multicolumn{2}{|c|}{$\begin{array}{c}\text { Roles (R) } \\
(\mathrm{m} 1)\end{array}$}} & \multicolumn{2}{|c|}{ Roles (R) } & \multirow{2}{*}{\multicolumn{2}{|c|}{ Roles (R) }} & \multicolumn{2}{|c|}{ Roles (R) } & \multicolumn{2}{|c|}{ Roles (R) } & \multicolumn{2}{|c|}{ Roles (R) } & \multicolumn{2}{|c|}{ Roles (R) } & \multicolumn{2}{|c|}{ Roles (R) } \\
\hline & & & \multicolumn{2}{|c|}{$(\mathrm{m} 2)$} & $(\mathrm{m} 3)$ & & \multicolumn{2}{|c|}{$(\mathrm{m} 4)$} & \multicolumn{2}{|c|}{ (m5) } & \multicolumn{2}{|c|}{$(\mathrm{m} 6)$} & \multicolumn{2}{|c|}{ (m7) } & \multicolumn{2}{|c|}{$(\mathrm{m} 8)$} \\
\hline & $b$ & RSE & $b$ & RSE & $b$ & RSE & $b$ & RSE & $b$ & RSE & $b$ & RSE & $b$ & RSE & $b$ & RSE \\
\hline interviewer: female & -0.02 & $(0.02)$ & -0.01 & $(0.01)$ & -0.01 & $(0.01)$ & -0.01 & (0.01) & -0.01 & $(0.02)$ & -0.01 & $(0.02)$ & -0.02 & $(0.02)$ & -0.02 & $(0.02)$ \\
\hline age & & & 0.01 & $(0.02)$ & -0.02 & $(0.02)$ & -0.02 & $(0.02)$ & -0.02 & $(0.02)$ & -0.02 & $(0.02)$ & -0.02 & $(0.02)$ & -0.02 & $(0.02)$ \\
\hline age square & & & 0.00 & $(0.00)$ & 0.00 & $(0.00)$ & 0.00 & $(0.00)$ & 0.00 & $(0.00)$ & 0.00 & $(0.00)$ & 0.00 & $(0.00)$ & 0.00 & $(0.00)$ \\
\hline working & & & 0.01 & $(0.03)$ & 0.01 & $(0.03)$ & 0.01 & $(0.03)$ & 0.02 & $(0.03)$ & 0.02 & $(0.03)$ & 0.01 & $(0.03)$ & 0.01 & $(0.03)$ \\
\hline married & & & -0.03 & $(0.06)$ & -0.04 & $(0.06)$ & -0.03 & $(0.06)$ & -0.03 & $(0.06)$ & -0.04 & $(0.06)$ & -0.04 & $(0.06)$ & -0.03 & $(0.06)$ \\
\hline cohabitation & & & -0.04 & $(0.06)$ & -0.04 & $(0.06)$ & -0.04 & $(0.06)$ & -0.04 & $(0.06)$ & -0.04 & $(0.06)$ & -0.04 & $(0.06)$ & -0.04 & $(0.06)$ \\
\hline leave take-up & & & $-0.12 *$ & $(0.06)$ & $-0.12 *$ & $(0.06)$ & $-0.11 *$ & $(0.06)$ & $-0.11 *$ & $(0.06)$ & $-0.11^{*}$ & $(0.06)$ & $-0.11 *$ & $(0.06)$ & $-0.11 *$ & $(0.06)$ \\
\hline number children & & & -0.03 & $(0.02)$ & -0.02 & $(0.02)$ & -0.02 & $(0.02)$ & -0.02 & $(0.02)$ & -0.02 & $(0.02)$ & -0.03 & $(0.02)$ & -0.03 & $(0.02)$ \\
\hline net household income (log) & & & -0.05 & $(0.03)$ & -0.05 & $(0.03)$ & -0.05 & $(0.03)$ & -0.05 & $(0.03)$ & -0.05 & $(0.03)$ & -0.05 & $(0.03)$ & -0.05 & $(0.03)$ \\
\hline CAPI (ref. CATI) & & & & & $0.08^{* *}$ & $(0.03)$ & $0.09 * *$ & $(0.03)$ & $0.09 * *$ & $(0.03)$ & $0.09 * *$ & $(0.03)$ & $0.08^{*}$ & $(0.04)$ & 0.08 & $(0.04)$ \\
\hline interviewer's education: medium (ref. low) & & & & & & & $-0.06 *$ & $(0.03)$ & $-0.06^{*}$ & $(0.03)$ & $-0.06 *$ & $(0.03)$ & $-0.06 *$ & $(0.03)$ & $-0.06 *$ & $(0.03)$ \\
\hline interviewer's education: high & & & & & & & -0.02 & $(0.02)$ & -0.02 & $(0.02)$ & -0.02 & $(0.02)$ & -0.02 & $(0.02)$ & -0.02 & $(0.02)$ \\
\hline interviewer's age: $30-49$ (ref. <30) & & & & & & & & & 0.05 & $(0.03)$ & 0.05 & $(0.03)$ & 0.04 & $(0.03)$ & 0.05 & $(0.03)$ \\
\hline interviewer's age: 50-65 & & & & & & & & & 0.04 & $(0.03)$ & 0.03 & $(0.03)$ & 0.03 & $(0.03)$ & 0.04 & $(0.03)$ \\
\hline interviewer's age: $65+$ & & & & & & & & & 0.03 & $(0.03)$ & 0.01 & $(0.03)$ & 0.01 & $(0.03)$ & 0.02 & $(0.03)$ \\
\hline interviewer's experience: $1-2$ y (ref. $<1$ y) & & & & & & & & & & & -0.02 & $(0.02)$ & -0.02 & $(0.02)$ & -0.02 & $(0.02)$ \\
\hline interviewer's experience: $2-3 y$ & & & & & & & & & & & 0.01 & $(0.02)$ & 0.01 & $(0.02)$ & 0.01 & $(0.02)$ \\
\hline interviewer's experience: $3 y+$ & & & & & & & & & & & 0.02 & $(0.02)$ & 0.02 & $(0.02)$ & 0.01 & $(0.02)$ \\
\hline interview duration in minutes & & & & & & & & & & & & & 0.00 & $(0.00)$ & 0.00 & $(0.00)$ \\
\hline number of previous interviews & & & & & & & & & & & & & & & 0.02 & $(0.02)$ \\
\hline respondent tired & & & & & & & & & & & & & & & -0.01 & $(0.01)$ \\
\hline _cons & $3.56^{* * *}$ & $(0.01)$ & $3.30 * * *$ & $(0.52)$ & $4.45 * * *$ & $(0.67)$ & $4.55^{* * *}$ & $(0.67)$ & $4.58^{* * *}$ & $(0.67)$ & $4.58 * * *$ & $(0.66)$ & $4.52^{* * *}$ & $(0.68)$ & $4.61^{* * *}$ & $(0.67)$ \\
\hline Observations & \multicolumn{2}{|c|}{5464} & \multicolumn{2}{|c|}{5464} & \multicolumn{2}{|c|}{5464} & \multicolumn{2}{|c|}{5464} & \multicolumn{2}{|c|}{5464} & \multicolumn{2}{|c|}{5464} & \multicolumn{2}{|c|}{5464} & \multicolumn{2}{|c|}{5464} \\
\hline Individuals & \multicolumn{2}{|c|}{2732} & \multicolumn{2}{|c|}{2732} & 273 & & 27 & & 27 & & 273 & & 27 & & 27 & \\
\hline Number of Interviewers & 44 & & 44 & & 44 & & 44 & & 44 & & 44 & & 44 & & 44 & \\
\hline$F$ & 1.3 & & 5.5 & & 6.3 & & $6 .($ & & $5 . c$ & & 4.6 & & 4. & & 4. & \\
\hline r2_w & $0 . c$ & & 0.0 & & 0.0 & & $0 .($ & & $0 . c$ & & 0.0 & & 0. & & 0. & \\
\hline $\mathrm{p}$ & 0.2 & & 0.0 & & 0.0 & & $0 .($ & & $0 . c$ & & 0.0 & & 0. & & 0. & \\
\hline
\end{tabular}

Note: Higher attitude scores indicate less traditional attitudes. Robust standard errors (RSE) in parentheses. Reference category indicated with .ref, net household income deflated with base year 2015.

${ }^{*} p<0.05, * * p<0.01, * * * p<0.001$

Source: NEPS:SC6:10.0.0, own calculations. 
Table 17. Fixed-effects-regression models for male respondents in West and East Germany.

\begin{tabular}{|c|c|c|c|c|c|c|c|c|c|c|c|c|}
\hline & \multicolumn{6}{|c|}{ West Germany } & \multicolumn{6}{|c|}{ East Germany } \\
\hline & Index & $\begin{array}{c}\text { Profession } \\
\text { (R) } \\
\end{array}$ & Politics & Household & $\begin{array}{c}\text { Techno- } \\
\text { logy }\end{array}$ & Roles (R) & Index & $\begin{array}{l}\text { Profession } \\
\text { (R) }\end{array}$ & Politics & Household & $\begin{array}{c}\text { Techno- } \\
\text { logy }\end{array}$ & Roles (R) \\
\hline & $(\mathrm{m} 1)$ & $(\mathrm{m} 2)$ & (m3) & (m4) & (m5) & $(\mathrm{m} 6)$ & $(\mathrm{m} 1)$ & $(\mathrm{m} 2)$ & $(\mathrm{m} 3)$ & $(\mathrm{m} 4)$ & (m5) & (m6) \\
\hline interviewer: female & $0.09 * * *$ & $0.08 * *$ & $0.17^{* * *}$ & $0.05 * *$ & $0.15^{* * *}$ & -0.01 & $0.10 * * *$ & $0.14^{* *}$ & 0.07 & $0.08^{*}$ & $0.15^{* * *}$ & 0.04 \\
\hline age & $0.03^{*}$ & $0.08^{* *}$ & 0.05 & 0.02 & 0.05 & $-0.07^{* *}$ & 0.06 & 0.09 & -0.10 & $0.18^{* *}$ & $0.15^{*}$ & -0.03 \\
\hline age square & -0.00 & -0.00 & -0.00 & 0.00 & -0.00 & $0.00^{*}$ & -0.00 & -0.00 & 0.00 & $-0.00 * *$ & -0.00 & 0.00 \\
\hline working & -0.03 & -0.06 & $-0.09 *$ & -0.07 & 0.09 & -0.03 & -0.00 & 0.06 & -0.04 & -0.11 & 0.02 & 0.06 \\
\hline married & -0.03 & -0.06 & 0.14 & -0.06 & -0.13 & -0.02 & -0.07 & 0.14 & $-0.66 * * *$ & $-0.31^{*}$ & $0.42 * *$ & 0.08 \\
\hline cohabitation & $0.10^{* *}$ & 0.08 & 0.12 & 0.09 & $0.27^{* *}$ & -0.07 & 0.04 & -0.26 & $0.79 * * *$ & -0.02 & -0.08 & -0.22 \\
\hline leave take-up & 0.14 & -0.05 & 0.36 & 0.08 & 0.11 & 0.19 & $0.12^{*}$ & 0.15 & -0.18 & 0.30 & 0.80 & -0.46 \\
\hline number children & -0.01 & 0.03 & -0.04 & -0.04 & -0.02 & 0.00 & 0.05 & -0.04 & 0.06 & 0.06 & 0.11 & 0.05 \\
\hline net household income (log) & 0.02 & 0.06 & -0.04 & 0.04 & 0.05 & -0.01 & -0.08 & -0.01 & 0.08 & -0.12 & $-0.42 * * *$ & 0.06 \\
\hline CAPI (ref. CATI) & $-0.11 * * *$ & $-0.24 * * *$ & -0.09 & $-0.12 * *$ & $-0.14^{* *}$ & 0.05 & $-0.10^{*}$ & $-0.26^{*}$ & -0.03 & -0.05 & -0.17 & 0.02 \\
\hline interviewer's education: medium (ref. low) & $0.05^{* *}$ & 0.00 & 0.05 & 0.06 & $0.12^{* *}$ & 0.04 & -0.08 & $-0.18^{*}$ & -0.06 & $-0.16^{*}$ & 0.01 & 0.00 \\
\hline interviewer's education: high & $0.07^{* * *}$ & 0.04 & 0.03 & $0.08 * *$ & $0.11^{* * *}$ & $0.10^{* * *}$ & 0.07 & -0.02 & 0.16 & -0.01 & $0.23 * *$ & 0.01 \\
\hline interviewer's age: $30-49$ (ref. <30) & 0.02 & -0.04 & $0.11^{* *}$ & 0.05 & -0.02 & 0.00 & 0.06 & -0.10 & 0.12 & $0.12^{*}$ & $0.19 * *$ & -0.03 \\
\hline interviewer's age: $50-65$ & -0.01 & $-0.08^{*}$ & 0.03 & -0.01 & -0.01 & 0.01 & 0.03 & -0.10 & 0.06 & 0.06 & $0.19^{*}$ & -0.05 \\
\hline interviewer's age: $65+$ & 0.03 & 0.06 & -0.00 & 0.01 & 0.01 & 0.07 & 0.03 & -0.05 & -0.01 & 0.15 & 0.13 & -0.09 \\
\hline interviewer's experience: $1-2$ y (ref. $<1$ y) & $-0.04 * *$ & -0.01 & $-0.07 *$ & $-0.11 * * *$ & -0.01 & -0.02 & $0.08^{*}$ & 0.09 & 0.06 & 0.10 & 0.06 & 0.08 \\
\hline interviewer's experience: $2-3 y$ & -0.03 & 0.02 & -0.05 & -0.03 & -0.06 & -0.03 & $0.06^{*}$ & 0.04 & 0.02 & $0.13^{*}$ & $0.14^{*}$ & -0.03 \\
\hline interviewer's experience: $3 y+$ & 0.01 & 0.00 & -0.03 & 0.04 & 0.00 & 0.01 & $0.06^{*}$ & 0.01 & 0.11 & $0.13^{*}$ & 0.04 & 0.03 \\
\hline interview duration in minutes & $0.00 *$ & 0.00 & -0.00 & $0.00^{*}$ & 0.00 & 0.00 & 0.00 & 0.00 & -0.00 & 0.00 & -0.00 & $0.00 * *$ \\
\hline number of previous interviews & 0.00 & -0.02 & 0.02 & -0.00 & -0.01 & 0.02 & $-0.04 *$ & 0.00 & -0.06 & $-0.09 * * *$ & 0.00 & -0.03 \\
\hline respondent tired & -0.01 & 0.01 & $-0.03^{*}$ & -0.01 & 0.01 & $-0.03^{*}$ & -0.02 & -0.00 & $-0.05^{*}$ & -0.00 & 0.01 & -0.04 \\
\hline _cons & $1.46 * * *$ & -1.09 & 1.05 & $2.04 * *$ & -0.03 & $5.32 * * *$ & 1.35 & -0.93 & 4.50 & -0.54 & 0.64 & 3.10 \\
\hline Observations & 3978 & 3978 & 3978 & 3978 & 3978 & 3978 & 966 & 966 & 966 & 966 & 966 & 966 \\
\hline Individuals & 1989 & 1989 & 1989 & 1989 & 1989 & 1989 & 483 & 483 & 483 & 483 & 483 & 483 \\
\hline Number of Interviewers & 404 & 404 & 404 & 404 & 404 & 404 & 258 & 258 & 258 & 258 & 258 & 258 \\
\hline $\mathrm{F}$ & 9.14 & 5.24 & 5.28 & 5.65 & 5.60 & 3.81 & 10.14 & 2.07 & 3.23 & 3.31 & 4.12 & 3.00 \\
\hline r2_w & 0.04 & 0.03 & 0.03 & 0.02 & 0.02 & 0.02 & 0.07 & 0.04 & 0.06 & 0.05 & 0.08 & 0.06 \\
\hline $\mathrm{p}$ & 0.00 & 0.00 & 0.00 & 0.00 & 0.00 & 0.00 & 0.00 & 0.00 & 0.00 & 0.00 & 0.00 & 0.00 \\
\hline
\end{tabular}

Note: Higher attitude scores indicate less traditional attitudes. Reference category indicated with .ref, net household income deflated with base year 2015

$* p<0.05, * * p<0.01,{ }^{* * *} p<0.001$

Source: NEPS:SC6:10.0.0, own calculations. 
Table 18. Fixed-effects-regression models for female respondents in West and East Germany.

\begin{tabular}{|c|c|c|c|c|c|c|c|c|c|c|c|c|}
\hline & \multicolumn{6}{|c|}{ West Germany } & \multicolumn{6}{|c|}{ East Germany } \\
\hline & Index & $\begin{array}{l}\text { Profession } \\
\text { (R) }\end{array}$ & Politics & Household & $\begin{array}{c}\text { Techno- } \\
\text { logy }\end{array}$ & Roles (R) & Index & $\begin{array}{c}\text { Profession } \\
\text { (R) } \\
\end{array}$ & Politics & Household & $\begin{array}{c}\text { Techno- } \\
\text { logy }\end{array}$ & Roles (R) \\
\hline & $(\mathrm{m} 1)$ & $(\mathrm{m} 2)$ & (m3) & $(\mathrm{m} 4)$ & (m5) & (m6) & (m1) & $(\mathrm{m} 2)$ & (m3) & $(\mathrm{m} 4)$ & (m5) & (m6) \\
\hline interviewer: female & $0.04 * * *$ & -0.03 & $0.10 * * *$ & $0.09 * * *$ & $0.04^{*}$ & -0.02 & 0.03 & -0.01 & 0.08 & -0.00 & $0.12^{* *}$ & -0.02 \\
\hline age & 0.02 & $0.07^{*}$ & -0.03 & 0.02 & $0.06^{*}$ & -0.01 & 0.03 & -0.11 & 0.11 & $0.10^{*}$ & 0.04 & -0.01 \\
\hline age square & -0.00 & $-0.00^{*}$ & 0.00 & -0.00 & $-0.00 *$ & 0.00 & -0.00 & $0.00 *$ & -0.00 & -0.00 & -0.00 & -0.00 \\
\hline working & 0.01 & 0.02 & -0.06 & $0.08^{*}$ & -0.01 & 0.00 & 0.02 & 0.04 & 0.12 & 0.02 & $-0.16^{*}$ & 0.05 \\
\hline married & -0.03 & -0.07 & 0.02 & -0.02 & 0.03 & $-0.14^{*}$ & $0.12 * *$ & -0.36 & 0.23 & 0.15 & 0.23 & $0.37^{*}$ \\
\hline cohabitation & $-0.11 * *$ & -0.06 & -0.05 & -0.09 & $-0.30 * * *$ & -0.07 & 0.15 & 0.29 & 0.19 & -0.04 & 0.13 & 0.18 \\
\hline leave take-up & -0.02 & 0.05 & $-0.17^{*}$ & $0.14^{*}$ & -0.02 & -0.11 & $-0.19 *$ & -0.28 & 0.11 & -0.10 & $-0.56 * * *$ & -0.10 \\
\hline number children & -0.01 & 0.01 & -0.00 & -0.03 & 0.01 & -0.02 & -0.03 & $0.16^{*}$ & -0.06 & $-0.10^{*}$ & -0.06 & -0.08 \\
\hline net household income (log) & $-0.04^{*}$ & -0.01 & -0.06 & 0.02 & $-0.11^{* *}$ & -0.04 & -0.02 & 0.12 & -0.09 & -0.00 & -0.06 & -0.07 \\
\hline CAPI (ref. CATI) & -0.05 & -0.07 & -0.08 & -0.04 & -0.05 & 0.01 & -0.01 & 0.21 & $-0.20^{*}$ & -0.22 & -0.03 & $0.22 * *$ \\
\hline interviewer's education: medium (ref. low) & -0.02 & 0.04 & 0.00 & $-0.06^{*}$ & -0.02 & $-0.08^{*}$ & $0.07^{*}$ & $0.19 *$ & -0.12 & 0.13 & 0.14 & 0.02 \\
\hline interviewer's education: high & 0.00 & 0.05 & 0.05 & $-0.05^{*}$ & -0.02 & -0.02 & 0.03 & 0.02 & -0.10 & 0.06 & $0.13^{*}$ & 0.01 \\
\hline interviewer's age: $30-49$ (ref. <30) & $0.04 * *$ & 0.01 & 0.06 & $0.11^{* * *}$ & -0.02 & 0.05 & 0.01 & -0.01 & 0.06 & -0.04 & -0.03 & 0.06 \\
\hline interviewer's age: $50-65$ & $0.05^{* *}$ & 0.05 & 0.03 & $0.07^{*}$ & 0.03 & $0.07^{*}$ & $-0.07 *$ & -0.13 & -0.15 & -0.02 & 0.02 & -0.05 \\
\hline interviewer's age: $65+$ & 0.04 & -0.03 & 0.08 & 0.06 & 0.02 & 0.06 & $-0.10 *$ & $-0.24 *$ & -0.01 & 0.02 & -0.11 & $-0.16^{*}$ \\
\hline interviewer's experience: $1-2$ y (ref. $<1$ y) & 0.02 & $0.08^{*}$ & -0.01 & 0.00 & 0.04 & -0.05 & -0.01 & -0.01 & -0.05 & -0.08 & -0.04 & $0.10^{*}$ \\
\hline interviewer's experience: $2-3 y$ & 0.01 & 0.08 & -0.01 & 0.03 & 0.00 & -0.03 & -0.03 & -0.06 & -0.09 & -0.07 & -0.08 & $0.15^{* *}$ \\
\hline interviewer's experience: $3 y+$ & 0.00 & 0.06 & -0.02 & 0.02 & -0.01 & -0.04 & 0.03 & -0.13 & -0.02 & 0.02 & 0.11 & $0.15^{* *}$ \\
\hline interview duration in minutes & 0.00 & -0.00 & -0.00 & -0.00 & 0.00 & 0.00 & -0.00 & 0.00 & -0.00 & -0.00 & -0.00 & 0.00 \\
\hline number of previous interviews & 0.00 & -0.02 & 0.02 & 0.00 & -0.01 & $0.04 *$ & $-0.04 *$ & $-0.14 * * *$ & 0.03 & 0.01 & -0.05 & -0.04 \\
\hline respondent tired & 0.00 & -0.01 & -0.00 & -0.01 & 0.01 & 0.00 & $-0.01 *$ & -0.03 & 0.02 & -0.01 & -0.02 & $-0.03 *$ \\
\hline _cons & $2.87^{* * *}$ & 0.28 & $4.49 * * *$ & $2.78 * * *$ & $2.61 * *$ & $4.19 * * *$ & $2.11^{* *}$ & 3.09 & 0.42 & 0.51 & 2.17 & $4.34 * *$ \\
\hline Observations & 4308 & 4308 & 4308 & 4308 & 4308 & 4308 & 1156 & 1156 & 1156 & 1156 & 1156 & 1156 \\
\hline Individuals & 2154 & 2154 & 2154 & 2154 & 2154 & 2154 & 578 & 578 & 578 & 578 & 578 & 578 \\
\hline Number of Interviewers & 415 & 415 & 415 & 415 & 415 & 415 & 260 & 260 & 260 & 260 & 260 & 260 \\
\hline $\mathrm{F}$ & 3.37 & 1.45 & 4.09 & 3.86 & 2.84 & 3.22 & 4.28 & 3.14 & 4.48 & 3.17 & 3.59 & 5.61 \\
\hline r2_w & 0.02 & 0.01 & 0.02 & 0.02 & 0.01 & 0.02 & 0.06 & 0.06 & 0.06 & 0.05 & 0.05 & 0.07 \\
\hline $\mathrm{p}$ & 0.00 & 0.09 & 0.00 & 0.00 & 0.00 & 0.00 & 0.00 & 0.00 & 0.00 & 0.00 & 0.00 & 0.00 \\
\hline
\end{tabular}

Note: Higher attitude scores indicate less traditional attitudes. Reference category indicated with .ref, net household income deflated with base year 2015.

${ }^{*} \mathrm{p}<0.05,{ }^{* *} \mathrm{p}<0.01,{ }^{* * *} \mathrm{p}<0.001$

Source: NEPS:SC6:10.0.0, own calculations. 


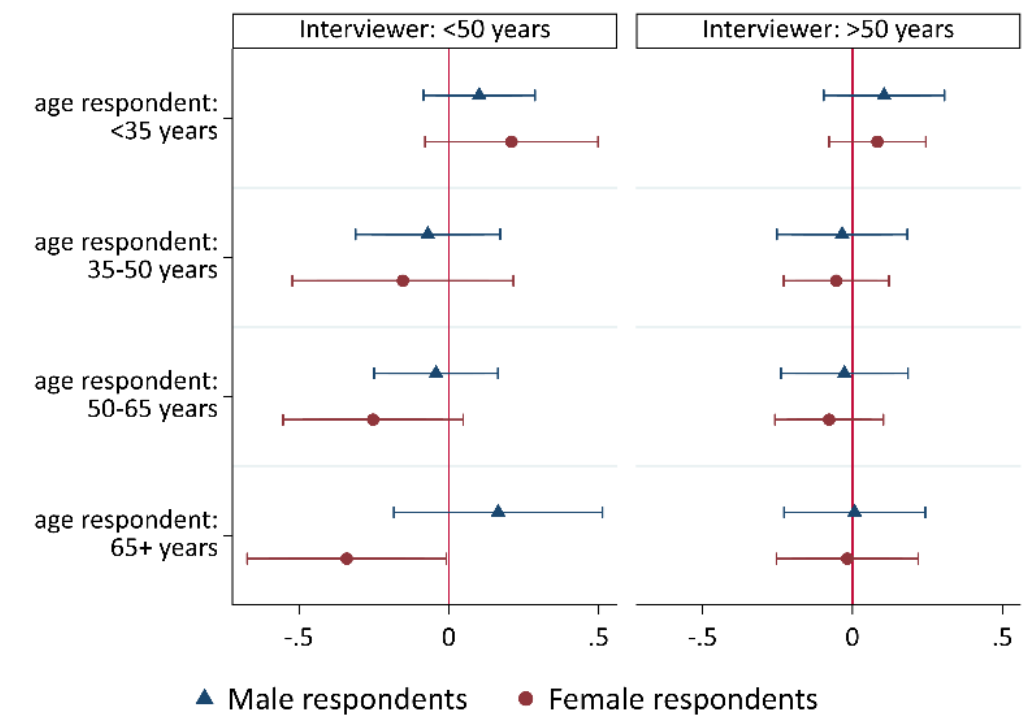

Fig. A1 Interaction effect between a female interviewer, interviewer's and respondent's age

Note: The figure plots the interaction effects with $95 \%$ confidence intervals between a female interviewer, her age and respondents' age on the respondent's gender ideology index (Source N=10410 (Males=4946, Females=5464), Own calculations).

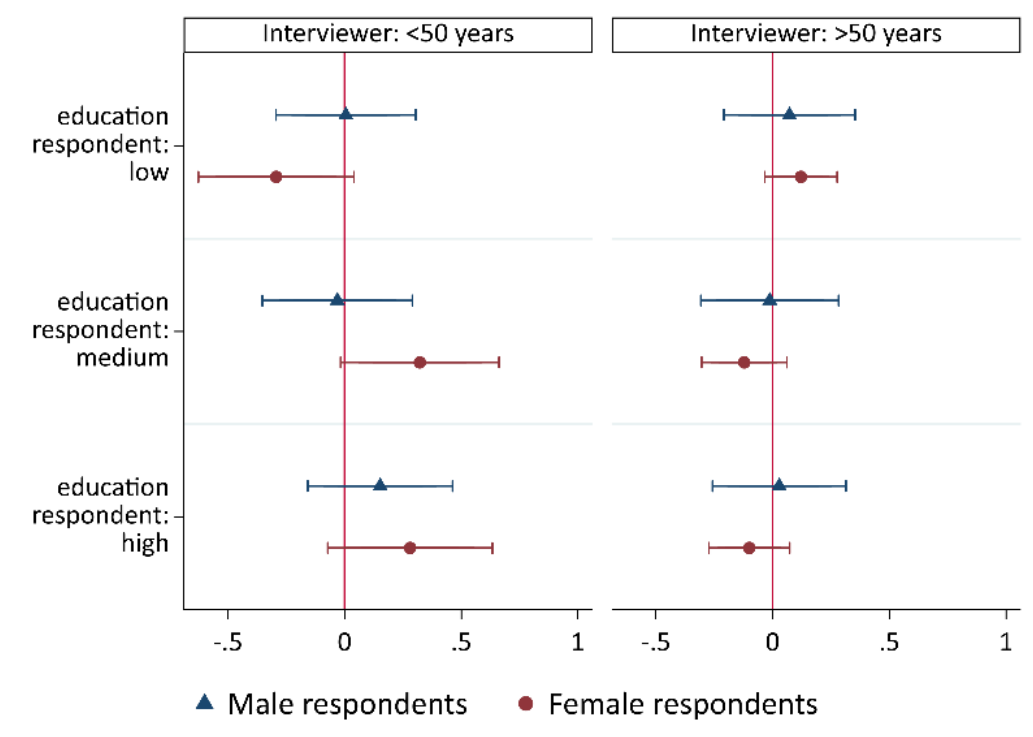

Fig. A2 Interaction effect between female interviewer's age and respondent's educational level

Note: The figure plots the interaction effects with $95 \%$ confidence intervals between a female interviewer, her age and respondents' educational on the respondent's gender ideology index (Source: NEPS SC6, $\mathrm{N}=10410$ (Males=4946, Females=5464), Own calculations). 